\title{
Modified Delphi Investigation of Lesson Planning Concepts for Physical Education Teacher Education
}

Jack W. Sager

West Virginia University

Follow this and additional works at: https://researchrepository.wvu.edu/etd

\section{Recommended Citation}

Sager, Jack W., "Modified Delphi Investigation of Lesson Planning Concepts for Physical Education Teacher Education" (2012). Graduate Theses, Dissertations, and Problem Reports. 195.

https://researchrepository.wvu.edu/etd/195

This Dissertation is protected by copyright and/or related rights. It has been brought to you by the The Research Repository @ WVU with permission from the rights-holder(s). You are free to use this Dissertation in any way that is permitted by the copyright and related rights legislation that applies to your use. For other uses you must obtain permission from the rights-holder(s) directly, unless additional rights are indicated by a Creative Commons license in the record and/ or on the work itself. This Dissertation has been accepted for inclusion in WVU Graduate Theses, Dissertations, and Problem Reports collection by an authorized administrator of The Research Repository @ WVU.

For more information, please contact researchrepository@mail.wvu.edu. 
Modified Delphi Investigation of Lesson Planning Concepts

for Physical Education Teacher Education

\author{
Jack W. Sager
}

Dissertation submitted to the
College of Physical Activity and Sport Sciences
at West Virginia University
in partial fulfillment of
the requirements for the degree of

\author{
Doctor of Education in \\ Physical Education Teacher Education
}

Andrew Hawkins, Ph.D., Chair

Sean Bulger, Ed.D.

DJ Hendricks, Ed.D.

Jack Watson, III, Ph.D.

Robert Wiegand, Ed.D.

Department of Coaching and Teaching Studies

Morgantown, West Virginia

2012

Keywords: Lesson planning, Teacher education, Delphi study

Copyright 2012 Jack W. Sager 


\section{Abstract \\ Modified Delphi Investigation of Lesson Planning Concepts for Physical Education Teacher Education}

\section{Jack W. Sager}

Improving the methods of instructing future educators, through program evaluation and improvement, should be a goal of all teacher education programs. In physical education, the National Association for Sport \& Physical Education created standards for initial preparation of physical education teachers. The six standards for preparation include Planning and Implementation, which include tenants pertaining to unit and lesson planning. Despite the significant importance of planning in the growth of preservice teachers as they complete a Physical Education Teacher Education (PETE) program, there is currently no consensus on what concepts to be included in lesson planning for physical education teacher education. The purpose of the study was to determine the essential lesson planning concepts for PETE. Following a nationwide pilot study of PETE programs in the United States to gather lesson planning concepts, a modified Delphi investigation using PETE experts was conducted to gain consensus on the pertinent lesson planning concepts for preservice teachers. Results of the study indicated 31 lesson planning concepts that experts found essential for preservice teachers to use when planning for teaching vignettes, peer teaching experiences and student teaching. Implications for use in PETE programs are also discussed. 
TABLE OF CONTENTS

CHAPTER I INTRODUCTION 1

$\begin{array}{ll}\text { Introduction } & 1\end{array}$

Purpose of the Study 4

Definition of Terms 5

Significance of the Study $\quad 5$

$\begin{array}{ll}\text { Research Question } & 6\end{array}$

CHAPTER II REVIEW OF LITERATURE 7

The Link between Curriculum and Planning $\quad 7$

$\begin{array}{ll}\text { Curriculum } & 7\end{array}$

Planning $\quad 8$

$\begin{array}{ll}\text { Evolution of Curriculum and Planning } & 11\end{array}$

$\begin{array}{ll}\text { Curricular and Planning History } & 12\end{array}$

Planning Studies from the General Teacher Education Literature 28

$\begin{array}{ll}\text { Physical Education Planning Studies } & 34\end{array}$

Miscellaneous Planning Articles 46

Alternative Physical Education Planning 47

Physical Education Planning Textbooks $\quad 50$

$\begin{array}{ll}\text { Delphi Method } & 51\end{array}$

Delphi Method Features $\quad 53$

Delphi Method Protocol 54

Modified Delphi $\quad 66$

$\begin{array}{lll}\text { CHAPTER III METHODOLOGY } & 57\end{array}$

Pilot Study $\quad 57$

Lesson Plan Assessment $\quad 58$

Concept Consolidation $\quad 59$

$\begin{array}{ll}\text { Participants } & 60 \\ & 61\end{array}$

$\begin{array}{ll}\text { Research Design } & 61\end{array}$

Two-round modified Delphi for lesson plan concepts 61

$\begin{array}{ll}\text { Instrumentation } & 62\end{array}$

$\begin{array}{ll}\text { Administrative Procedures } & 63\end{array}$

Selection of Participants $\quad 63$

Round I Procedures $\quad 63$

Inter-round Procedures $\quad 65$

Round II Procedures 66 
$\begin{array}{llr}\text { CHAPTER IV Results } & 68\end{array}$

$\begin{array}{ll}\text { Expert Panel } & 68\end{array}$

$\begin{array}{ll}\text { Contextual Information } & 69\end{array}$

Pre-instruction Concepts $\quad 69$

$\begin{array}{ll}\text { Instruction Concepts } & 70\end{array}$

$\begin{array}{ll}\text { Post-instruction Concepts } & 70\end{array}$

$\begin{array}{ll}\text { Comments } & 70\end{array}$

$\begin{array}{ll}\text { Concept Outline } & 71\end{array}$

$\begin{array}{lll}\text { Chapter V Discussion } & 72\end{array}$

$\begin{array}{ll}\text { Accepted Concepts Overview } & 72\end{array}$

Contextual Information Concepts 72

Pre-instruction Concepts $\quad 73$

Instruction Concepts $\quad 73$

Post-instruction Concepts $\quad 74$

Commentary on Accepted Concepts $\quad 74$

$\begin{array}{ll}\text { Remarkable Rejected Concepts } & 79\end{array}$

$\begin{array}{lr}\text { Concept Nomenclature } & 80\end{array}$

Round II Comments $\quad 81$

$\begin{array}{lr}\text { Future Considerations } & 81\end{array}$

Program Improvement $\quad 81$

Lesson Plan Template $\quad 83$

Length of Round II Survey $\quad 83$

Delphi Process $\quad 84$

REFERENCES

TABLE

Table 1: Final Concept List $\quad 99$

\section{APPENDICES}

$\begin{array}{ll}\text { Appendix 1: Pilot Study Survey Email } & 101\end{array}$

Appendix 2: Pilot Study Cover Letter 102

Appendix 3: Instructions for coding lesson plan templates 104

Appendix 4: Lesson Plan Assessment Document 105

Appendix 5: Lesson Planning Concept Consolidation 108

Appendix 6: Lesson Plan Concept Reduction 112

Appendix 7: E-mail for Modified Delphi Round I Participant Recruitment 114

Appendix 8: Script for Modified Delphi Participant Recruitment 115

Appendix 9: E-mail to Provide Delphi Study Detailed Information 117

Appendix 10: Delphi Round I Survey Introduction 118

Appendix 11: Delphi Round I Survey Instructions 119

Appendix 12: Delphi Round I Survey 120

Appendix 13: Round I Results Excel Spreadsheet 152 
$\begin{array}{ll}\text { Appendix 14: Round II Survey Email } & 166\end{array}$

Appendix 15: Round II Survey Introduction 167

Appendix 16: Delphi Round II Survey Instructions 168

Appendix 17: Round I Concept Outline $\quad 169$

Appendix 18: Delphi Round II Survey 170

Appendix 19: Final Research Report 195

Appendix 20: Final Concept Outline 197

Appendix 21: Concept Definitions 198 


\section{Introduction}

The United States federal government has been involved in education legislation since 1787 (United States Department of Education, 2003). Attempts to improve the nation's primary and secondary public school systems began with the Elementary and Secondary Education Act (ESEA) of 1965, which described federal requirements for public schools. ESEA's latest version, the No Child Left Behind (NCLB) Act of 2001(National Education Association, 2002), builds on the tenants of ESEA and retains

its basic framework of accountability, assessment, and standards (Learning First Alliance, 2003).

One of the features of NCLB is Title 2, Preparing, Training, and Requiring High Quality Teachers and Principals. Title 2 requires that all teachers of core academic subjects be highly qualified according to three criteria: (a) earning a bachelor's degree or better in the subject taught, (b) obtaining full state teacher certification, and (c) demonstrated knowledge in the subjects to be taught (United States Department of Education, 2006). Unfortunately, Physical Education was not included in NCLB (American Alliance for Health, Physical Education, Recreation, and Dance, 2004).

Regardless of physical education's exclusion from NCLB, two professional organizations, the National Council for Accreditation of Teacher Education (NCATE) and the National Association for Sport \& Physical Education (NASPE), work to establish, maintain and assess teacher education programs in physical education. NCATE is a non-profit, non-governmental alliance of 33 professional education and public organizations that support quality teaching. NCATE is the teaching profession's organization to assist in the establishment of high quality teacher, specialist, and 
administrator preparation through the process of accreditation of schools, colleges, and departments of education (National Council for Accreditation of Teacher Education, 2007). NASPE is the preeminent authority on physical education whose members include K-12 physical education teachers and college and university faculty who prepare physical activity professionals. NASPE's mission is to improve professional practice, enhance knowledge, and increase support for high quality physical education, sport and physical activity programs via research and the development of standards (National Association for Sport \& Physical Education, 2006).

To ensure that colleges are preparing physical education teacher education (PETE) undergraduate students, NASPE created standards for initial preparation of physical education teachers. The revised standards and outcomes have been adjusted to: (a) align with the National Standards for Physical Education, (b) reflect the best practices of teacher education as found in current literature, and (c) include only those standards that are measurable and achievable in an initial licensure program (NASPE, 2008a). The six standards (Scientific and Theoretical Knowledge, Skill and Fitness Based Competence, Planning and Implementation, Instructional Delivery and Management, Impact on Student Learning, and Professionalism), all contain outcome measures that teacher candidates will be required to exhibit as they progress through a PETE program (NASPE, 2008c). Of particular interest to this present study is Standard 3, Planning and Implementation, which states the following: "Physical education teacher candidates plan and implement a variety of developmentally appropriate learning experiences and content aligned with local, state, and national standards to develop physically educated individuals" (NASPE, 2008b, p. 11). Planning can be defined as "...a basic psychological 
process in which a person visualizes the future, inventories means and ends, and constructs a framework to guide his or her future action" (Clark, 1983, p. 8).

Lesson planning, included within NASPE Standard 3, has been an essential tool for teachers since its formulation in the 19th century (Strangis, Pringle, \& Knopf, 2006). Instructional planning plays a critical role in teaching and school learning (Baylor, Kitsantas, \& Chung, 2001) and helps teachers to understand the content of a lesson, to create a logical sequence of events, and link activities to instructional objectives (Johnson, 2000). Planned lessons have a positive effect on some preservice teachers' (PSTs) instructional behaviors (Byra \& Coulon, 1994) and teacher candidates, or preservice teachers (PST), believe that planning is the third most frequent indicator of lesson success, behind instruction and management and organization (O'Sullivan \& Tsangaridou, 1992).

However, the lesson planning process is a complex endeavor, with a host of problems that must be solved, including the determination of the objective, what students should know and be able to do, and how information is to be organized to promote student comprehension (Johnson, 2000). In addition, the planning process can be quite daunting because PSTs are limited in terms of the instructional strategies in which they are competent and the teaching experiences they have had (Strangis, Pringle, \& Knopf, 2006).

Despite the significant importance of planning in the growth of PSTs as they complete a Physical Education Teacher Education (PETE) program, there was currently no consensus on what concepts to be included in lesson planning for physical education teacher education. A comprehensive list of lesson plan concepts would include all of the 
pertinent information required of curriculum programs today and would benefit preservice teachers just entering teacher education programs by providing students with all of the pedagogical categories and nomenclature essential for writing quality lesson plans for their initial classes, peer teaching, pre-student teaching field experiences, and student teaching. As preservice teachers continue through a PETE program, each student could choose which concepts of a lesson plan to complete in detail, based upon their unique knowledge of the particular subject matter, general pedagogical knowledge, content knowledge, pedagogical content knowledge, and curricular knowledge.

In addition, if a consensus on pertinent lesson plan concepts were available in PETE, then a corresponding scoring rubric for preservice teacher grading and improvement could be developed. Rubrics, which are sets of multidimensional rating scales functioning as scoring guidelines used to evaluate student work, are helpful to students as rubrics remove the guesswork when completing a learning activity. From a teacher's point of view, rubrics also remove the guesswork when grading students' work (Morrell \& Ackley, 1999). In terms of uniformity, a lesson plan scoring rubric could enable a teacher education program's faculty, graduate teaching assistants, cooperating teachers and university supervisors to provide consistent and reliable feedback and grading of PSTs' planning.

\section{Purpose of the Study}

The purpose of this study was to clarify the lesson planning process for PETE preservice teachers by determining the essential lesson planning concepts to be included in a lesson plan template. 


\section{Definition of Terms}

1. general pedagogical knowledge - broad principles and strategies of organization and classroom management that transcend subject matter (Shulman, 1987).

2. content knowledge - describes what a teacher understands about the subject matter of physical education, such as dance, sports, games, exercise and the like (Graber, 2001).

3. pedagogical content knowledge $-"$ "...includes overarching conceptions of what it means to teach a particular subject, knowledge of curricular materials and curriculum in a particular field, knowledge of students' understanding and potential misunderstanding of a subject area, and knowledge of instructional strategies and representations for teaching particular topics" (Grossman, 1989, p. 25).

4. curricular knowledge - "...the ability to select, understand, transform, convey, and implement appropriate content into lessons, units, and programs." (Graber, 2001, p. 496).

\section{Significance of the Study}

Despite the absence of consensus as to what should be contained within a comprehensive lesson plan, several models to describe teacher planning have been described (Taylor, 1970; Tyler, 1949; Yinger, 1980) and developed (Casten, 2006; Kelly \& Melograno, 2004; Rink, 2006; Zakrajsek, Carnes, \& Pettigrew, 2003). Similarly, several tools for scoring lesson plans have been developed in particular areas of education. These tools were derived from needs in the areas of technology (Baylor, 
Kitsantas, \& Chung, 2001; Johnson, 2000), literacy (Hansen, 2006), mathematics

(Panasuk \& Todd, 2005; Wilkerson \& Scheffler, 1992), as well as in general areas of education (Golland, 1998; Wild, 2000). Therefore, a comprehensive list of lesson plan concepts that could in the future comprise a lesson planning instrument and corresponding scoring rubric was needed to assist PSTs' in planning their lessons.

\section{Research Question}

The purpose of the study was to determine the essential concepts to be included in a lesson plan template for PSTs in physical education teacher education programs. The following research question guided the development of the instrument:

1. What are the essential concepts that should be included in a comprehensive lesson planning template for preservice teachers in physical education teacher education? 


\section{Review of Literature}

The purpose of this study was to derive a comprehensive list of essential lesson planning concepts for use by preservice physical education teacher education students or preservice teachers (PSTs) as they develop lesson plans for their many teaching experiences. The following literature review provided a description of the link between the curriculum and planning, introduced planning in general and lesson planning in particular as a construct for decision making while teaching, reviewed the pertinent planning literature in general education and physical education, and detailed the pilot study investigation on PETE lesson planning templates.

\section{The Link between Curriculum and Planning}

Prior to describing the planning process and, more specifically, lesson planning, a description of the curriculum process is helpful when considering planning within the larger context of a curriculum. A discussion of curriculum and planning within the context of schools follows.

Curriculum. Curriculum can be delineated into four levels from the broadest to the most specific. The broadest level, the school curriculum, includes all of the activities planned for the school. This level includes activities sanctioned by the school, but for which no credit is given, as well as activities which receive academic credit. The academic curriculum is the entire array of activities that constitute the course offerings at a school. It is differentiated from the school curriculum because the activities are formalized through designation of formal courses, grades, and transcripts. Subject-matter curriculum includes the array of activities planned within a particular discipline or subject matter. Examples include curriculum in biology and art. The narrowest curriculum, the 
course curriculum, includes the content, organization, and evaluations of the course teachers teach (Eisner, 1965).

The operation of curricular construction is the decision-making process (discussions of how and what to teach) that goes on in every district, school, and classroom. The construction of a curriculum is one initial step in the establishment of a program. The product of the curriculum-building process is often a syllabus or guide intended for an entire school system or for a single course or class. Whether planning a curriculum as broad as a school curriculum, or as narrow as the course curriculum, at each level, activities are planned by students and/or faculty to perform educational functions for which the school is responsible (Eisner, 1965). The thinking, planning, and decision making of teachers comprises a large part of the psychological context within which curriculum is interpreted and acted upon and within which teachers teach and students learn (Clark, 1983).

Planning. Planning has been defined in a myriad of ways. Planning can first be defined in terms of what teachers do. Planning has been described as a basic psychological process in which a person visualizes the future, inventories means and ends, and creates a framework to guide a future action (Clark, 1983); or any activity of a teacher concerned with organizing his or her school-related activities, or the activities of students, other teachers, aids, parent volunteers, and so on (Clark \& Yinger, 1980).

Planning may also be defined in terms of when it occurs. Metzler and Young (1984), divided teaching into three broad sets of decision-making operations. Preactive teaching, in which planning occurs, is the act of deciding what to teach and how to order the instructional environment to facilitate student learning prior to the teaching event. 
Interactive-teaching, the actual teaching episode, is the immediate and often unanticipated decisions that arise during actual teaching. Postactive teaching is the process of deciding how the lesson met the stated instructional goals and determining prescriptions for further preactive planning.

Planning has been described in terms of its link and importance to the act of teaching. The practice of teaching incorporates both the planning aspect and the delivery of instruction (Gagné, 1976) and planning and teaching are of equal importance (Reiser \& Dick, 1996). The central purpose of teaching is the promotion of learning by students and this should always serve as the primary goal of the teacher (Gagné, 1976). Decisions made during the planning and interactive phases of teaching influence what students learn and are influenced by the teacher's intentions for and vision of student learning (DarlingHammond, et al., 2005). The link between planning and instruction is no less important in physical education teaching. Planning is a critical portion of the teaching process and the products of planning describe in detail the teacher's intent for not only student outcomes but also the teacher's strategy to bring students to said outcomes (Rink, 2006). Planning appears to play a functional role in linking curriculum to instruction, and in turn, influencing what occurs in the interactive teaching environment (Byra \& Coulon, 1994).

Decision-making is pervasive in teaching and the list of instructional decisions made by teachers is infinite. These decisions, whether conscious or not, are involved in almost every aspect of a teacher's life, especially in planning, implementing, and evaluating instruction (Shavelson, 1976). Of all the things that teachers do prior to teaching, planning is probably the most important because of the variety of factors 
involved, such as meeting school and district objectives, the wide range of student aptitudes, and the wealth of instructional materials that are available (Yinger, 1979).

The significance of lesson planning cannot be overemphasized (Darst \& Pangrazi, 2009) and the value and productivity of a teaching/learning encounter depends upon thorough and meticulous planning (Imwold, et al., 1984). When a teacher plans and teaches a lesson, he or she encounters various issues requiring pedagogical decisions aimed at promoting the process of learning (Penso \& Shoham, 2003), including the kinds of stimulation to present to the learner, what communications to make, what questions to ask students, and what sorts of confirmation of the learner's productions to provide (Gagné, 1976). Planning helps teachers present quality instruction and maintain meaningful interaction with students because, regardless of experience and ability, teachers have many things to remember while teaching. During a lesson, situations occur that are impossible to predict, such as discipline problems, modifying lessons spontaneously, and providing feedback and reinforcement. If a lesson's content is planned, greater emphasis can be placed on other important phases of teaching (Darst \& Pangrazi, 2009).

Thoughtful planning creates better lessons by linking the curriculum to the particulars of instruction, by allowing more purposeful instruction, and enhancing the possibility of effective lessons. Planning in a thoughtful manner also helps the teacher to understand the content of a lesson (Johnson, 2000), create a logical sequence of instructional events, and links activities to instructional goals and objectives that include a structured and progressive format that will be used to guide students toward the accomplishment of specific goals and objectives (Johnson, 2000; Stroot \& Morton, 
1989). Planning serves several additional functions in that it allows teachers to anticipate instructional needs in advance to allow for the gathering and organization of materials (Kauchak \& Eggen, 2007), makes teachers better able to incorporate new instructional strategies and utilize complex learning activities (Johnson, 2000; Strangis, Pringle, \& Knopf, 2006), provides a script that directs interactions with students, and provides a form of psychological and emotional security for the teacher that bolsters his or her confidence (Johnson, 2000; Kauchak \& Eggen, 2007) and helps to reduce the anxiety associated with teaching (Kauchak \& Eggen, 2007).

The cycle of avoiding planning often begins early in a teacher's career as preservice student teachers observe inservice teachers engaging in little, if any, planning. In the student teacher's view, the emphasis placed on developing meaningful lesson plans in preparation courses appears unnecessary when the master teacher teaches without the aid of thoughtful planning. The beginning teacher is often unable to meaningfully judge the effectiveness of a master teacher because of a lack of perspective and experience. The master teacher has taught the material for years and has developed a method of presentation through trial and error (Darst \& Pangrazi, 2009).

\section{Evolution of Curriculum and Planning}

A history of the planning literature indicates that planning evolved not only from the general education literature, but also from areas outside of higher education. This evolution began with general theories about how to organize curricula, to general curricular models, to actual curricular, unit, and lesson planning methods developed for many different educational fields. It is the desire of this author that the lesson plan 
concepts accepted in this study are organized based upon the forthcoming evolution of the general or linear curricular planning model.

Curricular and Planning History. A history of planning often begins with Ralph Tyler's book, Basic Principles of Curriculum and Instruction, where the author provides a rationale for viewing, analyzing and interpreting the curriculum and instructional program of an educational institution. While the author states that his text is not a manual for curricular construction, it is a book that outlines a way of viewing an instructional program as a functioning instrument of education (Tyler, 1949). This model is described as a cognitive planning model to emphasize teacher thinking and decision making in the planning process (Kauchak \& Eggen, 2007).

Tyler posed four fundamental questions that need to be answered when developing any curriculum or plan for instruction (1949). These questions are: (a) What educational purposes should the school seek to attain? (b) What educational experiences can be provided which are likely to attain these purposes? (c) How can these educational experiences be effectively organized? and (d). How can we determine whether these purposes are being attained?

If an educational program is to be planned and if improvements are to be an important component within that planning, then it is important to have a conception of the goals. Objectives become the criteria by which materials are chosen, content is outlined, instructional procedures are developed, and tests are prepared

Learning experiences refer to the interaction between the learner and the external conditions in the environment to which it can react. General principles that apply to the selection of learning experiences include the following: (a) the student must have 
experiences that give him or her the opportunity to practice the kind of behavior implied by the objective, (b) learning experiences must be such that the student obtains satisfaction from carrying out the type of behavior implied by the objectives, (c) The reactions desired in the experience are within the range of possibility for the students, (d) there are many particular experiences that can be used to realize the same educational objectives, and (e) the same learning experience will bring about several outcomes The three major criteria to be met when organizing learning experiences are continuity, sequence, and integration. Continuity refers to the vertical reiteration of major curriculum elements. Sequence emphasizes the importance of having each successive experience build upon the preceding one and to go more broadly and deeply into the matters at hand. Integration refers to the horizontal relationships of curriculum experiences.

It is important to make an inclusive check as to whether the plans for learning experiences actually function to guide the teacher introducing the type of outcomes desired. In summary, this linear model results in four general steps to curricular planning: specifying objectives, selecting learning activities, organizing learning activities, and evaluation procedures (Tyler, 1949).

Several authors either elaborated upon or added additional constructs to Tyler's ideas in curricular planning. Taba (1962) believed that it was the special function of the school to arrange experiences for children and youth that ensures desirable learning takes place. If the curriculum is to be a plan for learning, then its content and learning experiences must be organized to serve the educational objectives. Taba developed a seven-step formula for curricular planning that is similar to Tyler's: (a) Diagnosis of the 
problem, (b) Formulation of objectives, (c) Selection of content, (d) Organization of content, (e) Selection of learning experiences, (f) Organization of learning experiences, and (g) Determination of what to evaluate and of the ways and means of doing it. In addition, Taba provided similar steps for the development of what he called a teachinglearning unit: (a) Diagnosing needs, (b) Formulating specific objectives, (c) Selecting content, (d) Organizing content, (e) Selecting learning experiences, (f) Organizing learning experiences, (g) Evaluating, and (h) Checking for balance and sequence.

Eisner (1965) provided both a description of the major tasks curricular educators engage in and described four levels of curriculum in schools. The three major tasks that persons working in curriculum engage in are curricular construction, taxonomies, and theories. Curricular construction is the decision-making process, of how and what to teach, that goes on in every classroom, school and district. The construction of a curriculum is one initial step in the establishment of that program. The product of the curriculum-building process is often a syllabus or guide intended for an entire school system or for a single course or class. Curriculum taxonomies are conceptual schemes that identify the major elements and questions to be considered when constructing a curriculum. One of the most useful designs was Tyler's work.

The four levels of curriculum are the school, academic, subject-matter, and course. At each level, activities are planned by students and/or faculty to perform educational functions for which the school is responsible. The basic unit of the curriculum is the activity. By viewing a curriculum as a series of activities, we become aware of what we are asking the student to do. The first and broadest level of curriculum is the school curriculum, which includes all of the activities planned for the school, both 
credit bearing and non credit bearing. This level includes activities sanctioned by the school, but for which no credit is given, as well as activities which receive academic credit. The second level is the academic curriculum, which includes the entire array of activities that constitute the course offerings at a school. It is differentiated from the school curriculum as the activities are formalized through formal course, grades, and transcripts. The third level, the subject-matter curriculum, is the array of activities planned within a particular discipline or subject matter. Examples of such curriculum are biology, art and music. The fourth, and most specific curricular level, is the course curriculum. This involves the content, organization, and evaluation of the course teachers teach. It is at this level where the curriculum is closest to the student (Eisner, 1965).

Robert Mager, in 1962, expanded upon Tyler's conception of writing learning objectives to include conditions under which learners demonstrate the behavior and the criteria for acceptable performance (Kauchak \& Eggen, 2007). The format for preparing instructional objectives includes three characteristics that help an objective to communicate an intent: performance, conditions, and criterion. In terms of performance, an objective should state what a learner is expected to be able to do and/or produce to be considered competent. An objective should also describe the important conditions under which the performance is to occur. An effective objective also describes the criteria for acceptable performance, or, how well someone would have to perform to be considered competent (Mager, 1997).

Several authors questioned the use of Tyler's model and rational, decision-making approach in planning curricula and lessons. While the review of these authors is important in understanding the evolution of curricula and planning, one must take into 
account the context of their studies. The forthcoming authors' findings and comments are based on experienced teachers' planning practices, rather than on preservice teachers' needs for formal planning exercises. In addition, the methods that some authors used in their studies were questionable in terms of scientific rigor.

Macdonald (1965) states that the idea that teachers make a series of rational decisions about objectives, learning experiences, organization and evaluation is questionable because it is difficult to see how meaningful behavior arises from a formal series of sequential and rational decisions. Macdonald uses the model and use of objectives to prove his point. Objectives are used as directives in the rational approach but we can only know what we wanted to accomplish after the fact. In this opposing view, objectives are heuristic devices which provide initiating sequences which become altered in the flow of instruction. Macdonald states that it can be argued that the teacher should say, "What am I going to do?" rather than "What am I trying to accomplish?"

Eisner (1967) both questioned and elaborated upon the use of educational objectives. The author states that the metaphors used in the formation of objectives have been associated with conceptions of education that the author believes to be alien to the educational values of those who teach. The problem of determining how educational objectives should be stated is a question of value and directly related to one's conception of education. Eisner divided educational objectives into two forms: instructional and expressive. Instructional objectives are those that specify unambiguously the particular behavior the student is to acquire after having completed one or more learning activities. They are drawn from the cultural products such as the disciplines and are laid out in intervals of time appropriate for children who are to acquire them. These objectives are 
used in a predictive model of curricular development where objectives are formulated which are predicted to be useful in enabling children to attain the specific behavior embodied in the objective.

Expressive objectives do not specify the behavior the student is to acquire after engaging in one or more learning activities. Rather, it describes an educational encounter: it identifies a situation in which children are to work, a problem with which they are to cope, a task they are to engage in. But it does not specify what from that encounter or problem or task they are to learn. An expressive objective provides the teacher and the student with an invitation to explore and is evocative rather than prescriptive.

Eisner concludes by stating that curriculum can be developed with an eye toward alternating instructional and expressive objectives in hopes of determining the relationships between them that are the most productive for various types of students and learning and for various subject matters (Eisner, 1967).

Zahorik (1975) questioned the ends-means planning model by studying 194 teachers to determine what types of plans they make prior to the time they enter the classroom. Data regarding how teachers plan were collected by having teachers indicate the decisions they make as they plan to teach one or more class sessions or periods. The data collection instrument consisted of two parts. Part I requested teachers to list in writing the decisions they made prior to teaching in the order that they usually made them. Part II, occurring after Part I had been collected, requested those teachers who had indicated that they did make decisions about objectives and activities to give an example of an objective and of an activity that they had recently used. Results indicated that the decision that came closest to being used by all teachers was activities $(81 \%)$, followed by 
content (70\%), and objectives and materials (both 56\%), evaluation $35 \%$, diagnosis $25 \%$, organization $21 \%$, and instruction $16 \%$. In terms of order, $51 \%$ listed content first, $28 \%$ listed objectives first, and 3\% listed activities first. Zahorik concluded that objectives are not particularly important planning decisions in terms of quantity of use. In addition, in terms of quantity of use, activities are an important planning decision. Content is one of the most important planning decisions in terms of quantity of use. Zahorik goes on to state that neither the separate ends-means planning model as prescribed by Tyler (1949) or by Popham (Popham \& Baker, 1970) is being used in this group of teachers to any great extent, nor is the integrated ends-means model as prescribed by Macdonald (1965). Since only about a quarter of the teachers began their planning with objectives, the separate ends-means model may be more of a theoretical formulation than a functioning reality. However, the type of objective used, specific objective, is the one consistent with the ends-means model. Zahorik states that since almost no one begins to plan by identifying learning activities, the integrated ends-means model also does not appear to be a functioning reality. Zahorik does provide a suggestion for planning templates by stating if proposed planning models are to become helpful tools for teachers, perhaps the place of content in the planning models ought to be more clearly delineated (Zahorik 1975).

In terms of determining and organizing lesson plan concepts for new PETE students, Zahorik's 1975 study provides some interesting data concerning new teachers. Of those teachers with one to five years of experience $(\mathrm{N}=122), 55 \%$ chose content as their first planning decision, $24 \%$ chose objectives, and only $2 \%$ chose activities. Although these figures are virtually identical for the total group of teachers $(\mathrm{N}=194)$, 
those teachers with 6-20 years of experience $(\mathrm{N}=72)$ chose content less often first $(43 \%)$ but chose objectives more first (35\%) than their inexperienced counterparts (Zahorik, 1975). Although it is unknown as to the number of education programs that taught the separate ends-means model to its students, it may be safe to surmise that those new teachers quickly shed Taylor's model in whatever form they learned it.

In terms of this study applying to physical education, no physical education teachers were identified as subjects, although eight teachers from the middle and high school area were identified as teaching in other areas than those major subjects offered in secondary education (Zahorik, 1975). This may or may not explain why activities were identified first in only $3 \%$ of the total sample population.

In a study of school teachers, Taylor (1970) found that teachers begin with the context of teaching, consider learning situations that were likely to interest and involve students, and then considered the purposes that their teaching would serve. Taylor concluded with eight considerations when planning a course of study: (a) curricular planning should begin with important contextual considerations such as time, sequencing and resources; (b) considerations for pupil interests and attitudes; (c) aims and purposes of the course; (d) learning situations to be created; (e) philosophy of the course; (f) criteria for judging the course; (g) degree of pupil interest fostered by the course; and (h) evaluation of the course.

Popham \& Baker (1970) provided a collection of self-instruction programs dealing with various aspects of instruction that intended to provide tangible competencies that could be employed by teachers to make instructional decisions. Their general instructional model is one that can be used by teachers in deciding the instructional 
activities to include in a teacher sequence, and whether the instructional sequence was effective. The four-stage empirical approach is as follows: (a) specify objectives: What goals to achieve. Objectives must unambiguously communicate what the educator intends to accomplish or else they are of little instructional value. The three behavioral divisions of educational objectives are the cognitive, affective, and psychomotor; (b) pre-assess learners by assessing the student's status with respect to the intended objectives; (c) selection of learning activities: Teachers should approach this step by asking themselves, "What behavior changes do I want my students to achieve?" rather than, "What shall I do?"; and (d) evaluation: Evaluation of the teacher, and not the students, to determine the adequacy of his or her objectives.

Shavelson (1976) viewed the teacher as an instructional designer and took recommendations from learning and instruction models to help to identify the options available in teaching. These recommendations usually include four common elements: (a) outcomes are stated explicitly as observable student behavior, (b) the students' present capabilities or entry behaviors are identified, (c) an instructional sequence is planned that will move students from their current capabilities towards the instructional outcomes, and (d) the outcomes ${ }^{1}$ of instruction are evaluated. Shavelson then described an application of a decision model to instructional planning by Atkinson and Paulson (1972), ("An approach to the Psychology of Instruction"). Teachers' instructional planning can be characterized as a problem in instructional design that can be described as a decision problem. This decision problem involves (a) specifying outcomes of instruction, (b) specifying instructional design alternatives, (c) specifying students' entry behavior; (d)

\footnotetext{
${ }^{1}$ The description of Tyler's (1949) curricular model as a means-ends model by Yinger (1980) and as an ends-means model by Zahorik (1975) beginning on p. 25 is confusing. Nevertheless, Yinger and Zahorik are referring to the same curricular model of Tyler.
} 
estimating the outcome of each combination of an instructional alternative and state of nature, (e) choosing the optimal course of action, and (f) evaluating instruction by observing student behavior.

R. J. Yinger provided a lucid review of prior research in curriculum and lesson development, and carried out several studies that altered the way professional educators conceptualize planning. In his 1980 study, Yinger, in reviewing the literature up to that time, stated that education had adopted a rational model of planning, which he referred to as a Rational Choice Model. This model requires the (a) setting of goals, (b) formulation of alternatives, (c) prediction of outcomes for each alternative, and (d) evaluation of each alternative in relation to the goals and outcomes. The author refers to Tyler's approach to planning, that was elaborated by Taba (1962), and Popham and Baker (1970), and having four essential steps (specify objectives, select learning activities, organize learning activities, and specify evaluation procedures), as a means-ends ${ }^{1}$ model in which the planner's first task is to decide on desired ends, or what is to be accomplished, and then selecting appropriate learning activities to accomplish them. The author states that a departure from the means-ends model was the integrated ends-means model of Zahorik (1975), which was suggested by Macdonald (1965) and Eisner (1967). In this model, teachers focus on type of learning activity that will be provided for students. Ends for learning become integrated with means for learning and the specification of goals prior to an activity becomes meaningless. Yinger then described, via a study of one $1^{\text {st }} / 2^{\text {nd }}$ grade teacher, the mental processes involved in teacher planning decisions made prior to teaching. Two central aspects of the teacher's planning and instruction emerged: planning for instructional activities and the use of teaching routines. Yinger found that activities 
functioned as the basic structural units of planning and action in the class. Through planning the teacher was able to structure activities to increase the likelihood of signaling, eliciting and supporting behavior that met her purposes. Seven features were identified that characterized instructional activities in the classroom: location, structure and sequence, duration, participants, acceptable student behavior, instructional moves, and content and materials. The subject made planning decisions regarding each of these seven features. Routines, defined as established procedures whose main function is to control and coordinate specific sequences of behavior, were the mechanism through which the teacher used to establish and regulate instructional activities. Four types of routines were identified in the study: activity, instructional, management, and executive planning. Yinger then formulated a general model, termed a Process Model of the teacher planning. The model has two purposes: to describe and represent in a schematic form speculations about concepts of teacher planning and their interrelationships and to serve as a basis for further theory and research on teacher planning. The model was grounded in three data bases: (a) data collection in the field research portion of the study, (b) other studies of teacher planning, and (c) psychological studies of problem solving and planning conducted in deliberative situations in mathematical problem solving, chess playing, musical composition, chess playing, art, and architectural design. The similarities among the situation in teacher planning and those of selecting a move in chess, or planning for space utilization in a building suggested the usefulness of adopting concepts from research on these thinking processes. With regard to other studies of teacher planning, two findings when reviewing the literature were of interest to the author: the failure to identify objectives as a primary object of teacher decision making 
during the planning process (Peterson, Marx, and Clark, 1977; Zahorik, 1975), and the lack of well developed alternatives in teacher plans (Morine, 1975). These studies indicated a greater concern for content and activities, rather than on the process advocated for in the rational choice model. Yinger's model portrays planning as "purposeful problem solving" as opposed to "rational choice". The model deviates from traditional models of planning primarily in that the emphasis is on the discovery and design processes in planning rather than on the choice processes. The General Process Model has three stages:

1. - Problem Solving: The general planning task is translated into a specific planning problem. The major process at this stage is a discovery process through which problem finding occurs. This involves interactions between the planning dilemma, teaching goal conceptions, knowledge, experience, and materials.

2. - Problem formulation/Solution Design:

The primary process of interest in this stage is the design cycle where the initial activity idea is repeatedly elaborated and tested until a satisfactory solution is found. This design process of lesson planning involves the alternation of problem development (elaboration, construction) and problem reformulation (adaptation, transformation). In other words, this design process entails continual goal development involving a cycling between solution anticipations and the results of attempts at solving subproblems.

3. - Implementation, Evaluation, and Routinization

This stage is where the activity is actually implemented and evaluated in the classroom. This stage provides the teacher with information on the workability of the activity with one's group of children and may lead to further modification or even rejection of the 
activity. If an activity is successful, it may eventually be routinized. Experience with both successful and unsuccessful activities and routines eventually is fed back to long-term memory where it becomes part of a teacher's repertoire of knowledge and experience for future planning (Yinger, 1980).

Reiser and Dick, (1996) developed a planning approach to traditional, instructional systems design. Their principles of instructional planning contain the following: (a) begin the planning process by clearly identifying the general goals and specific objectives students will be expected to obtain, (b) plan instructional activities that are intended to help students attain the objectives, (c) develop assessment instruments that measurer attainment of these objectives, (d) revise instruction in response to student performance on each objective and student attitudes towards your instructional activities.

The systematic planning process contains the following seven steps:

1. Identify instructional goals. Instructional goals are general statements of desired instructional outcomes that are broken down into a variety of much more specific behaviors. Goals are derived from a number of different sources including state and local legislation, accrediting agencies, text books and individual teachers. Goal statements should be should be expressed in terms of what is expected of students.

2. Identify objectives: Objectives, which describe the aforementioned specific behaviors, are explicit descriptions of what students will be able to do as a result of the instruction they receive. An objective contains three parts: a. a behavior that we expect students to exhibit; $b$. the conditions under which the student will be required to exhibit 
the desired behavior; and c. the criterion or standard that must be met in order for the performance to be judged acceptable.

3. Plan instructional activities: The types of activities include those that motivate students, inform students of objectives, helping students to recall prerequisite skills, presenting information and examples, providing practice and feedback, and summarizing the lesson.

4. Choose instructional media: Media include all of the traditional means of delivering instruction, such as chalkboards, workbooks, textbooks and other supplementary print materials, as well as the use of computer hardware and software. When identifying the proper media to use for an instructional period, teachers must consider the practicality of the media, their students' characteristics, and the instructional activity it is intended to represent.

5. Develop assessment tools in order to assign grades to students, to determine what students know in order to provide appropriate remediation, and to identify ineffective portions of instruction.

6. Implement instruction through the use of mastery learning, where the time available to acquire a set of objectives varies among students. This allows most students to eventually achieve the same level of performance.

7. Revise instruction: The collection of data on student pretests and posttests, practice exercises and quizzes, as well as student attitudes during and following instruction, should be completed prior to an examination and possible revision of a teacher's instructional plans. (Reiser and Dick, 1996). 
Ornstein (1997) claims that there is no one ideal format to follow for a lesson plan. Teachers should modify the suggestions of methods experts and learning theorists to coincide with their personal teaching style and the suggestions of their school or district. The author recommends that beginning teachers include the following seven concepts in a lesson plan: (a) specific objective of the lesson; (b) appropriate motivation to capture the student's interest and maintain it throughout the lesson; (c) development or outline of a lesson (sometimes referred to as content or activities); (d) varied methods, including drill, questions, and demonstrations, designed to keep the lesson on track; (e) materials and media to supplement and clarify content; (f) summaries to review and close class time; and (g) provision for assignment or homework. The teacher can vary how much time he or she spends on each component, how much detail is included in each, and which concepts are included. With experience the teacher discovers the most useful concepts to include and the amount of detail needed in the plan as a whole.

Kauchak \& Eggen (2007) provided a working planning model through combining their knowledge of curricular planning with the ideas and history of planning from various sources. Cognitive learning theory has become increasingly influential as a framework for education and within this framework, teacher knowledge and thinking is prominent; and teacher thinking is at the core of planning. Citing Tyler's (1949) work as having a major influence on planning, the authors describe a "cognitive" planning model to emphasize teacher thinking and decision making in the planning process. The components of the model provide a framework for yearly, unit, or lesson planning. The four components are selecting topics, specifying learning objectives, preparing and organizing learning activities, and preparing assessments. 
1. Selecting Topics: What is important for students to learn depends upon sources such as textbooks, curriculum guides, and standards, as well as a teacher's personal philosophies, students' interests in the topic, and real-world applications.

2. Specifying Learning Objectives: these are statements that specify what students should know, understand, or be able to do with the respect to a course of study or topic. The authors cite Tyler (1949) when expressing objectives as both the kind of behavior to be developed in the student and the content in which the behavior is to operate. The authors continue their review and construction of their planning model by citing the work of Mager (1962), who expanded upon Tyler's conception of writing learning objectives to include conditions under which learners demonstrate the behavior and the criteria for acceptable performance. Gronlund (2004) offered an alternative to Mager's approach by suggesting that teachers state a general objective, such as know, understand, or apply, followed by specific learning outcomes. Each of these approaches to planning is influenced by behaviorism, although education is moving towards a cognitive approach. Educational leaders recommend stating objectives in terms of students' cognitive processes instead of behaviors and replace the concept of content with knowledge to reflect what students should know. This idea has led to the idea of learning objectives being described with their taxonomies for the cognitive, affective, and psychomotor domains.

3. Preparing and Organizing Learning Activities: The thinking involved in preparing and organizing learning activities needs to answer the following question: What will I have students do that will help them reach the learning objective? Task analysis, the process of breaking content down into component parts and making decisions about sequencing said 
parts, helps the teacher design and sequence the learning activity. The four steps of task analysis are (a) specify terminal behavior, (b) identify prerequisite skills, (c) sequence subskills, and (d) diagnose students. Task analysis is important because it encourages teachers to clarify their thinking by specifying learning objectives to and allows for the break down of complex skills into smaller subskills that make it easier for students to master.

4. Preparing Assessments: Assessments can determine not only if students have reached the learning objectives, but also can facilitate learning. Instructional alignment, the matching of learning objectives and learning activities, and assessments, provides, helps students understand what is important to learn and assists teachers in matching learning objectives to instructional strategies and assessments. Another tool for the teacher is that of backward design. This process identifies the desired learning outcomes or objectives, and then delineates learning experiences to reach the objective. Assessments are thought of prior to thinking about learning experiences Kauchak \& Eggen (2007).

\section{Planning Studies from the General Teacher Education Literature}

A plethora of studies from virtually all subjects in education have been completed that review various aspects of planning. Unfortunately, few of the studies have produced viable lesson plan templates and/or scoring rubrics.

Hunter (1984) described her seven-part design for effective lessons. She described the creation of an explicit, basic lesson design as "welcome news" to many educators, although she lamented that it had unfortunately become a rigid measuring stick of "correctness" in teaching. The seven steps are: 
1. Anticipatory set: The author asks the question "Has the teacher developed for the students a mental set that enables them to focus on what will be learned?" The anticipatory set may also provide some practice in helping students achieve learning and yield diagnostic data for the teacher.

2. Objective and purpose: The teacher often states, in words meaningful to students, what will be learned and how it will be useful. Not only do students learn more effectively when they know what they're supposed to be learning and why that learning is important to them, but teachers teach more effectively when they have the same information. 3. Input: Students must acquire new information about the process, knowledge or skill they are to achieve. The teacher, regardless of whether the information comes via discovery, discussion, reading, listening, observing, or lecture, must have task-analyzed the final objective to identify knowledge and skills that need to be acquired. 4. Modeling: "Seeing" what is meant is an important adjunct to learning, and is usually facilitated for students to directly perceive the process or product they are expected to acquire. To prevent stifling of creativity, several examples should be a routine part of most lessons. Demonstrations should be facilitating and not restricting.

5. Checking for understanding: Prior to having students engage in the process of acquiring knowledge, teachers should ascertain that students understand what they're supposed to do and that they have the minimum skills required to successfully complete the skill or lesson.

6. Guided practice: Students practice their new knowledge under direct supervision of the teacher to prevent early errors that may hinder learning. 
7. Independent practice: Only assigned after the teacher is reasonably sure students will not make serious errors.

Hunter discussed a typical error in supervision where the assumption is that all good things must be in every lesson. Each element described above must be considered and thought out by the teacher and exclusion is a matter of professional practice. As long as the decision is thoughtful and theory-based, when theory is available, and "wizardbased", when theory is not available, the teacher is acting as a professional (Hunter, 1984).

Panasuk and Todd (2005) developed the Four Strategies for Lesson Planning (FSLP) and a Lesson Plan Evaluation Rubric (LPER) as part of the Middle School Mathematics Initiative. The initiative was established as a result of the Third International Mathematics and Science Study of 1999, which determined the need for comprehensive lesson planning. Conceptual design for the lesson plan and rubric was based upon Gagné's $(1962,2001)$ instructional theory that emphasized task analysis, Ausubel's (1968) model of advanced organizers, Shulman's (1987) idea of pedagogical content knowledge (PCK), Tabachneck-Schijf, Leonardo, and Simon's (1997) ideas regarding multiple representations, and concept and task analysis, based on Gagné's (1965) hierarchy of principles and notion of organized knowledge structures. The FSLP includes (a) the formulation of cognitive objectives formulated in terms of students' observable behavior; (b) homework that is linked to the objectives; (c) developmental activities that reflect the objectives and advance development and learning; and (d) mental mathematics that activate prior knowledge, prepare students for the acquisition of 
new concepts. The corresponding evaluation rubric contained 34 subcategories scored on zero to four (0-4) scales.

Baylor, Kitsantas and Chung (2001) built a planning model, the Instructional Planning Self-Reflective Tool (IPSRT), which facilitates the implementation of the aforementioned instructional systems design planning model of Reiser and Dick (1996) and research in self-regulated learning (Zimmerman, 1999). The reasoning behind the use of this tool was that providing students with strategic tools to guide learning during selfdirected practice would be useful because practice usually occurs when an instructor in not present. Components of the IPSRT are: (a) instructional goal, (b) objective(s), (c) materials/preparation, (d) level and learner characteristics, (e) assessment, and (f) overall. Under each major section were specific yes/no questions asking if each section and subsections were properly and completely developed. The IPSRT was tested using 175 students in an Introduction to Educational Technology class. Following a brief training period, students, were given a lesson scenario and told to develop a lesson plan using the IPSRT. As a preliminary measure, students were asked to assess the value of the IPSRT in terms of its usefulness, with answers were coded yes or no for value due to selfevaluation, organization, and monitoring strategies. Eighty percent reported useful for monitoring, $75 \%$ for self-evaluation, and 25\% useful for organization (Baylor, Kitsantas \& Chung, 2001). Despite the weak and simplified manner of validation, at face value, the IPSRT appeared to be a useful tool for lesson planning when self-regulation is the primary objective.

Golland (1998) stated that understanding of the elements has become complex, sophisticated, and flexible as the disciplines of pedagogy and psychology have 
developed. He proposed a model for the supervision of student teachers using the elements of lesson planning for its structure. The elements of Golland's lesson plan are: (a) objective; (b) pre-assessment:, which determines the appropriateness of a specific, primary objective; (c) motivation: Motivation is a psychological state within each student of wanting to learn what the teacher has to teach. Motivation should be an attitude that is sustained throughout the lesson and not only a gimmick that begins the class.; (d) techniques and sequencing: activities, demonstrations, questions, reinforcements, media, materials, grouping and summaries are included here; (e) application, evaluation, \& follow-up: These concluding portions of a lesson speak to matters of utility, effectiveness, and the place of the lesson in the learning sequence; and (f) interpersonal skills and class management. These items are not part of the formal lesson plan but need to be addressed in planning and supervision. Golland then used the elements of the lesson plan for the structure of his supervisory student teaching duties.

Johnson (2000) provided a universal lesson plan format that the author claims can be used in any teaching situation. The author viewed the traditional lesson plan, the one that Madeleine Hunter (1984) devised, as cumbersome, unwieldy, and not applicable to every teaching situation. The author also believed that Hunter's plan did not reflect the way teachers think as they design learning experiences. Johnson's basic set of lesson parts begin with a specific objective that is completely descriptive and sequential with all questions and activities clearly explained. A rule of thumb is that a substitute teacher should be able to pick up the plan and teach the lesson. The following is a complete description of Johnson's lesson plan format: 
1. Objective: What exactly do you want to teach students? Lesson objectives should sound something like what young students tell their parents what they learned at school that day; behavioral objectives are not to be used as they are not consistent with a cognitive approach to learning. In addition, a reliance on behavioral objectives implies that learning is a finite endeavor rather than an interaction between what is known and new information. Also, behavioral objectives are not pragmatic, they complicate the lesson planning process, and they place less emphasis on a constructivist approach to learning.

2. Introduction: A quick method of introducing students to the concepts in the lesson. Links new ideas to known ideas, sparks curiosity, and creates interest in the lesson. 3. Input: Learning involves the construction of knowledge as new information is given meaning in terms of prior knowledge. All activities need to be organized in a knowledgebased context. The teacher organizes and lists in outline form exactly what is to be taught. If a skill is to be taught, the steps should be written out in sequence.

4. Activity: Involves the manipulation of the input. Examples include creative writing, drawing, simulation, discussion, problem solving, worksheets, and games.

5. Closure/Review: A short review of the main ideas covered in the lesson and is sometimes a preview of the next day's lesson.

An evaluation, although not part of the lesson plan format, was mentioned as it was assumed that teachers would be completing a formative evaluation to monitor learning and to adjust their planning and teaching accordingly.

The author also provided a scoring rubric in the form of a nine-point checklist (yes, no, sometimes), termed the criteria for effective lesson planning. This rubric can be 
used by both teacher educators and preservice teachers (Johnson, 2000). While Johnson considered Hunter's lesson planning format to be too lengthy and cumbersome, the details of Johnson's suggested lesson plan format and rubric often asked for a level of detail that was similar to that of Hunter's lesson plan format. The differences were in the placement of the details within each format and the use or absence of pedagogical terminology.

Kauchak \& Eggen (2007), in addition to their aforementioned cognitive planning model, provided a basic lesson planning model with the belief that it must be specific enough to provide structure for the lesson but general enough to ensure flexibility when the situation warrants. The lesson plan model, based on the thinking of authors in this area, (Arends, 2006; Orlich, Brown, Callahan, Harder, \& Trevisan, 2004), is composed of the following elements: (a) Unit title: identifies the relationship between the current lesson and other lessons in the unit; (b) instructional goal: identifies the broad goal for the lesson; (c) objective(s): identifies specifically what the students should learn; (d) rationale: explains why the lesson is important; (e) content: identifies and organizes the major skills and ideas in the lesson; (f) learning activities: describes the experiences that will be used to facilitate student learning and to reach the objective(s); (g) assessment procedures: specifies how student learning will be measured; and (h) materials and aids.

\section{Physical Education Planning Studies}

Despite a number of studies on planning in the physical education literature, it was somewhat limited with studies on lesson planning for early preservice teachers. Despite this fact, a review of these studies gleaned evidence for the importance of explicit planning for preservice teachers as many of the studies exhibited the importance of many pedagogical practices and teaching methods as planning is linked with teaching 
behaviors. This portion of the literature review described thirteen studies that were relevant to lesson planning. A description of these studies was organized based upon both by the type of study and the participants involved as they relate to lesson planning. While one study each viewed the planning behaviors of experienced teachers and one compared novice to experienced teachers, the remainder of the studies viewed planning of either preservice teacher versus experienced teachers or preservice teachers only.

Placek (1984) conducted a multi-case study to examine how four physical education teachers planned lessons in a naturalistic setting to determine how each of the subjects plan and to see what influences teachers as they plan. The four teachers, with teaching experience ranging from four to fifteen years, had their planning events documented through observation in their natural setting, and through formal and informal interviews and document collection. The amount of written planning varied by teacher, with two subjects writing only a list of activities and the other two choosing not to write plans prior to teaching. Results indicated that the subjects did not follow the format taught in curriculum or methods classes and were instead, limited to an abbreviated list of activities accompanied half the time with notes regarding equipment and class organization. Student goals were mentioned once by one subject during an interview. Overall, these teachers did most of their planning mentally and relied upon their memory of past teaching experiences in choosing activities for the class. Teachers usually planned in the morning either before school or immediately prior to class. Teachers were primarily focused upon student behavior and practical situations such as class organization, a list of activities, and space. 
Placek's data collection did not include a rubric for scoring either written or oral planning data despite the accumulation of a large amount of information through triangulation. This may have been due to the descriptive nature of the study and the types of research questions put forth. While not stated as such, the four teachers could be considered to be experienced teachers, with the least amount of teaching experience being four years. Tyson (1991), in his study of math teachers, considered a novice teacher one which has four or less years of experience. These teachers may not have needed a more concrete, or explicit plan for their classes.

Five physical education studies involved the comparison of preservice teachers and experienced teachers. Metzler and Young (1984) viewed the planning and teaching behaviors of an experienced teacher with over ten years of experience and a student teacher who taught a 20 minute experimental teaching unit (ETU) to fourth grade school children. Lessons were analyzed using the Flow of Teacher Organizational Pattern system to verify that teachers were consistently implementing their plans. The Academic Learning Time (ALT-PE) instrument was used to code student process behaviors. Differences between the two teachers in both the planning strategy and in ALT-PE values were noted and discussed. Although both teachers implemented seemingly well-planned lessons, review of ALT-PE values resulted in contrasting learning opportunities. A single teacher planning decision made before class can begin a chain of small events that will eventually and collectively become critical contributors to effective or ineffective student process behavior. The authors stated that preactive lesson plans must attend to not only the mobilization of material, and temporal and human resources, but also to the appropriateness of the assigned tasks. In addition, the very nature of, and course of, 
preactive decisions will determine the upper limits for student opportunity to learn in class.

Housner and Griffey (1985) studied the planning and interactive decision making processes of eight elementary physical education teachers with five or more years of teaching experience and eight preservice teachers to describe the planning decisions made by experienced and inexperienced teachers. A teacher planning decision coding system was developed to classify planning decisions. Results indicated that experienced teachers made more information requests than inexperienced teachers prior to planning, with major differences regarding the experience or background of students and the facilities to be used. Experienced teachers made almost twice as many instructional strategy decisions as inexperienced teachers, with the categories of management, assessment/feedback, demonstrations, focus attention, and equipment use contributing the most to the difference. The authors concluded by stating that experienced and inexperienced teachers vary considerably in terms of the decision making strategies employed as they plan to teach physical education and that these strategies could be used to train beginning teachers (Housner \& Griffey, 1985).

Griffey and Housner (1991) examined the relationship of planning to classroom process occurrences by comparing experienced and inexperienced teachers on the variables of planning decisions, instructional interactions, student engagement, and climate of the instructional environment. The think aloud technique was again used as teachers planned during a 60 minute session and the audiotapes of these sessions were analyzed to determine the number and type of planning decisions made by teachers. Teacher planning results indicated that experienced teacher made more information 
requests than inexperienced teachers in terms of student background and experience and facility use. In terms of instructional strategy decisions, marked between-group differences were found as experienced teachers made almost twice as many decisions as inexperienced teachers. Categories that contributed most to this difference were equipment use, focus attention, demonstrate, assess/feedback, and management. These findings indicate that experienced teachers were more concerned with managing activities during instruction and providing students with information that facilitates motor skill acquisition than inexperienced teachers. In terms of interaction analysis, experienced teachers' classes were characterized by more praise and lecturing than occurred in inexperienced teachers' classes. The marked difference in the occurrence of lecturing among experienced teachers echoes their planning decisions aimed at providing students with information regarding skill performance. Inexperienced teachers' plans reflected a lack of contingencies and accommodations based on abilities and experiences of students that were manifested in their teaching.

These two studies by Griffey and Housner provided teacher educators with insights into how competent teachers plan and teach their lessons. These particular teaching methods provided a framework for inexperienced, or, preservice, teachers to improve their planning and teaching.

Solmon and Lee (1991) contrasted the planning behaviors of expert and novice (preservice) adapted physical education teachers to determine the information they needed to plan a lesson and the way they conceptualized a lesson. Four expert and four senior, preservice teachers were asked to plan a 30 minute fictitious lesson on catching. Results indicated that qualitative differences in the content of the questions asked prior to 
planning existed between the two groups of teachers, with expert teacher questions focusing around student characteristics and preservice teacher questions revolving around how to write a lesson plan and whether assistance would be available to them during a lesson. When comparing written plans of the two groups, qualitative differences were quite apparent. The plans of novices were teacher centered and remarkably similar and did not incorporate student performance levels. Expert written plans were complex and diverse. Expert teachers used unique introductory activities, varied teaching techniques, and creative approaches to lesson. Explicit in plans were evaluation of skill level, provision for feedback, progressions of skill, and differentiated activities to address individual differences. Overall, experts' plans reflected their vast store of knowledge about handicapped children, how they acquire fundamental skills, and their diverse approaches to teaching fundamental skills.

As with other studies, this investigation did not include a lesson plan scoring rubric, although the written plans were examined for components such as objectives, time allotment, evaluation, and the selection and sequence of activities (Solmon \& Lee, 1991). As with previous studies in this section, this study provided insight into the effective methods employed by expert teachers. The authors lament that teacher education programs will not produce experts in their field during their first year of teaching and cited a need for experience (Solmon \& Lee, 1991). Berliner's (1994) assessment of this situation is identical, as he stated that we should not expect the novice teacher to perform like an experienced teacher and we should not believe that teacher education programs can turn out competent teachers. They can produce educable novices and advanced beginners. That being said, the fact remains that an identification of pertinent lesson plan 
concepts that could be organized in the future to produce a functioning lesson plan template and accompanying rubric could be incorporated into the early classes of a teacher preparation curriculum to improve the thinking abilities of preservice teachers.

Graham and his compatriots studied the situational decision making of novice and experienced teachers by comparing the planning and teaching procedures as they taught elementary school students basketball dribbling. Results of the research indicated that the written plans of the novice teachers were far more extensive than those of the experienced teachers. In particular, it was found that each of the novice teachers intentionally over planned for the lesson fearing that they would run out of things to do. The authors state that these plans needed to be more extensive because novice teachers didn't have the information stored away, via schemata, like experienced teachers did. This study did not mention the collection of lesson plans for analysis and relied upon an extensive, ethnographic investigation using interviews, field notes, videotapes, and lesson analyses (Graham, Hopple, Manross, \& Sitzman, 1993).

Seven studies in physical education focused solely on preservice teachers. Imwold, et al., (1984) compared the teaching process interaction behavior of teachers who planned versus those that did not plan. Twelve senior preservice teachers were randomly assigned to either the planning or no planning group. The planning group subjects were provided with one hour to plan and were given a lesson plan format and information regarding the skill to teach, the length of class, facilities and equipment, and the characteristics of the students to be taught. Although there were significant differences only in terms of the amount of instruction given and the amount of silence during the lesson, the subjects who planned made better use of equipment and facilities, 
had a greater variety of learning activities, and provided students with a closure that included a review of the lesson and a time for questions and comments (Imwold, et al., 1984).

Byra and Coulon (1994) also compared the teaching behaviors of preservice teachers who planned versus those who did not plan while teaching elementary students. Results indicated that planning had a positive effect on some preservice teachers' instructional behaviors. Students taking part in planned lessons spent less time in noninstructional aspects of activity, less time waiting their turn, and less time engaging in off-task behavior during activity time. Teachers were more attentive to the actions of students during pretask presentations and provided specific corrective feedback that matched the skill focus of the lesson more frequently during task presentations. The authors concluded that it is important for preservice teachers to be given ample opportunity to plan, implement, and evaluate instruction on a regular basis early in their preservice training.

The studies by Imwold, et al. (1984) and Byra and Coulon (1994) provided solid evidence for preservice teachers to engage in planning as evidenced by preservice teachers' planning and its link to successful instructional behaviors. The importance of lesson planning is often irrelevant to preservice teachers as they have a mistaken notion that expert teachers "wing it". Preservice teachers also believe that planning is effortless and that it is not necessary to sufficiently plan ahead (Hansen, 2006). These two studies should help to convince preservice teachers for the need for comprehensive planning early in their PETE curriculum. 
Twardy and Yerg (1987) examined how teachers plan by investigating how lesson plans influenced teacher-learner interactive behaviors. Preservice teachers' planning and teaching were studied using the Florida Performance Measurement System (FPMS), which views teacher behaviors in terms of three major categories: planning, implementation, and evaluation. The planning variables measured in frequencies of teacher attention were content coverage, utilization of instructional materials, activity structure, goal focusing, and diagnosis. Results indicated that preservice teachers focused more on activity structure than any other planning category $(53 \%$ of all generic planning statements). Particular planning behaviors were related to specific teaching behaviors. Planning behaviors associated with identifying content, analyzing learning activities, and assessing learner needs are related to the teaching behaviors of lecturing and providing demonstrations. Therefore, it appears that what teachers plan to do prior to instruction does have an effect on learner in-class behavior. The results suggested significant relationships between teacher planning behaviors and in-class teacher and learner behavior (Twardy \& Yerg, 1987).

Byra and Marks (1991) examined the effects of an intervention, in the form of data-based feedback, on first year preservice teachers' preactive and interactive behaviors as they planned and taught gymnastics and fundamental movement. Planning information provided to the preservice teachers focused on development of objectives and activities for meeting stated objectives. Three data collection instruments included one for coding selected components of lesson plans, based on instructional objectives, task progressions, and critical skill cues. As a result of the intervention, where subjects received written and verbal information about their lesson plans regarding the development of objectives and 
activities for meeting stated objectives, mean scores for all three planning components increased substantially after first intervention and plateaued thereafter. The authors concluded by stating that preservice teachers can write complete lesson objectives consistently and can incorporate task progressions and critical skill cues in their lesson plans soon after having received data-based feedback. In addition, the study showed that as preservice teachers planning behaviors improved, their teaching behaviors also improved. The authors stated that if permanent changes are to be realized in the planning behaviors of future physical education teachers, then trainees need to plan, teach, and receive objective feedback on a regular basis during preservice training (Byra \& Marks, 1991).

Brown and Cheffers (1991) stated that physical education practitioners (inservice teachers) view their teacher preparation courses as presenting lofty planning methods that are not applicable in the actual school setting. They further stated that PETE programs emphasize planning for learning while practitioners plan for management. Practitioners should adopt an approach of planning for key results, which partitions the job of teacher into its basic functions and activities. The authors suggested that teachers identify critical areas of teaching and learning episodes by identifying the essential skills of an activity receiving the focus of the instructional attention. Using Morrisey's (1983) five guidelines, teachers should complete the following: (a) Identify the major skill area within unit; (b) identify those areas during the teaching and learning process to direct priority effort; (c) limit each key result to one, two or three words; (d) identify those areas where results will occur; and (e) identify those elements of the students' behavior that are measurable. (Brown \& Cheffers, 1991). 
The authors were correct in stating that experienced teachers do not need the explicit lesson plans that were written during preservice teaching classes in PETE programs and are correct in the reduced need for inservice teachers to write detailed objectives. The lesson plan format they provide is detailed in terms of the importance they place on identifying skills, the subsequent design of those skills, and the eventual assessment of student learning (Brown \& Cheffers, 1991). The authors should, however, take into account the purpose of explicit lesson planning formats for inexperienced PETE students. The preservice teachers usually lack the pedagogical, pedagogical content, and subject matter knowledge that experienced inservice teachers possess, and therefore, need to write and think through the planning process carefully prior to a teaching episode. Rather than asking PETE programs to revise their planning format for their preservice teachers to meet the realities of the gymnasium, the authors may suggest that teaching programs provide this lesson design as a transitional plan to be used during the first few years of a novice teacher's professional career.

O'Sullivan and Tsangaridou (1992) sought to determine physical education teacher education majors' conceptions of the teaching-learning process and their role as a teacher in that process by asking four questions: (a) What issues did the majors attend to as significant incidents from their teaching and did they change during the experience, (b) What were the characteristics of their lessons that they perceived as successful, (c) What were the characteristics of the lesson that were unsuccessful?, and (d) What were their conceptions of teaching? Thirty-nine junior PETE majors, involved in their first teaching experience, taught a short, instructional unit to six to ten middle school students for four lessons during the first five weeks of the semester and in a secondary school during the 
last three weeks of the semester. The critical incident technique, along with an openended questionnaire on their views of effective teaching, teachers, and programming for secondary physical education during the debriefing sessions, was implemented. Six critical incidents and their categories were identified and planning was included among them. In terms of the focus of the teacher trainees' writing during the field experience overall, $18 \%$ of the critical incidents dealt with planning, which ranked third behind instruction $(23 \%)$ and management and organization $(21 \%)$. In terms of the characteristics of lessons that were perceived as successful, planning was the third most frequent indicator of a successful lesson (21\%) behind instruction (28\%) and management and organization (24\%). Preservice teachers' indicators of an unsuccessful teaching experience included appropriate or inadequate planning at 17\%, which was tied for third behind failure to achieve instructional goal and student demeanor.

Preservice teachers' perceptions of successful teaching are understandable: they place the most importance on instruction, management, and organization. Inexperienced teachers are often most concerned with the delivery of their instruction and the movement and behavior of their students. While these preservice teachers rated planning as the third most important feature of a successful lesson, they may not realize that a successful teaching episode may correlate with proper planning, which includes the proper design of a lesson for instruction, management and organization. Preservice teachers' top two perceptions of an unsuccessful lesson, failure to achieve the instructional goal and student demeanor, may also be improved through proper planning.

Reflecting upon the need to best prepare PETE students for their first teaching experience, Gurvitch \& Hawkins (2004) studied the effects of lesson planning on the 
behaviors of teachers and students. Eighteen preservice teachers with no previous teaching experience taught soccer and volleyball units to third grade students under two planning conditions: self-made lesson plans (SM) and ready-made lesson plans (RM) using the Sports, Play and Active Recreation for Kids(SPARK) curriculum. Following the same lesson objectives, RM plans were administered to subjects one week prior to teaching and SM lessons were planned by pre-service teachers. Using an alternating treatment design, teaching episodes were videotaped and coded using an academic learning time-physical education (ALT-PE) based instrument. Significant differences were found in favor of SM lesson plans with regard to student motor appropriate and offtask behavior. The authors concluded by stating that engagement in planning has a positive effect on students' behaviors of preservice teachers and that SM plans produced better teaching practice. The authors' recommendation for teacher educators was to provide more SM planning opportunities to encourage better teaching practices during teacher preparation programs.

\section{Miscellaneous Planning Articles}

Charrette (2009) was dissatisfied with the available options for lesson planning and wanted a plan that was easy to use, detailed in nature, and yet be flexible so that it could be applied in a number of situations. With this in mind, the author developed a comprehensive lesson plan format that is versatile, inclusive and practical. The VIP design is versatile because, being a Mircrosoft Word document, titles and text boxes can be easily modified. In addition, the template can be used as a unit guide, a grouped lesson guide, an individual lesson plan, a separate activity or game plan, or as a special event plan. The VIP plan is inclusive because it includes a wide variety of critical lesson plan 
components that include the following: lesson/unit title, grade level(s), overview and purpose, learning outcomes, materials/resources, essential questions, instructional activities, movement components, header and footer tags, week number and day, unit focus, standards addressed, modifications, safety concerns, assessment methods, fitness components, and closure items. This VIP plan is versatile because it fits onto one page of paper, can be shared with other colleagues, student teachers and administrators, and is easily used to assess students with the checklist provided at the bottom of every VIP plan.

\section{Alternative Physical Education Planning}

Over the years several curricular models have been developed that range from constructivism to health-related fitness. As a result, corresponding lesson plans of varying detail have been formulated to correspond with their particular curricular model.

Prusak, Wilkinson, Pennington, and Graser, (2008) describe health-related fitness (HRF) lesson content and describe instructional strategies in object-lesson format to be implemented by secondary school physical education teachers to increase student understanding and personal construction of meaning. This was an example of a movement-education approach through constructivist methods, where values, experiences, and knowledge that their students bring to the classroom assist teachers in developing their content to make the topic personal and to improve the connections between what students already know and what they will learn in the class. The lesson plans described activities that allowed students to engage in self-directed learning opportunities in order to find personal meaning through first experiencing concepts and then by teacher-guided discovery of concepts that solidifies and deepens their understandings. One object-lesson was described for each of the five HRF components: 
cardiorespiratory fitness, body composition, flexibility, muscle strength and muscle endurance. The major content of the lesson plan for HRF is as follows: (a) What is it? Introduces the HRF concept and describes it in detail; (b) Why should I care? Importance and benefits of the HRF topic; (c) Activity: Students perform particular function or activity; and (d) Assignment/Assessment: Answer questions for homework on topic and activity.

The Sport, Play \& Active Recreation for Kids! (SPARK) physical education curriculum, created for physical education specialists and classroom teachers, began as a study funded through the Heart, Lung, and Blood Institute in 1989 in order to reduce cardiovascular disease risk factors such as high blood pressure, obesity, and sedentary lifestyles. The five year study resulted in the SPARK programs, which eventually evolved to encompass programs for early childhood, elementary, middle, and high school PE, as well as those for after school PE and coordinated school health (Rosengard, Baranowski, Williston, McKenzie, \& Short,, 2008). SPARK PE, in particular, "......was designed to encourage health-related physical education by maximizing physical activity participation during class to improve students' fitness, skills, and enjoyment." (Dowda, Sallis, McKenzie, Rosengard, \& Kohl, 2005, p. 12). Each SPARK manual includes resources on how to teach using SPARK, teaching strategies to promote moderate-tovigorous physical activity (MVPA), and yearly, unit and lesson plans. Lesson plan content is differentiated based upon grade level ranges. K-2 lesson plans, for example, are divided into three major sections: (a) Ready: equipment and materials are gathered and optional student assistants are chosen; (b) Set: activities are prepared beforehand and equipment is set-up. Students are prompted to walk and talk with a friend as music is 
played and instant activities, termed ASAP (active, soon as possible) engage students in physical activity almost immediately.; (c) Go!: The ASAP activity provides the warm-up for five to seven minutes prior to the 15-20 minute activities of the unit. A three to five minute cool down and conclusion (Wrap it Up) end each lesson (Rosengard, et al.,, 2008).

Hellison (2003) developed the taking personal and social responsibility (TPSR) model out of necessity driven by a response to the attitudes, values, and behaviors of the underserved children to whom he was teaching high school physical education. This model combines physical education teaching with the ideas of character development, social problems, and teaching values. The five goals of the TPSR model include the following levels and their sublevels: Level I: Respecting the rights and feelings of others, through self-control, the right to peaceful conflict resolution, and the right to be included; Level II: Participation and effort, via self-motivation, exploration of effort and new tasks, and courage to persist when the going gets tough; Level III: Self-direction, via on-task independence, goal-setting progression, and the courage to resist peer pressure; Level IV: Helping others and leadership, which includes caring and compassion, sensitivity and responsiveness, and inner strength; and Level V: Outside the gym, which focuses upon trying the above ideas in other areas of life and being a role model.

The four themes of the TPSR model, which provide consistency across lessons and units, are integration, transfer, empowerment, and the teacher-student relationship. The TPSR levels and strategies must be integrated into the physical education lesson rather than taught separately. Students need to be able to transfer what they have learned in the gymnasium into other classes and situations in the school. Student responsibility 
through their choices in class leads to empowerment. This is the basis behind self-control, self-motivation and self-direction that is built into the levels and sublevels of the TPSR. Being able to recognize and respect the qualities of students can lead to a successful teacher-student relationship (Hellison, 2003).

Hellison also provided a specific progression for integrating the model into physical activity lessons. Beginning strategies include the introduction of inclusion activities and rules, self-pace challenges such as individualized progression at stations, and reciprocal coaching. Lesson strategies for discipline and motivation problems, as well as advanced lesson strategies such as implementing the accordion principle and allowing for a choice of games (competitive or recreational, competitive or cooperative) provide the teacher with several methods of integrating TPSR principles directly into a physical education lesson (Hellison, 2003).

\section{Physical Education Planning Textbooks}

Several text books for practitioners have been developed that provide written lesson plans for physical education. Zakrajsek, Carnes, \& Pettigrew (2003) developed unit and lesson plans for secondary physical education that purportedly responds to the need for a serviceable book that communicates fundamental physical education principles through complete unit and lesson plans. The authors state the text is also of use to undergraduate PETE students because it allows them to concentrate on the refinement of

teaching and management skills without the need to formulate specific physical education content. Each lesson plan included the following components: lesson number and title, purpose, facility and equipment, warm-ups, skill cues, teaching cues, safety tips, 
activities, optional activities, closure, variations, and resources. The text also provides a chapter on assessment.

Casten (2006) designed a text for use with Darst and Pangrazi's Dynamic Physical Education for Secondary Students. Casten's text provides the overall lesson plan format which includes the introductory activity, fitness development activity, lesson focus activities, game activity, evaluation/review, and cheer (Casten, 2006) while the Darst and Pangrazi (2009) text provides the details of the activities. In addition, Darst and Pangrazi provide a detailed account of the components of a well-written lesson plan, including cogent pedagogical points to consider when planning, teaching and organization hints, expected student outcomes, and a detailed questionnaire that aids in the reflection process.

\section{Delphi Method}

Expert opinion, and not general or informal opinion, is often sought to develop educational policy. Decisions regarding the professional development of teachers require critical thinking and reasoning. Questions such as "What are the teaching competencies required of today's teachers?" is a substantive question that university academics, among others, need to consider. Therefore, critical decisions in program improvement require accurate information, careful consideration, and involvement of more than one decisionmaker (Clayton, 1997).

The Delphi method is a research technique that has been endorsed for deriving consensus with expert judgment (Bulger, 2004). The Delphi procedure offers decisionmakers a rigorous and systematic strategy for the collection and dissemination of critical information and is technique for collecting judgments that attempts to overcome the 
inherent weaknesses in relying on a single expert, a one-shot group average, or a roundtable discussion (Clayton, 1997). It's an iterative process (a procedure in which repetition of a sequence of operations yields results successively closer to a desired result) to collect and distill the anonymous judgments of experts using a series of data collection and analysis techniques interspersed with feedback. It is well suited as a research instrument when there is incomplete knowledge about a problem. The Delphi method works especially well when the goal is to improve the understanding of problems, opportunities, solutions, or to develop forecasts (Skulmoski, Hartman, \& Krahn, 2007). The Delphi method has also been recommended for use when the complexity associated with a particular problem exceeds the intellectual capabilities of a single decision maker (Bulger, 2004). The Delphi model is flexible in terms of its usage, as it is a method for structuring a group communication process to facilitate group problem solving and to structure models, can be applied to program planning and administration and to problems that do not lend themselves to precise analytical techniques but rather could benefit from subjective judgments of individuals on a collective basis, and can be used to investigate what does not yet exist (Skulmoski, Hartman, \& Krahn, 2007).

In fields of education, the Delphi method has been used for the investigation of medical teacher competencies (Yeates, Stewart, \& Barton, 2008), teacher competencies in higher education (Tigelaar, Dolmans, Wolfhagen, \& van der Vleuten, 2004), and literacy competence standards (Wen \& Shih, 2008). The Delphi method has also been used in the study of physical education teacher education for the development of exercise science competencies (Bulger, 2004) historical, philosophical, and sociological competencies (Metcalf, 2010), and adapted competencies (Suphawibul, 1992), as well as 
for program evaluation (Mendes, do Nascimento, Nahas, Fensterseifer, \& de Jesus, 2006), for future trends in physical education (Ishee, 2003), for essential assessment criteria in PETE (Jacobs, 1997), and for validating teacher competencies (Cicek \& Demirhan, 2001).

Delphi Method Features. The Classical Delphi method was developed by Norman Dalkey at the Rand Corporation in the 1950s for a military project. Its four key features are as follows: 1 . Anonymity of Delphi participants, which allow individuals to freely express their opinions without social pressures to conform to others in the group. (i.e., decisions are based on merit rather than personality or influence; 2. Iteration: allows individual participants to refine their views in light of the progress of the group's work from round to round; 3 . Provides for controlled feedback which informs participants of the other participants' views and perspectives and provides the opportunity for Delphi individuals to clarify or change their views; 4 . Allows for a quantitative analysis and interpretation of data (Skulmoski, Hartman, \& Krahn, 2007).

The Delphi usually undergoes four phases. The first includes the exploration of the subject matter at hand, where each individual contributes information that he or she feels pertinent to the issue. The second phase involves the process of coming to an understanding of how the group of individuals views the issue. If significant disagreement occurs, then said disagreement is explored during the third phase to uncover the reasons for the differences and to possibly reevaluate them. In the fourth phase, a final evaluation occurs where all previously gathered information has been initially analyzed and the evaluations have been fed back for consideration (Linstone \& Turoff, 1975). 
Delphi Method Protocol. In general terms, "...Delphi may be characterized as a method for structuring a group communication process so that the process is effective in allowing a group of individuals, as a whole, to deal with a complex problem" (Linstone \& Turoff, 1975, p. 3). To meet the criteria for such "structured communication", the following characteristics are needed: (a) feedback of individual contributions of information and knowledge, (b) assessment of the group judgment or view, (c) the opportunity for individuals to revise their views, and (d) a degree of anonymity for the individuals involved in the Delphi process.

The Delphi method of investigation requires the proper selection of experts in the subject matter under investigation (Clayton, 1997). Research sample selection is a critical component because it is the expert opinions upon which the output of the Delphi is based. Four requirements of expertise need to be considered: (a) knowledge and experience with the issues under investigation, (b) willingness and capacity to participate, (c) sufficient time to participate, and (d) effective communication skills. Because expert opinion is needed, a purposeful sample is required (Skulmoski, Hartman, \& Krahn, 2007). Depending on the purpose of the study, both the complexity and the expertise required of the Delphi panel may be small or large, and local, state, national and international. Despite variations, a homogeneous population (one that is comprised of experts in the same discipline) should consist of 15-30 members and a heterogeneous population should consist of five to ten members in total (Clayton, 1997). There are several additional considerations in terms of panel selection. There is a tradeoff between the quality of the decisions to be made and the manageability of the group of experts. There is a reduction in group error (or an increase in decision quality) as sample size increases. However, 
above a certain number of participants, managing the Delphi process and analyzing the data becomes cumbersome. In addition, there is the decision of internal or external verification. The larger the group, the more convincingly the results can be said to be verified. However, a smaller sample size may be used, with results verification conducted with follow-up research (Skulmoski, Hartman, \& Krahn, 2007).

Typical Delphi process includes three rounds and includes the following steps: (a) Develop the research question, which may be derived by the researcher and his or her supervisor. A literature review is conducted to determine if a theoretical gap exists. Pilot studies may be completed to identify the problem, to conceptualize the study, to design the study, to develop the sample, to refine the research instrument, and to develop and test data analysis techniques; (b) Design the research from a macro to micro perspective by reviewing different research methods (both quantitatively and qualitatively). The researcher selects the Delphi method when desiring the collection of judgments of experts in a group decision making setting; (c) Selection of the Delphi participants as detailed above; (d) Develop Delphi round one questionnaire: attention needs to be devoted to developing the initial broad question so that participants do not provide inappropriate answers or become frustrated; (e) A pilot study is often conducted with the goals of testing and adjusting the Delphi questionnaire in order to improve comprehension and to correct any procedural problems; (f) Release and analyze round one questionnaire: Questionnaires are distributed to participants and then collected and analyzed by the researcher. Reality maps, which are graphical representations of the key constructs under investigation, can be developed and shared with participants to improve understanding and to facilitate the emergence of collective intelligence in subsequent rounds; (g) 
Develop round two questionnaire: Round two questions will be based upon the responses from the initial round. If the purpose of round one was to generate a list, then round two's purpose is to pair down that list; (h) Release and analyze round two questionnaire: Experts are first given the chance to review and verify their round one response to be sure they reflected their opinions. Ranking and rating responses from the first round is common; (i) Develop round three questionnaire: Round two responses are used to develop round three questions. These questions verify results, may help to understand boundaries of the research, and to understand where these results can be extended. The questions in this round are typically more specific; (j) Release and analyze round three questionnaire; and (k) Verify, generalize, and document research results: Delphi results are verified (usually continuously through the Delphi) and the extent that results can be generalized is also investigated (Skulmoski, Hartman, \& Krahn, 2007).

Modified Delphi. A modified Delphi investigation was employed for the current study as panel members were given an initial list of possible lesson planning concepts accumulated from the pilot study. The expert panel members were given the opportunity to provide comments on each lesson planning concept as they were completing both Rounds of the survey. 


\section{Methodology}

The purpose of this study was to determine and organize a list of lesson planning concepts that could then be used by preservice physical education teacher education students in preparing lesson plans for their undergraduate courses and teaching episodes. The research methodology for this chapter is organized into the following sections: (a) Pilot Study, (b) Participants, (c) Research Design, (d) Instrumentation, (e) Administrative Procedures, and (f) Data Analysis.

\section{Pilot Study}

To date, there has been little consensus as to what should be included in a PETE undergraduate lesson plan. In preparation for the current modified Delphi study where experts assessed and rated existing lesson plan concepts, and to aid in the generation of a list of PETE lesson plan concepts, a survey of all known PETE programs in the United States was created in order to accumulate lesson plan template information.

The Institutional Review Board for the Protection of Human Subjects was consulted for approval for this research. The board found that this pilot study was not considered to be human subjects research and, therefore, was declared to be exempt from approval. All known NCATE accredited PETE undergraduate programs ( $\mathrm{n}=198)$, as determined from the NCATE website, were surveyed regarding their use of lesson planning templates. Fifty-eight programs (29.29\%) responded to the survey and 51 programs $(25.76 \%)$ sent their program's lesson plan template via email correspondence.

An email sent to all of the known PETE programs included a brief introduction, a purpose and the short survey itself (see Appendix 1). The survey contained two questions each with two parts. The questions asked if the PETE professional and program had a: 1). 
lesson plan template that they used when teaching lesson planning, and 2) lesson plan scoring rubric that they used to score PETE undergraduate lesson plans. The subjects were then asked to forward any templates and rubrics that they had in their possession. Despite being considered exempt from human subjects research approval, an email attachment was also sent to all PETE undergraduate programs that included an introduction, the purpose of the study, a description of procedures, risks and discomforts, alternatives, benefits and contact persons, as well as statements regarding confidentiality and voluntary participation (see Appendix 2). Two weeks following the submission of the first email, a follow-up email was sent to all programs which had failed to initially respond to the survey.

Lesson Plan Assessment. To code the submitted lesson plan templates, a Lesson Plan Assessment Document (see Appendices 3 and 4) and instructions were developed by the researcher. The assessment document explained how terms were to be recorded and in which particular area of the assessment document the terms should be recorded. Once all available documentation (lesson plan templates) had been emailed to the researcher, the researcher coded the lesson plans according to the instructions. To verify the results of the coding by the researcher, a fellow doctoral student who had been formally trained in the lesson plan assessment document and instructions coded $10 \%$ of the lesson plan templates. This doctoral student completed the coding without the aid of the researcher. Once completed, the researcher and fellow doctoral student completed an item analysis on the $10 \%$ of the lesson plans to determine the reliability of the scoring. A predetermined reliability coefficient of 0.80 or higher was established prior to the item analysis. All 10\% of the lesson plans were coded above the 0.80 level. 
Concept Consolidation. A total of 507 concepts were identified from the 51 lesson plans. These concepts were placed into the following general categories: Background Information, Objectives/Outcomes/Domains, Standards, Safety, Content/Tasks/Activities, Assessment, References, Reflection, and Other Terms. Rating all 507 concepts would have been much too time consuming for a panel of curriculum and instruction professionals to complete. A consolidation of concepts was completed by the researcher to identify those concepts that were identical or quite similar in nature and were consolidated into a manageable amount for a rating of significance in the modified Delphi study (see Appendix 5). Grouping of concepts was done with consideration for each lesson plan's context when possible. Some concepts, such as objectives and lesson focus, occured in more than one of the nine general categories and were therefore analyzed as such. An Excel spreadsheet was used to tabulate the consolidation of concepts.

A total of 245 unique concepts were identified from the term consolidation. Despite the reduction in terms by about half, this large number of lesson plan concepts continued to be an unworkable number to provide to a modified Delphi panel. Therefore, a decision was made to identify those existing concepts that occurred only in at least five percent (a minimum of three) lesson plans. When tabulated, a total of 66 unique concepts were identified (See Appendix 6). 


\section{Participants}

The selection of panel participants is of utmost importance to the Delphi and serves to authorize the Delphi's superiority over less rigorous survey procedures. As stated previously, the Delphi method requires that a panel of experts on the subject matter under investigation be selected (Clayton, 1997). "By expertise we mean expert knowledge upon which professional authority can be founded. This expert knowledge can be 'proven' by demonstration or by recourse to confirmation through third parties" (Brockhoff, 1975; p. 295). Expertise implies that individuals have more knowledge about the subject matter than most people or possess particular work experience in the area of relevance (Murry \& Hammons, 1995). Clayton (1997) recommended 15-30 people for a homogenous population, or experts coming from the same discipline. Researchers employing the Delphi method in educational fields have selected 16 (Harris \& Rogers, 2008), 32 (Yang, 2000), and 23 (Gange, 2010) experts. In physical education teacher education, researchers have selected 20 (Bulger \& Housner, 2007), 25 (Metcalf, 2010), and 26 (Gurvitch, 2004) experts. To ensure a proper number of Delphi panel members, all candidates identified as possible panelists were asked to participate in this study.

As the purpose of this study was to determine essential lesson planning concepts for use by undergraduate students, the expert panel was a homogenous one. Based on the aforementioned recommendations on panel size, a group of experts (a minimum of $n=20$ ) was selected and recruited from a pool of 72 candidates representing current PETE faculty members or those employed in entities promoting physical education curriculum and instruction. Regardless of the employment field, all candidates had earned a terminal degree. These individuals met at least one (1) of the following criteria for inclusion as a 
Delphi panel member: These panel members had either (a) published studies on lesson planning in physical education teacher education ( $\mathrm{n}=13)$, (b) published text book(s) on lesson planning and/or curriculum development ( $\mathrm{n}=17)$; (c) engaged in curricular instruction and development as part of their professional duties $(n=72)$; or $(d)$ were current or former members of NASPE's Curriculum and Instruction Academy ( $\mathrm{n}=44)$. Qualifications for this Delphi panel were not limited to only those engaged in published journal articles and textbooks on lesson planning because of the relatively small number of professionals in that specific area of scholarship. The pool of possible candidates was widened to include those in the area of curriculum and instruction because they were all ultimately engaged in planning, whether it be at the lesson, unit, or curricular level.

\section{Research Design}

This research entailed a two-round modified Delphi protocol to determine a consensus regarding the essential concepts of a PETE undergraduate lesson plan. The resulting list of lesson plan concepts could be utilized by undergraduate students preparing for preservice teaching experiences with their peers and with local physical education students at K-12 public schools. In the future, a lesson plan template and corresponding scoring rubric could be created and then be utilized by PETE professionals to score students' lesson plans for completeness.

Two-round modified Delphi for lesson plan concepts. During each round of questioning, the panel experts were asked to rate lesson plan concepts (derived from the pilot study results) for importance and use by undergraduate PETE students. During the first round of questioning, panel members were also asked to provide any comments they have regarding each concept. 
The selected concepts that will be included in a PETE lesson plan will provide new PETE undergraduate students with a comprehensive list of pedagogical terms with which to consider in their lesson planning duties. In the future, the placement of these concepts in a template, along with an appropriate value or score for each item, will provide these preservice teachers with an organized tool with which to construct individual lesson plans for both laboratory and field placements they will engage in as they complete a teacher education program. This template and corresponding scoring rubric will also allow the preservice teacher to review their lesson plan design for completeness prior to implementation. PETE faculty, university supervisors and cooperating teachers will also benefit from the rubric as they provide constructive feedback to their preservice teachers. The template and rubric may also be of use to faculty as a component of program evaluation.

\section{Instrumentation}

An attempt to identify the pertinent concepts for an undergraduate PETE program lesson plan was completed during the pilot study. The list of 66 concepts from the pilot study was reviewed by the expert panel for content validity using a five-point Likert scale. A rating of four or five indicated that the concept was recommended by the panel member as a valid lesson plan item to be incorporated into the lesson plan template. A rating of three meant that the panel member was neutral regarding the concept. A rating of one or two indicated that the panel member recommended that the concept should be eliminated from the final version of the questionnaire because it lacked validity. As stated previously, panel members were able to provide comments regarding each of the two modified Delphi rounds. 


\section{Administrative Procedures}

The administrative procedures were adapted from those of Bulger (2004). These procedures are described in the following sections: (a) Selection of Participants, (b) Round I Procedures, (c) Inter-Round Procedures, (d) Round II Procedures, and (e) Construction and Validation Procedures.

Selection of Participants. Prospective Delphi panel members were invited to participate in the study via a pre-notification email (see Appendix 7) and a Round I participant recruitment e-mail (see Appendix 8) describing the purposes of the study, an explanation of the modified Delphi method, an explanation of the time requirements, and an invitation to participate.

Due to the voluntary participation and time requirements of a modified Delphi study, participant attrition was a primary concern (Jacobs, 1996). Response rates vary widely in the literature, with Cooney, et al., (1995) reporting 8\%, and Pilon, Sullivan and Coulombe (1995) reporting 100\%. Despite the lack of a uniform response rate, a preset experimental mortality target was employed to determine the deleterious effects of participant attrition on the results of the study. While no specific guidelines exist for an acceptable response rate for Delphi studies (Keeney, Hasson, \& McKenna, 2011), several authors (Bork, 1993; Walker \& Selfe, 1996; Sumsion, 1998) recommended a 70\% response rate for each Delphi round to maintain rigor. It was therefore, desired that at least $70 \%$ of panel members who participated in Round I of the current study would also complete Round II.

Round I Procedures. Following approval from the Institutional Review Board for the Protection of Human Subjects, the survey instrument design was completed, and 
the selection of participants was finalized. A total of $n=28$ experts agreed to participate in the study. Of the 28 participants, $25 \%$ published studies on lesson planning in physical education teacher education, $25 \%$ published text book(s) on lesson planning and/or curriculum development, $100 \%$ engaged in curricular instruction and development as part of their professional duties, and 75\% were current or former members of NASPE's Curriculum and Instruction Academy. The 28 experts included 25 from the United States, two from Europe, and one from Asia. Of the 25 experts from the United States, one worked in the Northeast, eleven in the Southeast, eight in the Midwest, and five in the West.

Each modified Delphi participant received an email with additional details of the study (see Appendix 9) and a link to the questionnaire website via Survey Monkey. The website contained a survey introduction (see Appendix 10), Round I instructions (see Appendix 11), and the actual questionnaire (see Appendix 12). The questionnaire, as per the aforementioned five-point Likert scale, asked each participant to rate each potential lesson plan concept. In addition, Delphi participants had the opportunity to provide comments after rating each concept.

Within ten days after the first round emailing, each modified Delphi panel member received a follow-up email to answer any remaining questions and to prompt a timely completion of the online questionnaire. The participants who failed to return the survey within three weeks of the email date were contacted via email to reiterate the importance of the study and were emailed a second notification with the link to the survey. 
Inter-Round Procedures. Following the receipt of all Round I questionnaires, participant responses were evaluated after the individual and group means of each lesson plan concept were calculated via the questionnaire website. An unexpectedly large number of comments were collected ( $\mathrm{N}=343)$, which provided useful feedback to fellow panel members and the investigator. These comments were primarily of two types. Some comments supplemented the Likert score they assigned a lesson plan concept and provided an opinion as to either (a) the worthiness of a concept for inclusion in a future template, or (b) whether or not two or more concepts were redundant in nature. Other comments were organizational in nature and provided opinions regarding the placement and structure of particular concepts as headings or subheadings of other concepts.

Content analysis was chosen to analyze the comments from Round I of the Delphi study in order to group statements generated by the panel into similar themes. Similar comments were grouped together into their particular areas. These grouped statements were then examined to see if any were exactly the same, in which case a decision was made to collapse these comments into one statement (Keeney, Hasson, \& McKenna, 2011). Other statements were left intact and displayed on the Round I results Excel spreadsheet.

Based upon panel member comments and when necessary, a review of the pilot study lesson plans to determine the contextual nature of a particular concept, the list of concepts for Round II were intuitively organized into an outline to make it easier for panel members to understand the context of each concept. In addition, those concepts that were determined to be identical or redundant in nature were combined or collapsed into a single concept. The original 66 concepts were therefore collapsed to form 52 concepts. 
The 52 concepts, along with their corresponding comments, were organized into an Excel spreadsheet document that included the following: (a) the panel member's individual rating (I) of each concept; (b) the group mean rating (GM) for each concept; (c) a column stating whether the concept currently meets the criteria for inclusion in a planning template (Include?); (d) the moderator comments, and; (e) a summary of panel member comments for each survey item (see Appendix 13).

Round II Procedures. The second round of questioning adhered to the above, Round I procedures. A Round II welcome email (see Appendix 14) was sent to each panel member containing an email link to the second round modified Delphi survey and the aforementioned Excel spreadsheet with Round I results (see Appendix 13). The survey website contained an introduction detailing the collapsing of the original concepts (see Appendix 15), Round II survey instructions (Appendix 16), the aforementioned concept outline (see Appendix 17), and the actual Round II survey (see Appendix 18). Panel members were asked to reevaluate their individual Round I responses based on the mean group ratings for each questionnaire item. The administrative procedures for completion of the questionnaire online, provision of feedback, and data recording were identical to those described in Round I.

Each modified Delphi panel member also received a final research report (see Appendix 19) following the completion of all Round II questionnaires and the completion of the final data analysis via email. This report included all of the lesson plan concepts that met the criteria for inclusion in the forthcoming lesson plan template. The Delphi panel members were thanked for their participation and expertise required for completion of this lengthy process via email and by a ground mail note card. 


\section{Data Analysis}

The purpose of this study was to develop a list of PETE lesson plan concepts for use by undergraduate students. The modified Delphi was completed by the panel of experts with the desire that a list of essential lesson plan concepts would be determined. The data collected during the Round II of questioning will be used to provide a measure of consensus regarding essential concepts for use when designing physical education lesson plans. To be considered as a valid lesson plan concept, the concept must (a) receive a mean rating of at least four in the area of relevance, and (b) receive a rating of at least four by $75 \%$ of the individual panel members. Concepts that failed to meet the criteria were not included in the final list of lesson plan concepts. 


\section{Results}

The purpose of the study was to determine the essential concepts to be included in a lesson plan template for PSTs in physical education teacher education programs. The research question that guided the study was the following: What are the essential concepts that should be included in a comprehensive lesson planning template for preservice teachers in physical education teacher education? Upon completion of the second (final) round of the study, 31 of the 52 lesson planning concepts met the criteria for inclusion as per the aforementioned criteria, and therefore, answered the research question. Of the 31 lesson plan concepts that were found to have group consensus, nine were considered contextual information concepts, four were pre-instruction concepts, 16 were instruction concepts, and two were post-instruction concepts. The results are presented in the following categories: (a) Expert panel (b) Contextual Information, (c)

Pre-instruction, (d) Instruction, (e) Post-instruction, (f) Comments, and (g) Concept outline. The final list of concepts in all categories can be found in Table 1 .

\section{Expert panel}

During this modified Delphi study, 28 experts both agreed to, and participated in, Round I of the study. During Round II of the study, 16 of the original 28 experts completed the online survey, which means the response rate was $57.1 \%$. This was below the response rate target of $70 \%$ stated prior to the initiation of the study. Of the twelve participants who did not complete the second round survey, nine failed to reply to the email letters and reminders. One expert cited numerous professional obligations and family health issues as the reasons for not participating. Another expert corresponded via email several weeks after the close of the Round II survey deadline and apologized for 
not participating. One other expert declined to participate in Round II due to an issue with the assumption that all lesson plans can be generic. The expert stated that different instructional models can and should lead to different kinds of lesson planning that will not fit any general template.

\section{Contextual Information}

As indicated in Table 1, the Delphi panel members reached a consensus of agreement for nine of the 19 contextual information concepts. Contextual concepts are those that provide pertinent school, class, and lesson information in order to prepare the teacher for a particular teaching episode. A consensus of agreement was found by the expert panel for content validity for the following contextual concepts: (a) unit, (b) lesson topic/activity, (c) equipment, (d) materials/resources, (e) grade: pre-k-12, (f) class size, (g) length of class, (h) safety, and (i) NASPE standards. These concepts' group means ranged from 4.06 to 4.56 and the percentage of panel members who rated those concepts as being essential (rating the concept as either a '4' or '5') ranged from $75.00-93.75 \%$. Two concepts in this area that were rejected by the panel, Focus or Skill Theme and Lesson \#, acquired the needed group means (4.13 and 4.00, respectively), but failed to receive a '4' or ' 5 ' rating by $75 \%$ of the experts $(66.66 \%$ and $73.33 \%$, respectively).

\section{Pre-instruction Concepts}

Delphi panel members reached a consensus of agreement regarding four of the five concepts from the pre-instruction area, deeming Objectives, Psychomotor objective, Cognitive objective, and Affective objective as valid lesson plan concepts to be incorporated into a lesson plan template. Group means for these concepts ranged from 4.56 to 4.81 and the percentage and the percentage of experts rating these concepts as 
essential ranged from 87.50 to $100 \%$. The only concept in this area not deemed as essential was the Fitness objective (group mean=3.69).

\section{Instruction Concepts}

Delphi panel members reached consensus regarding 16 of the 26 Instruction concepts from Round II of the survey. These essential concepts included the following: (a) Introductory/instant/fitness activity \& warm-up, (b) Anticipatory set/set induction, (c) Instruction, (d) Cues, (e) CFU (checking for understanding), (f) Content development/activities/lesson focus, (g) Organization/formation, (h) Time, (i) Management/procedures, (j) Progression, (k) Demonstration, (l) Extension task, (m) Refinement task, (n) Application task, (o) Adaptation/modification/intratask variation, and (p) Closure. Group means for these concepts ranged from 4.13 to 4.88 and the percentage of experts rating these concepts as essential ranged from $75-100 \%$. One concept in this area, Transition, had a group mean of 4.25 , but failed to receive the necessary rating by the required percentage of experts $(68.75 \%)$.

\section{Post-instruction Concepts}

Both of the Post-instruction concepts, Assessment/evaluation $(\mathrm{m}=4.63)$ and Reflection $(\mathrm{m}=4.67)$ were accepted by the expert panel as valid lesson plan concepts and both were rated as essential by most of the panel members $(93.75 \%$ and $93.33 \%$, respectively).

\section{Comments}

There were a total of 130 comments that accompanied the Likert scores for the second round of the Delphi study. A total of 77 comments were made regarding accepted lesson plan concepts. Some comments provided justification in favor of, or against, the inclusion of a particular concept in the concept list. A number of experts provided 
contextual comments pertaining to the specific use of a concept in a particular teaching situation. A few comments provided recommendations for collapsing concepts. Several panel member comments that were in the form of questions regarding the context, definition or organization/placement of a concept or a pair of concepts could have been answered by referring to the Round I Excel spreadsheet provided to each expert.

\section{Concept Outline}

The accepted lesson planning concepts were organized in a fashion identical to the outline of concepts that was created between rounds of the Delphi study (see Appendix 20). This outline organizes the concepts under headings and subheadings that resulted from previous feedback from round I. Definitions of these concepts can be found in Appendix 21. 


\section{Discussion}

This study was designed to determine a comprehensive list of lesson plan concepts with which undergraduate physical education teacher education students can use to design their lessons for practice, peer, and student teaching environments. While the results of this study are limited by the group of experts that participated in the surveys, and considering that each of the almost 200 PETE programs in the United States are somewhat unique in terms of how they teach the planning of lessons, the final list of concepts may provide fodder for discussions in terms of overall program improvement. Considering that the original list of 507 concepts found in the pilot study have been reduced to the final list of 31 concepts, the results of this study may also initiate a discussion on the benefits of an accepted and established set of planning concepts that will aid in the clarity of PETE pedagogical terminology. This section will include the following sections: (a) accepted concepts overview, (b) commentary on accepted concepts, (c) remarkable rejected concepts, (d) concept nomenclature, (e) round II comments, and(f) future considerations.

\section{Accepted Concepts Overview}

The 31 concepts accepted by the expert panel can provide preservice teachers with a solid basis for planning their initial teaching vignettes in laboratory environments, and for peer teaching, pre-student teaching field experiences, and student teaching duties. These concepts provide the lesson plan designer with the ability to write an organized plan while avoiding too many concepts that provide too much information.

Contextual Information concepts. The nine accepted lesson plan concepts from this section provide the preservice teacher with the needed background information to 
properly organize the teaching environment. The class size and length of class concepts enable the teacher to plan the proper amount of activities based upon the number of students in class and the available time. The equipment and materials/resources concepts enable the teacher to document all of the needed props, including technology, for a particular class. The unit and NASPE standards concepts allow the teacher to view the placement of the lesson within the context of the unit and the standards that need to be realized during the lesson. The lesson topic/activity provides the primary focus for the day's lesson.

Pre-instruction concepts. The four objectives concepts provide teachers with the prompts to provide descriptive statements on what will be achieved in class. The psychomotor, cognitive, and affective objectives concepts correspond directly to the psychomotor, cognitive, and affective domains recognized as important by the National Association for Sport \& Physical Education (2004) as they represent different types of knowledge that students will acquire from instruction (Metzler, 2011). These three objectives are described and utilized in textbooks written for PETE preservice teachers (Metzler, 2011; Rink, 2006).

Instruction concepts. The sixteen instruction concepts accepted by the expert panel provide the preservice teacher with the necessary methods for designing the main portion of the learning experience. As you view Appendix 19, you can see that several of the concepts in this area were collapsed/combined and the organization of the concepts into headings and subheadings as a result of the Delphi study.

The collapsed concept, introductory/instant/fitness activity \& warm-up, which is the initial physical activity that prepares students for the remainder of a class, reflects the 
differences in both the use of terminology and in how PETE programs approach the beginning of a lesson. Despite these differences, it is assumed that students begin the class with a method of increasing one's heart rate and preparing muscles and joints for the ensuing lesson.

Following the initial activity, teachers engage students in the tasks at hand by employing the anticipatory set/set induction. Instruction then begins with the use of cues and checking for students' understanding.

The content development/activities/lesson focus concept provides the major heading under which the methods for activity development are described in detail. The organization/formation and management/procedures concepts organize and manage students. The progression of activities begins with demonstration, followed by extension refinement, and application tasks, which may be modified through the adaptation/modification/intratask variation concept. A closure ends the lesson.

Post-instruction concepts. The assessment/evaluation and reflection concepts allow the teacher to review both their students' performance and their teaching skills, respectively. The assessment of students can also occur throughout the actual lesson.

\section{Commentary on Accepted Concepts}

The 31 accepted concepts constitute a set of ideas that can be incorporated into both the subject-matter and course curricula as described by Eisner (1965). The implementation of these concepts into what Metzler and Young (1984) termed, pre-active planning, can be justified by the significance of the lesson planning act itself (Darst \& Pangrazi, 2009). As stated previously, planning creates better lessons by linking the curriculum to the particulars of instruction (Johnson, 2000). Planning also creates an 
understandable sequence of instructional events and links activities to instructional objectives that allow for a structured format that guides students towards specific goals (Johnson, 2000; Stroot \& Morton, 1989). Many of the accepted concepts were supported by the literature review.

The accepted contextual concept, materials/resources, was deemed essential by the expert panel despite only being described as important by one citation (Kauchak \& Eggen, 2007). Preservice teachers need to consider the pertinent materials, separate from equipment, which can help both themselves and their students during a lesson.

Four of the five pre-instruction concepts, objectives, psychomotor objective, cognitive objective, and affective objective, were overwhelmingly chosen for inclusion as lesson planning concepts. Objectives were described as important for lesson planning in many studies (Baylor, Kitsantas, \& Chung, 2001; Golland, 1998; Hunter, 1984; Johnson, 2000; Kauchak \& Eggen, 2007; Ornstein, 1997; Panasuk \& Todd, 2005; Reiser \& Dick, 1996). These four concepts were also included in at least half of the lesson plans from the nationwide pilot study. Preservice teachers need to think through this concept to be sure that their objectives include all of the characteristics that ensure a communication of intent: performance, conditions, and criterion (Mager, 1997). In this way, objectives will provide students with goals with which they can attempt to accomplish and provide the preservice teacher with an organization of tasks rather than only following a meaningless list of activities. Meaningful objectives also allow the preservice teacher to better plan for assessments of their students during instruction.

The accepted instructional concept, anticipatory set/set induction, sets the tone for the lesson by orienting the students to what, how, why they will be engaging in the tasks 
set forth by the teacher (Rink, 2006). This simple, but often omitted concept may be trivialized by the preservice teacher because they may not realize that their students often do not understand the importance of a particular activity or lesson. In these cases, it may be essential to personalize the importance of the lesson focus to increase the interest of students. Several terms have been used to describe this concept. Although the use of the term anticipatory set was only cited by one author (Hunter, 1984), other terms or phrases were used to describe either all or portions of this concept: (a) motivation to capture student interest (Ornstein, 1997); (b) introduction (Johnson, 2000); (c) rationale (Kauchak \& Eggen, 2007); and (d) essential questions (Charrette, 2009). One other citation included this concept within their planning instructional activities step of their planning process (Reiser \& Dick, 1996).

The instructional concept, content development/activities/lesson focus, which describes in detail the actual tasks of the lesson, gained overwhelming support from the expert panel. This critical concept of preparing and organizing learning activities for students was also supported by the literature (Charrette, 2009; Golland, 1998; Johnson, 2000; Kauchak \& Eggen, 2007; Ornstein, 1997; Panasuk \& Todd, 2005; Popham \& Baker, 1970; Reiser \& Dick, 1996; Paramount in this concept is the ability of the teacher to plan an instructional sequence that will move students from their current capabilities towards the instructional outcome (Shavelson, 1976). As listed in Appendix 20, ten other accepted concepts are included within this important, overall concept.

The demonstration concept received solid support by the expert panel despite it being cited in only three articles (Golland, 1998; Hunter, 1984; Ornstein, 1997) and seven lesson plans from the pilot study. The live or recorded physical demonstration of skills 
and/or activities, either by the teacher or fellow students, is essential prior to allowing students to attempt a novel skill. This concept represents one aspect of teaching that makes physical education unique from most other subjects (save for some science curricula) due to the significant psychomotor component.

The post-instruction concept, assessment/evaluation, received a high level of importance from the expert panel, with almost $94 \%$ of respondents rating it as a four or five. As stated previously, this concept focuses on the students' performance levels. Several authors revealed the importance of student assessment. Assessment provides for the assignment of grades to students, determines what students have learned and not learned to provide necessary remediation, and helps to identify ineffective areas of instruction by the preservice teacher (Reiser \& Dick, 1996). Assessment is also important for the preservice teacher as it is a component of instructional alignment, which aligns objectives, activities, and assessments together to provide for congruent content (Kauchak \& Eggen, 2007).

Reflection, another accepted post-instruction concept, plays a major role in a preservice teacher's instructional maturity by allowing the teacher to review the positive and negative areas of a lesson for the purpose of designing future plans with alternative instructional methods to improve student performance. Preservice teachers need to plan, teach, and receive objective feedback on a routine basis if permanent changes in planning behaviors are to occur (Byra \& Marks, 1991). Most experts on the Delphi panel rated this concept as highly important for inclusion as a lesson plan concept. Several articles incorporated teacher evaluation/reflection as part of the planning cycle (Johnson, 2000; Popham \& Baker, 1970; Reiser \& Dick, 1996; Shavelson, 1976) and half of the pilot 
study lesson plans incorporated a teacher reflection section. The importance of reflection and feedback were exemplified in a study where data-based feedback was provided to preservice teachers during the preactive and interactive stages of teaching. When subjects were given written and oral feedback regarding particular aspects of their planning and teaching, improvements in writing objectives and designing activities were realized (Byra \& Marks, 1991). These results underscore the importance of the preservice teacher's communication with their university supervisor and cooperating teacher for the purpose of guiding the new teacher's improvement following self-examination of one's teaching episode.

The fact that the expert panel reached consensus on 31 lesson plan concepts for inclusion for preservice teachers gives credence to the idea that apprentice teachers need to be prompted on many of the pedagogical ideas in order to prepare to teach. One article in the literature that compared planning behaviors of novice and experienced teachers commented on the fact that the novices in the study needed to plan more extensively because they didn't have the necessary information stored away, via schemata, like experienced teachers did (Graham, Hopple, Manross, \& Sitzman, 1993). It could be speculated that even if preservice teachers did consider many of the concepts during planning, they may not think through the necessary details of each concept to make a lesson fruitful.

Are 31 planning concepts too many for any formal lesson plan, regardless of the type of teacher and experience? Some panel members made comments to the effect that particular concepts in the survey are inherent when writing lesson plans and therefore do not need to be listed as part of a lesson. Most panel members, however, took into 
consideration the preservice teacher's need for explicit planning. The mean number of concepts garnered from the pilot study lesson plans was 26.5 , which is close in number to the 31 from the current study. Based on this information, 31 lesson planning concepts for preservice teachers is a workable amount, considering that teachers can tailor the use of particular concepts as necessitated by the lesson itself.

\section{Remarkable rejected concepts}

One of the rejected contextual concepts, date/date taught, had a group mean of 3.56 and only half of the experts rating this concept as important. This concept may have been important to include for liability purposes as proof that a particular lesson was taught on a specific day. Courts may request that teachers produce lesson plans so that they may examine them for sequencing and methodology. In addition, student teachers and practicum students are held to the same standard as an experienced teacher and are expected to act in a manner of a reasonably prudent person who is qualified to carry out the responsibilities of teaching. (Hart \& Ritson, 2002).

As stated previously, three rejected concepts earned the required group mean of four but failed to have the required minimum $75 \%$ of experts rating them as a ' 4 ' or ' 5 '. The contextual concept, Focus or Skill Theme, had a group mean of 4.13 but only $66.66 \%$ of the experts ranked it as essential. This concept may have been considered redundant because the accepted concept, Lesson topic/activity, is very similar in nature. The other contextual concept that was rejected by the panel, Lesson \#, acquired the needed group mean of 4 , but failed to receive a ' 4 ' or ' 5 ' rating by at least $75 \%$ of the experts $73.33 \%$ ). This concept could have been useful for unit organizational purposes, but may have added "clutter" to the contextual section of the lesson plan. The rejected 
transition concept from the instruction concepts section had a group mean of 4.25 but only received an essential rating from $68.75 \%$ of panel members. Perhaps some panel members believed this concept to be intuitive in nature and not worthy as a distinct concept.

The rejected concept, facility, was soundly rejected (mean=3.31) by the expert panel. This concept may have provided preservice teachers with a prompt to imagine the unique space requirements required for a particular lesson. One expert commented on the importance of knowing the layout where one teaches, while another expert stated that preservice teachers must know the facility they will be teaching in and that a lesson planned for indoors versus outdoors will be different.

\section{Concept Nomenclature}

As described previously, some lesson planning concepts were combined or collapsed based upon the comments provided by the expert panel and a review of the pilot study lesson plans. This fact is indicative of the variety of ways in which individual PETE programs teach curriculum and instruction. While teacher education may not require a precise nomenclature for concepts as the hard sciences require, the results of this study may shed light on the need for further clarity of pedagogical terminology.

One example of a discrepancy in terminology is the confusion over the rejected concept, critical elements, with the accepted concept, cues. Three of the 16 experts from Round II questioned how these two concepts were different. One expert thought that they should be collapsed into a single concept. The Round I survey results Excel spreadsheet provided definitions for these two terms, which may have alleviated the confusion. 


\section{Round II Comments}

Comments for Round II of the Delphi study were collected to provide the investigator with possible useful information regarding the rating of concepts by each panel member. They were not collected to provide feedback to the experts as the second round was the final round of this study. While these comments did not provide pertinent details for the current investigation, they did provide useful information for the future design of Delphi studies. Several of the Round II comments asked for clarification of the details of particular concepts in the survey: Clarification that was clearly provided in the Excel spreadsheet document that contained means and investigator and panel member comments. However, the Excel document was lengthy, partly due to the clarification (e.g.: providing definitions and contextual notes) needed from Round I. In future Delphi studies of this nature, it would behoove the researcher to provide definitions and contextual information regarding items to be rated during the initial round in order to avoid the magnitude of clarification needed in future rounds. This may, in turn, help to maintain the response rates in subsequent Delphi rounds.

\section{Future Considerations}

Program improvement. The results of this study provide the opportunity for PETE program faculty to engage in minor program evaluation and improvement. Faculty could review their current lesson planning materials and the classes in which lesson planning is taught (usually within a preservice teacher's first pedagogy class) to determine whether the accepted Delphi panel concepts are taught, demonstrated, and implemented. Although the need for improvement may vary from program to program, a cursory review of both the pilot study lesson plans and the comments that were supplied 
via email regarding those plans, could shed light on why program improvement may be justified in terms of lesson planning.

In reviewing the pilot study lesson plans, it was found that some plans lack a number of the accepted concepts from the current study. While the intention of this investigator is not to critique particular programs and how they teach lesson planning, the inclusion of the accepted concepts in a program's lesson planning repertoire may aide the preservice teacher as they (a) think through and actually develop the details of the lesson plan; and (b) peruse PETE textbooks and literature; (c) correspond with cooperating teachers; and (d) interact with their peers once they become certified teachers.

In reviewing communications between this investigator and the program personnel who supplied the pilot study lesson plans, it was found that one PETE program curriculum was taught in two separate colleges of the same university. For example, strict pedagogy may be taught by the university's school of education while the specific content knowledge areas may be taught through the physical education department. These types of PETE programs could benefit from a mutually agreed upon set of lesson concepts to bridge the gap between both parties. This would obviously improve the understanding of preservice teachers as they engage with faculty from both entities.

The pilot study communications also indicated that some programs either (a) have multiple lesson plan formats; or (b) have no formal lesson plan format whatsoever. Requiring preservice teachers to write varied lesson plans based on each professor's methods may be confusing. On the other extreme, requiring preservice teachers, especially those early in the PETE program, to design and write their own lesson plans 
without formal guidance could be problematic because they may forget to include pertinent portions of the lesson planning sequence.

Lesson plan template. The final concept outline mentioned previously (Appendix 20) could provide preservice teachers with the organization to build a quality lesson plan. In turn, these lesson plan concepts could be given numerical designations that would become the basis for a scoring rubric. Or, the template could be as simple as a checklist. Individual PETE programs could develop and score the rubric based on the program's overall needs or based upon the focus of a particular teaching vignette.

Professors cooperating teachers and student teaching (university) supervisors could grade a preservice teacher's lesson plan to provide feedback for improvement and to determine readiness to teach a particular lesson in a laboratory, peer, or student teaching setting. Care must be taken, however, to ensure that all constituents of the student teaching triad, the preservice teacher, university supervisor, and cooperating teacher, (Veal \& Rikard, 1998) understand the concepts of the rubric and know how to properly critique a lesson plan based on the particular grading system employed. This may avoid differing expectations that university supervisors and cooperating teachers have for the preservice teacher (Murphy, 2010).

Length of round II survey. The length of any survey may preclude participants from completing a questionnaire. During Round I of the Delphi procedure, a total of twenty concepts met the criteria for inclusion. To shorten the second round of the survey, the author could have removed these twenty accepted concepts in order to reduce the number needing to be rated from 52 to 32 . This procedure may have helped to maintain the response rate of the Delphi process. Caution is needed, however, in order to 
determine if each initially accepted concept should be removed from succeeding rounds. Nineteen of the twenty concepts that met the criteria in Round I, also met the criteria for Round II. The concept, focus, failed to meet the criteria for inclusion in Round II, despite being accepted in Round I. Prior to excluding an accepted concept from subsequent rounds, the comments corresponding to each concept should be reviewed to determine if questions or concerns warrant further rating. In the case of the 'focus' concept, a clarification of its definition resulted in its falling out of favor with the expert panel.

\section{Delphi Process.}

Two factors may have led to participant attrition from Rounds I to II. The Round II questionnaire was sent at the beginning of the spring semester, rather than during the previous fall semester as originally planned. Some panel members may have had more pressing commitments during the spring that prevented them from completing Round II of the survey. The delay in the administration of the Round II questionnaire was due to the high number of comments recorded during Round I. The organization, dissemination, and reporting of these comments required significantly more time than the author had anticipated. Despite the consolidation of these Round I comments, a lengthy spreadsheet recording the comments, as well as individual and group means, may have precluded some panel members from completing Round II. Reading this spreadsheet while completing the survey may have required a time commitment that was too long for some panel members. 


\section{References}

American Alliance for Health, Physical Education, Recreation \& Dance (2004). Blueprint for Action: A Communications Plan for Promoting Physical Education and Health Education. [Electronic version]. Retrieved March 28, 2008, http://www.aahperd.org/aahperd/nclb/blueprintforaction.pdf

Arends, R. I. (2006). Learning to teach with "Guide to field experiences and portfolio development," interactive student CD-ROM, and Powerweb/Olc card (6th ed.). New York: McGraw-Hill.

Atkinson, R.C., \& Paulson, J. A. (1972). An approach to the psychology of instruction. Psychological Bulletin, 78, 49-61.

Ausubel, D. P. (1968). Educational psychology: A cognitive review. New York, NY: Holt, Rinehard, \& Winston.

Baylor, A., Kitsantas, A., \& Chung, H. (2001). The instructional planning self-reflective tool: A method for promoting effective lesson planning. Educational Technology, $41,56-59$.

Berliner, D. C. (1994). Expertise: The wonder of exemplary performances. In J. N. Mangieri, \& C. C. Block (Eds.), Creating powerful thinking in teachers and students (pp. 161-186). Ft Worth, TX: Holt, Rinehart \& Winston.

Bork, C. E. (1993). Research in physical therapy. Philadelphia, PA: J.B. Lippincott.

Brockhoff, K., A. J. (1975). Propensity to change responses in a Delphi round as a function of dogmatism. In H. A. Linstone and M. Turoff (Eds.), The _ultic method: Techniques and applications, (pp. 291-321). London: Addison-Wesley Publishing. 
Brown, R. H., \& Cheffers, T. F. (1991). Identifying key result areas during the planning process: A technique for simplifying lesson planning. Physical Educator 48, 5865.

Bulger, S. M. (2004). Modified Delphi investigation of exercise science in physical education teacher education. Unpublished doctoral dissertation, West Virginia University.

Bulger, S. M., \& Housner, L. D. (2007). Modified Delphi investigation of exercise science in physical education teacher education. Journal of Teaching in Physical Education, 26, 57-80.

Byra, M., \& Coulon, S. C. (1994). The effect of planning on the instructional behaviors of preservice teachers. Journal of Teaching in Physical Education, 13, 123-139.

Byra, M., \& Marks, M. C. (1991, April). Preservice teachers' planning and teaching behaviors in a clinical setting. Paper presented at the annual meeting of the American Educational Research Association, Chicago, IL.

Casten, C. M. (2006). Lesson plans for dynamic physical education for secondary school students. (5th ed.). San Francisco, CA: Pearson Benjamin Cummings.

Charrette, P. (2009). A versatile, inclusive and practical lesson plan design: The physical education "VIP" plan. Georgia Alliance for Health, Physical Education, Recreation and Dance, 42, 19-21.

Cicek, S. \& Demirhan, G. (2001). Validating teacher competencies for Turkish physical education teachers: a national study using "focus" Delphi method. International Journal of Physical Education, 38, 34-42. 
Clark, C. M. (1983). Research on teacher planning: An inventory of the knowledge base (Occasional Paper No. 66). The Institute for Research on Teaching.

Clark, C. M., \& Yinger, R. J. (1980). The hidden world of teaching: Implications of research on teacher planning. Research Series No. 77. Michigan State Univ., East Lansing. Inst. for Research on Teaching.

Clayton, M. J. (1997). Delphi: A technique to harness expert opinion for critical decisionmaking tasks in education. Educational Psychology, 17, 373-386.

Cooney, C. F., Stebbings, S. N., Roxburgh, M., Mayo, J., Keen, N., Evans, E., \& Meehan, T. C. (1995. Integrating nursing research and practice: Part II a Delphi study of nursing practice priorities for research-based solutions. Nursing Praxis in New Zealand, 10, 22-27.

Darling-Hammond, L., Banks, J., Zumwalt, K., Gomez, L., Sherin, M. G., Griesdorn, J., \& Finn, L-E. (2005). Educational goals and purposes: Developing a curricular vision for teaching. In L. Darling-Hammond \& J. Bransford (Eds.), Preparing teachers for a changing world (pp. 169-200). San Francisco, CA: Jossey-Bass.

Darst, P. W., \& Pangrazi, R. P. (2009). Dynamic physical education for secondary school students. (6th ed.). San Francisco, CA: Pearson Benjamin Cummings.

Davies, N., \& Housner, L. D. (2009). Effective teaching. In L.D. Housner (Ed.), Integrated physical education, (2nd ed.) (pp. 175-202). Morgantown, WV: Fitness Information Technology. 
Dowda, M., Sallis, J. F., McKenzie, T. L., Rosengard, P., \& Kohl, H. W. (2005). Evaluating the sustainability of SPARK physical education: A case study translating research into practice. Research Quarterly for Exercise and Sport, 76, 11-19.

Eisner, E. W. (1965). Levels of curriculum and curricular research. Elementary School Journal, 66, 155-162.

Eisner, E. W. (1967). Instructional and expressive educational objectives: Their formulation and use in curriculum. Retrieved from ERIC database. http://www.eric.ed.gov/ERICDocs/data/ericdocs2sq1/content_storage_01/000001 b/80/37/e2/25.pdf

Gagné, R. M. (1962). The acquisition of knowledge. Psychological Review, 69, 355-365.

Gagné, R. M. (1965). The conditions of learning. New York: Holt, Rinehart, \& Winston.

Gagné, R. M. (1976). The learning basis of teaching methods. In N. L. Gage (Ed.), The psychology of teaching methods, part I (75th ed.) (pp. 21-43). Chicago, IL: University of Chicago Press.

Gagné, R. M. (2001). Preparing the learner for new learning. Theory Into Practice, 19, 6-9.

Gange, K. N. (2010). The current status and future direction of post-professional Graduate athletic training education: A _ultic study. Unpublished doctoral Dissertation, North Dakota State University.

Golland, J. H. (1998). A lesson plan model for the supervision of student teaching. Education, 118, 376-380. 
Graber, K. C. (2001). Research on teaching in physical education. In V. Richardson (Ed.), Handbook of research on teaching (4th ed.) (pp. 491-519). Washington, DC: American Educational Research Association.

Graham, G. (2001). Teaching children physical education (2nd ed.). Champaign, IL: Human Kinetics.

Graham, G., Hopple, C., Manross, M., \& Sitzman, T. (1993). Novice and experienced children's physical education teachers: Insights into their situational decision making. Journal of Teaching Physical Education, 12, 197-214.

Griffey, D. C., \& Housner, L. D. (1991). Differences between experienced and inexperienced teachers' planning decisions, interactions, student engagement, and instructional climate. Research Quarterly for Exercise and Sport, 62, 196-204.

Gronlund, N. (2004). How to write and use instructional objectives (7th ed.). Upper Saddle River, NJ: Merrill/Prentice Hall.

Grossman, P. (1989). A study in contrast: Sources of pedagogical content knowledge in secondary English. Journal of Teacher Education, 40, 24-31.

Gurvitch, R. (2004). The development and validation of a computer mediated simulation (CMS) training application designed to enhance task modification decisions among preservice physical education teachers. Unpublished doctoral dissertation, West Virginia University.

Gurvitch, R., \& Hawkins, A. (2004). Lesson preparation: How teachers' planning effects students' behaviors. Research Quarterly for Exercise \& Sport, 75, (1), Suppl. p. A 66-A67. 
Hansen, C. C. (2006). Technology as an electronic mentor: Scaffolding preservice teachers in writing effective literacy lesson plan. Journal of Early Childhood Teacher Education, 27, 129-148.

Harris, K. S., \& Rogers, G. E. (2008). Secondary engineering competencies: A Delphi study of engineering faculty. Journal of Industrial Teacher Education, 45, 5-25.

Hart, J. E., \& Ritson, R. J. (2002). Liability and safety in physical education and sport. Oxon Hill, MD: National Association for Sport and Physical Education.

Hellison, D. (2003). Teaching responsibility through physical activity. (2nd ed.). Champaign, IL: Human Kinetics.

Housner, L. D., \& Griffey, D. C. (1985). Teacher cognition: Differences in planning and interactive decision making between experienced and inexperienced teachers. Research Quarterly for Exercise and Sport, 56, 45-53.

Hunter, M. (1984). Knowing, teaching, and supervising. In P. Hosford (Ed.), Using what we know about teaching (pp. 169-203). Alexandria, VA: Association for Supervision and Curriculum Development.

Imwold, C. H., Rider, R. A., Twardy, B. M., Oliver, P. S., Griffin, M., \& Arsenault, D. N. (1984). The effect of planning on the teaching behavior of preservice physical education teacher. Journal of Teaching in Physical Education, 4, 50-56.

Ishee, J. H. (2003). The future of physical education in higher education: A Delphi study. Chronicle of Physical Education in Higher Education 14, 4-5,17-18. 
Jacobs, J. M. (1996). Essential assessment criteria for physical education teacher education programs: a Delphi study. Unpublished doctoral dissertation, West Virginia University.

Johnson, A. P. (2000). It's time for Madeline Hunter to go: A new look at lesson plan design. Action in Teacher Education, 22 72-78.

Kauchak, D. P., \& Eggen, P. D. (2007). Learning and teaching: Research-based methods (5th ed.). Boston, MA: Pearson Education.

Keeney, S., Hasson, F., \& McKenna, H. (2011). The Delphi technique in nursing and health research. West Sussex, UK: Wiley-Blackwell.

Kelly, L. E., \& Melograno, V. J. (2004). Developing the physical education curriculum: An achievement-based approach. Champaign, IL: Human Kinetics.

Learning First Alliance. (2003). Major Changes to ESEA in the No Child Left Behind Act. [Electronic version]. Retrieved February 10, 2008, http://www.nea.org/esea/images/eseasummary.pdf

Linstone, H. A., \& Turoff, M. (1975). Introduction. In. H. A. Linstone and M. Turoff (Eds.), The_Delphi method: Techniques and applications, (pp. 3-12). London: Addison-Wesley Publishing.

Lund, J., \& Tannehill, D. (Eds.) (2010). Standards-based physical education curriculum development (2nd ed.). Sudbury, MA: Jones and Bartlett.

Macdonald, J. B. (1965). Myths about instruction. Educational Leadership, 22, 571-617.

Mager, R. (1962). Preparing instructional objectives. Palo Alto, CA: Fearon.

Mager, R. F. (1997). Preparing instructional objectives (3rd ed.). Atlanta, Georgia: CEP Press. 
Mendes, E. H., do Nascimento, J. V., Nahas, M. V., Fensterseifer, A., \& de Jesus, J. F. (2006). Evaluation of the initial formation in physical education: A Delphi study. Revista da Educacao Fisica, 17, 53-64.

Metcalf, A.A. (2010). History, philosophy, and sociology of sport recommendations for physical education teacher education. Unpublished Doctoral Dissertation, West Virginia University.

Metzler. M. W. (2011). Instructional models for physical education (3rd ed.). Scottdale, AZ: Holcomb Hataway.

Metzler, M. W., \& Young, J. C. (1984). The relationship between teachers' preactive planning and student process measures. Research Quarterly for Exercise and Sport, 55, 356-364.

Morine, G. (1975). A study of teacher and pupil perceptions of classroom interaction. Special study B. Beginning Teacher Evaluation Study (Technical report No. 75-11-6). San Francisco, CA: Far West Lab for Educational Research and Development.

Morrell, P. D., \& Ackley, B. C. (1999, April). Practicing what we teach: Assessing pre-service teachers' performance using scoring rubrics. Paper presented at the annual meeting of the American Educational Research Association, Montreal, Quebec, Canada.

Morrisey, G. L. (1983). Management-By objectives and results in the public sector. Reading, MA: Addison - Wesley Publishing Company. 
Murphy, K. (2010). Perceptions of the student teaching triad: An inquiry into relationships and supervision. Asian Journal of Physical Education \& Recreation, 16, 53-66.

Murray, J. W., \& Hammons, J. O. (1995). Delphi: A versatile methodology for conducting qualitative research. Review of Higher Education, 18, 423-436.

National Association for Sport \& Physical Education (2004). Moving into the future: National standards for physical education (2nd ed.). Reston, VA: Author.

National Association for Sport \& Physical Education (2006). NASPE Strategic Plan 2006-2008. [Electronic version]. Retrieved March 28, 2008, http:/www.aahperd.org/Naspe/pdf files/StrategicPlan06.pdf

National Association for Sport \& Physical Education (2008a). Initial physical education teacher education standards draft. Reston, VA: Author.

National Association for Sport \& Physical Education (2008b). Pro-link: Developing assessments and rubrics for NASPE/NCATE program reports. Reston, VA: Author.

National Association for Sport \& Physical Education (2008c). Initial physical education teacher education standards. [Electronic version]. Retrieved October 1, 2008, http://www.aahperd.org/naspe/pdf_files/2008\%20National\%20Initial\%20PETE\% 20Standards.pdf

National Council for Accreditation of Teacher Education (2007). NCATE's Mission. [Electronic version]. Retrieved March 28, 2008, http://www.ncate.org/documents/NCATEMission.pdf 
National Education Association (2002). Elementary and Secondary Education Act The Basics. [Electronic version]. Retrieved February 10, 2008, http://www.nea.org/esea/eseabasics.html

Orlich, D. C., Brown, A. H., Callahan, R., Harder, R., \& Trevisan, M. S. (2004). Teaching strategies: Guide to effective instruction (7th ed.). Boston: Houghton Mifflin.

Ornstein, A. C. (1997). How teachers plan lessons. High School Journal, 80, 227-237.

O'Sullivan, M., \& Tsangaridou, N. (1992). What undergraduate physical education majors learn during a field experience. Research Quarterly for Exercise and Sport, 63, 381-392.

Panasuk, R. M., \& Todd, J. (2005). Effectiveness of lesson planning: Factor analysis. Journal of Instructional Psychology, 32, 215-232.

Penso, S., \& Shoham, E. (2003). Student teachers' reasoning while making pedagogical decisions. European Journal of Teacher Education, 26, 313-328.

Peterson, P. L., Marx, R. W., \& Clark, C. M. (1978). Teacher planning, teacher behavior, and student achievement. American Educational Research Journal, 15, 417432.

Pilon, M., Sullivan, S. J., \& Coulombe, J. (1995). Persistent vegetative state: Which sensory-motor variables should the physiotherapist measure? Brain Inquiry,9, 365-376.

Placek, J. H. (1984). A multi-case study of teacher planning in physical education. Journal of Teaching in Physical Education, 4, 39-49. 
Popham, W. J., \& Baker, E. L. (1970). Establishing instructional goals. Englewood Cliffs, NJ: Prentice-Hall.

Prusak, K., Wilkinson, C, Pennington, T., \& Graser, S. V. (2008). Using object lessons to Teach health-related fitness concepts. Journal of Physical Education, Recreation And Dance, 79, 18-21.

Reiser, R. A., \& Dick, W. (1996). Instructional planning: A guide for teachers (2nd ed.) Boston, MA: Allyn and Bacon.

Rink, J. E. (2006). Teaching physical education for learning (5th ed.). New York, NY: McGraw-Hill.

Rosengard, P., Baranowski, M. L., Williston, B. J., McKenzie, T., \& Short, K. (2008). Sports, play \& active recreation for kids! Physical education program grades K-2. San Diego, CA: San Diego State University Foundation.

Shavelson, R. J. (1976). Teachers' decision making. In N. L. Gage (Ed.), The psychology of teaching methods, part I (75th ed.) (pp. 372-414). Chicago, IL: University of Chicago Press.

Shulman, L. S. (1987). Knowledge and teaching: Foundations of the new reform. Harvard Educational Review, 57, 1-22.

Skulmoski, G. J., Hartman, F. T., \& Krahn, J. (2007). The Delphi method of graduate research. Journal of Information Technology Education, 6, 1-21.

Solmon, M. A, \& Lee, A. M. (1991). A contrast of planning behaviors between expert and novice adapted physical education teachers. Adapted Physical Activity Quarterly, 8, 115-127. 
Strangis, D. E., Pringle, R. M., \& Knopf, H. T. (2006). Road map or roadblock? Science lesson planning and preservice teachers. Action in Teacher Education, 28, 73-84.

Stroot, S. S., \& Morton, P. J. (1989). Blueprints for learning. Journal of Teaching in Physical Education, 8, 213-222.

Sumsion, T. (1998). The Delphi technique: An adaptive research tool. British Journal of Occupational Therapy, 61, 153-156.

Suphawibul, M. (1992). Competencies for adapted physical educators in Thailand. Microform Publications: Eugene, OR.

Taba, H. (1962). Curriculum development. New York, NY: Harcourt, Brace \& World.

Tabachneck-Schijf, H. J. M., Leonardo, A. M., \& Simon, H. A. (1997). CaMeRa: computational model of multiple representations. Cognitive Science, 21, 305-350.

Taylor, P. H. (1970). How teachers plan their courses. Slough, Bucks, England: National Foundation for Educational Research in England and Wales.

Tigelaar, D. E.H., Dolmans, D. H.J., Wolfhagen, I. H.A.P., \& van der Vleuten, C. P.M. (2004). The development and validation of a framework for teaching competencies in higher education. Higher Education, 48, 253-268.

Twardy, B. M., \& Yerg, B. J. (1987). The impact of planning on inclass interactive behaviors of preservice teachers. Journal of Teaching in Physical Education, 6, $136-148$.

Tyler, R. W. (1949). Basic principles of curriculum and instruction. Chicago, IL: University of Chicago Press. 
Tyson, P. (1991). Talking about lesson planning: The use of semi-structured interviews in teacher education. Teacher Education Quarterly, 18, 87-96.

United States Department of Education (2003). A capsule view of the history of Federal Education Legislation. [Electronic version]. Retrieved February 10, 2008, http://nces.ed.gov/pubs2003/2003060d.pdf

United States Department of Education (2006). Highly Qualified Teachers for Every Child. [Electronic version]. Retrieved February 10, 2008, http://www.ed.gov/nclb/methods/teachers/stateplanfacts.html

Veal, M. L., \& Rikard, L. (1998). Cooperating teachers' perspectives on the student teaching triad. Journal of Teacher Education, 49, 108-119.

Walker, A.M., \& Selfe, J. (1996). The Delphi method: A useful tool for the allied health researcher. British Journal of Therapy and Rehabilitation, 3, 677-681.

Wen, J.R., \& Shih, W. L. (2008). Exploring the information literacy competence standards for elementary and high school teachers. Computers \& Education, 50, 787-806.

Wild, M. (2000). Design and evaluating an educational performance support system. British Journal of Educational Technology, 31, 5-20.

Wilkerson, T., \& Scheffler, A. J. (1992). Examining an assumption of linkage between lesson planning and implementation. Education, 113, 74-79.

Yang, Y. N. (2000, April). Convergence on the guidelines for designing a web-based art teacher education curriculum: A Delphi study. Paper presented at the annual meeting of the American Educational Research Association, New Orleans, LA. 
Yeates, P. J. A., Stewart, J. \& Barton, J. R. (2008). What can we expect of clinical teachers? Establishing consensus on applicable skills, attitudes and practices. Medical Education, 42, 134-142.

Yinger, R. J. (1979). Routines in teacher planning. Theory into Practice, 18, 163-169.

Yinger, R. J. (1980). A study of teacher planning. The Elementary School Journal, 80, 107-127.

Zahorik, J. A. (1975). Teachers' planning models. Educational Leadership, 33, 134-139.

Zakrajsek, D. B., Carnes, L. A., \& Pettigrew, F. E. (2003). Quality lesson plans for secondary physical education (2nd ed.). Champaign, IL: Human Kinetics.

Zimmerman (1999). Attaining self-regulation: A social cognitive perspective. In M. Boekaerts, P. Pintrich \& M. Seidner (Eds.), Self-Regulation: Theory, Research and Applications. Orlando, FL: Academic Press. 
Table 1

Final Concept List

Contextual Information

Concept

1. Unit

2. Lesson topic/Activity

3. Equipment

4. Materials/Resources

5. Grade: Pre-K to 12

6. Class size

7. Length of class

8. Safety

9. NASPE standards

Pre-Instruction Concepts

Concept

1. Objectives

2. Psychomotor objective

3. Cognitive objective

4. Affective objective

Instruction Concepts

Concept

1. Introductory/Instant/

Fitness activity \& Warm-up

2. Anticipatory set/

Set induction

3. Instruction

4. Cues

5. $\mathrm{CFU}$

6. Content development/

Activities/Lesson focus

7. Organization/Formation

8. Time

9. Management/Procedures

10. Progression

11. Demonstration

12. Extension task

13. Refinement task

14. Application task

15. Adaptation/Modification

/Intratask variation
4.40

Group Mean

4.19

4.56

4.56

4.19

4.56

4.06

4.19

4.31

4.06

Group Mean

4.81

4.56

4.56

4.56

Group Mean

4.13

4.14

4.81

4.40

4.81

4.69

4.13

4.44

4.69

4.44

4.44

4.25

4.60

4.13
Percentage rated as Essential

75.00

93.75

93.75

81.25

93.75

75.00

75.00

87.50

81.25

Percentage rated as Essential 100

87.50

87.50

87.50

$\underline{\text { Percentage rated as Essential }}$

81.25

86.66

78.57

100

93.33

100

93.75

75.00

87.50

100

81.25

87.50

75.00

93.33

86.66 
16. Closure

100

Post-Instruction Concepts

Concept

1. Assessment/Evaluation

2. Reflection
Group Mean

4.63

4.67
Percentage rated as Essential

93.75

93.33

*Each concept had to meet the following criteria for consensus:

(a) The concept received a mean rating of at least a four or higher in the area of importance

(b) The concept received at least $75 \%$ of all individual ratings at the four level or higher 
Appendix 1

Pilot Study Survey Email

Dear Department Chairperson: My name is Jack Sager and I am completing my doctoral degree from West Virginia University. I am conducting a study to determine the essential concepts of a physical education lesson plan. A four question survey below should take only a few minutes to complete.

This study is not considered human subjects research by the WVU's office of research compliance. A cover letter attached to this email provides additional information regarding the study. Thank you for your participation.

Lesson Plan Survey

Essential Components of a Physical Education Teacher Education Lesson Plan

Department Chairperson: This brief survey has been sent to you for completion by either you or by your fellow physical education teacher education (PETE) faculty at your institution.

\section{Survey Questions}

1a. Does the PETE faculty have a single lesson plan template or form (used universally across the program) that your preservice teachers use to develop daily lesson plans?

* If "Yes" then could you please email this template to the following address: jsager@mix.wvu.edu

1b. Do you, as an individual faculty member, have a single lesson plan template or form that your preservice teachers use to develop daily lesson plans?

*If "Yes" then could you please email this template to: jsager@mix.wvu.edu

2a. Does the PETE faculty have a single lesson plan scoring rubric (used universally across the program) to grade lesson plans?

* If "Yes" then could you please email this rubric to: jsager@mix.wvu.edu

2b. Do you, as an individual faculty member, have a lesson plan scoring rubric to grade lesson plans?

* If "Yes" then could you please email this rubric to: jsager@mix.wvu.edu

Note: Any documents that you send will be used only for the purposes of this research study and will not be adapted for use by the researchers or any other program. 
Appendix 2

Pilot Study Cover Letter

\section{COVER LETTER}

\section{Essential Components of a Physical Education Teacher Education Lesson Plan}

\section{Introduction}

You have been invited to participate in this research study that was explained to me in an email sent by Jack W. Sager, a doctoral student, and Andrew H. Hawkins, Ph.D., a professor in Physical Education Teacher Education (PETE) at West Virginia University. This research is being completed in partial fulfillment for a doctoral dissertation.

\section{Purposes of the Study}

The purpose of this study is to determine the important components of a lesson plan for preservice teachers completing an undergraduate PETE program. These components would be included in guidelines that may include, but are not limited to, lesson plan scoring rubrics, rating scales, checklists, or any items that outline important components of a lesson plan. Approximately 200 PETE programs are expected to participate in this study nationwide.

\section{Description of Procedures}

Faculty in PETE programs are asked to email the investigator any and all lesson planning guidelines. Once collected, these materials will be analyzed, using the constant comparison method, to determine recurrent themes and components involved in lesson planning for preservice teachers. Once categorized, these components will then be assessed by a panel of experts with the hope of developing a lesson plan scoring rubric for PETE undergraduate programs.

\section{Risks and Discomforts}

There are no known or expected risks from participation in this study, except for the time taken to locate and email any relevant documents.

\section{Alternative}

I understand that I do not have to participate in this study.

\section{Benefits}

I understand that this study may not be of direct benefit to me, but the knowledge gained may be of benefit to others.

\section{Contact Person}

For more information about this research, I can contact Dr. Andrew Hawkins at 304/2933295. 


\section{Confidentiality}

Any information about you obtained as a result of your participation in this research will be kept as confidential as legally possible. Your research records, and test results, just like hospital records, may be subpoenaed by court order or may be inspected by the sponsor, federal regulatory authorities, or the IRB without your additional consent.

\section{Voluntary Participation}

Participation in this study is voluntary. I understand that I am free to not participate or withdraw from this study at any time. 
Appendix 3

Instructions for coding lesson plan templates

1. Review each lesson plan in a systematic fashion (top to bottom/left to right).

2. Find and record each term by placing a checkmark on the Lesson Plan Assessment.

a. If the lesson plan contains a term that is not included in the Assessment,

then add it to the appropriate section of the Assessment.

b. If you are not sure of where to place the term, then add it to the "OTHER

Terms" section at the bottom of the Assessment.

3. If two or more terms are linked together via a coma, ampersand (\&), or forward slash, then count/list each term separately.

4. Content section: There is space under each part of this section (IA, Intro, Core, Closure) for additional terms. If you are not sure if a term belongs under any of these four sections, then place it in the Misc. Terms part.

5. Tasks/Activities section: Note that different types of tasks (informing, extension, etc.) are listed in this section. In addition, terms associated with these tasks are also listed.

\section{Heading/Background}

-Pertains to all terms and information usually found at the top of a lesson plan, such as teacher name, class, lesson, subject, unit, focus, number of students in class, equipment, materials, and teaching style.

\section{Objectives/Outcomes/Domains}

-Domains considered the same as objectives for this study.

\section{Standards}

National/NASPE: consider both one and the same

State: Do not list state

\section{Safety}

Content: This section includes any activity that deals directly with student involvement. Instant Activity, Warm-up, Introduction, Core, Closure, Miscellaneous terms

-Tasks/Activities: Instant and warm-up activities should be counted above in the Content section.

Informing, Extensions, Refinements, Application

\section{Assessment}

References

-May also be referred to as resources.

\section{Reflection:}

Other terms:

PLEASE INITIAL each assessment when finished

Lesson Plan\#: 
Appendix 4

Lesson Plan Assessment Document

Heading/Background: Check $(\sqrt{ })$ all that apply

-List and check additional terms

$\sqrt{ }$

\begin{tabular}{|l|l|l|l|l|l|l|l|l|}
\hline $\begin{array}{l}\text { teacher } \\
\text { name }\end{array}$ & focus & & date & & & & \\
\hline class & \#students & $\begin{array}{l}\text { length of } \\
\text { class }\end{array}$ & & & & \\
\hline & lesson & equipment & & & & & & \\
\hline subject & materials & & & & & & \\
\hline unit & grade & & & & & & \\
\hline
\end{tabular}

Notes:

Objectives/Outcomes/Domains: Check $(\sqrt{ })$ all that apply

-List and check additional terms

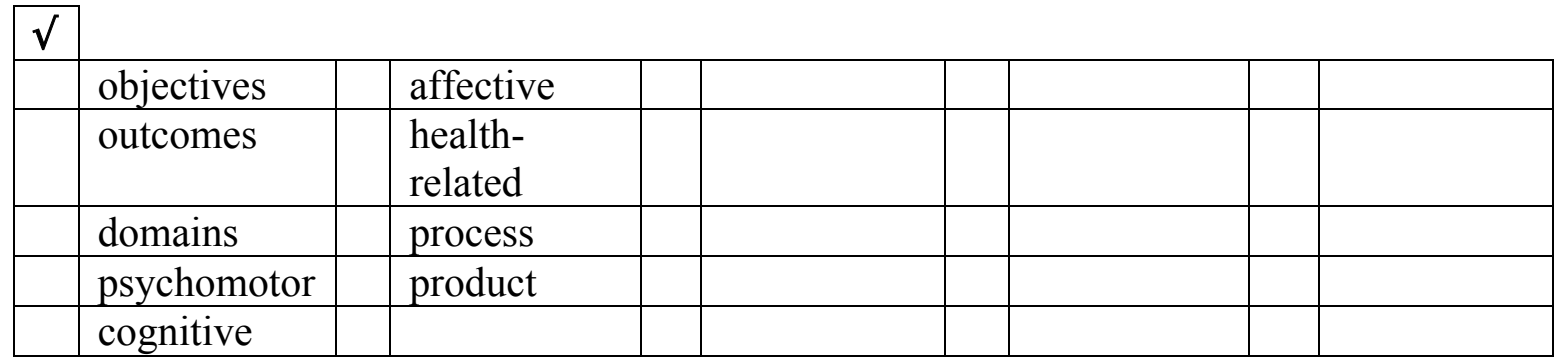

Notes:

Standards: Check $(\sqrt{ })$ all that apply

Safety:

-List and check additional terms

-List and check additional terms

\begin{tabular}{|l|l|l|l|l|l|l|l|l|} 
& $\sqrt{\mid}$ & $/$ & $\sqrt{ }$ & & & \\
\hline & national & & & $/$ & & & & \\
\hline & NASPE & & & $/$ & & & & \\
\hline & state & & & $/$ & & & & \\
\hline & regional & & & $/$ & & & & \\
\hline & district & & & & & & \\
\hline
\end{tabular}

Notes:

Content: Check $(\sqrt{ })$ all that apply

-List and check additional terms 


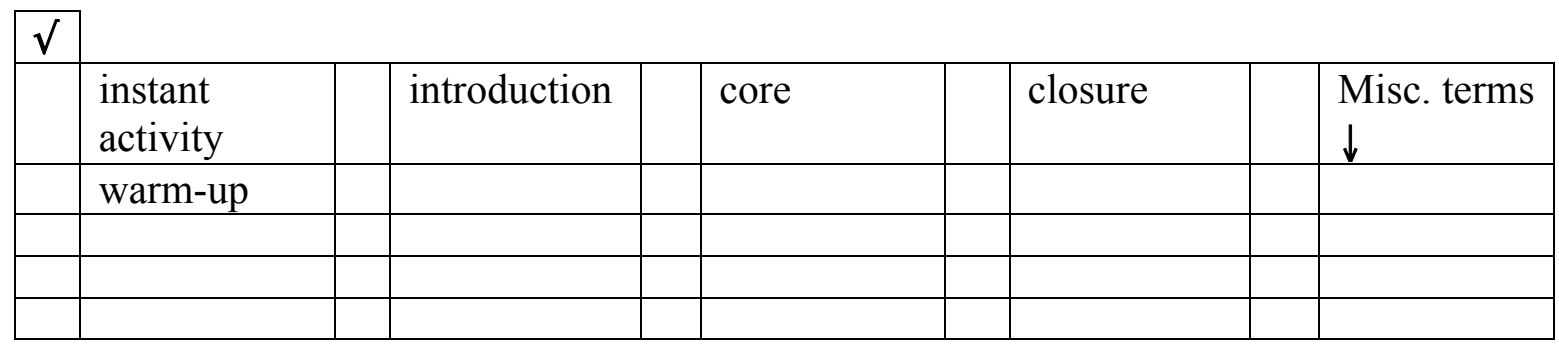

Notes:

Tasks/Activities: Check $(\sqrt{ })$ all that apply

turn over

-List and check additional terms

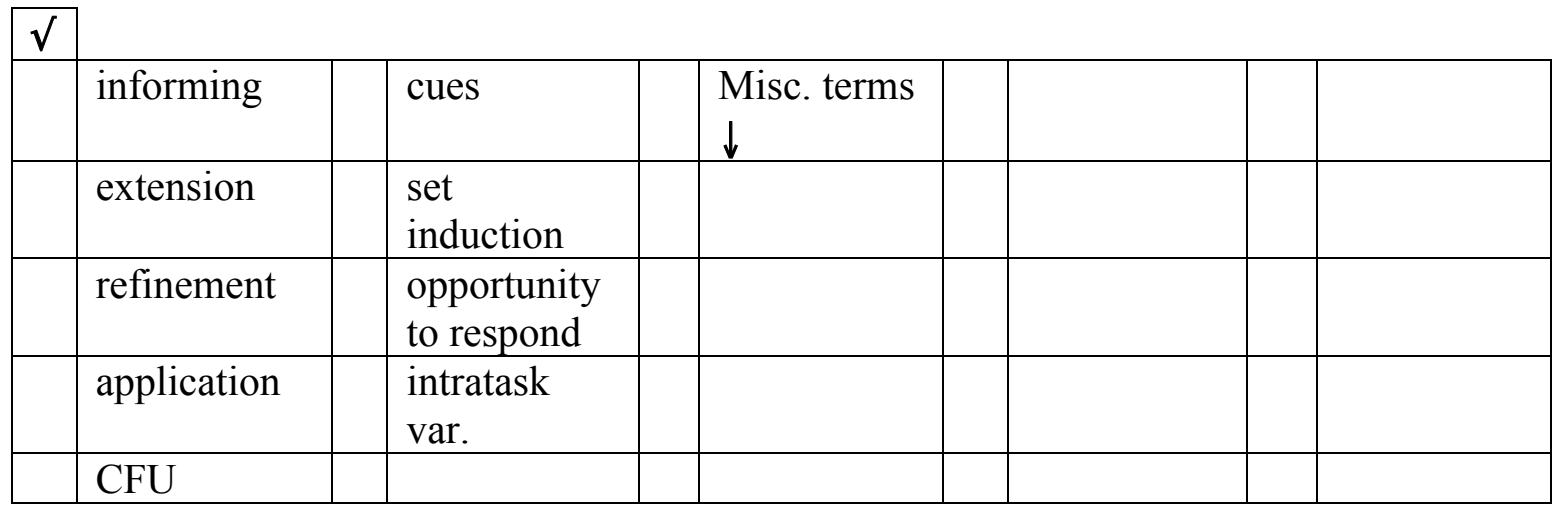

Notes:

Assessment: Check $(\sqrt{ })$ all that apply References: Check $(\sqrt{ })$ all that apply

-List and check additional terms

-List and check additional terms

$\sqrt{ }$

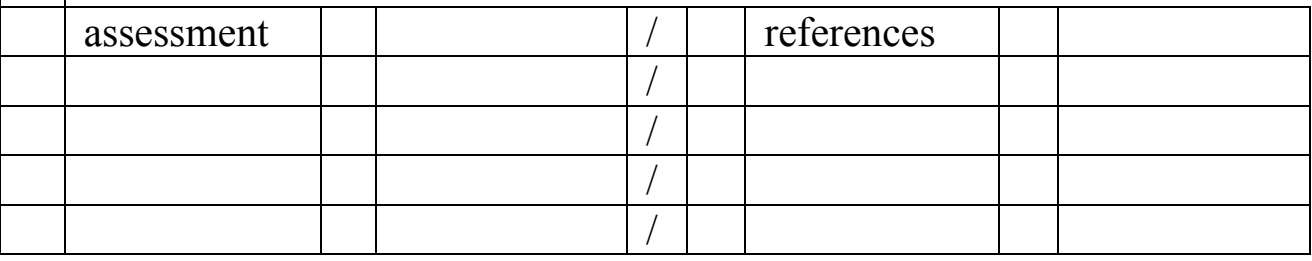

Notes:

Reflection: Check $(\sqrt{ })$ all that apply OTHER Terms: List and check additional terms -List and check additional terms

\begin{tabular}{|l|l|l|l|l|l|l|l|l|}
\hline$\sqrt{ }$ & \multicolumn{2}{|l|}{} & & $/$ & $\sqrt{ }$ & & & \\
\hline & reflection & & & $/$ & & & & \\
\hline & & & & $/$ & & & & \\
\hline & & & & $/$ & & & & \\
\hline & & & $/$ & & & & \\
\hline & & & & & & & & \\
\hline
\end{tabular}

Notes: 
Additional Notes and/or Concerns in assessing this lesson plan:

completed by (initials): 
Appendix 5

Lesson Planning Terminology Consolidation

-All NCATE accredited PETE undergraduate programs as determined from the NCATE website, $(n=198)$ were surveyed regarding their use of lesson planning templates. Fiftyone programs $(25.76 \%)$ responded by sending their program's lesson plan template.

-A total of 507 terms were identified from the 51 lesson plans. These terms were placed into the following general categories: Background Information, Objectives/Outcomes/Dmains, Standards, Safety, Content/Tasks/Activities, Assessment, References, Reflection, and Other Terms.

Problem: Rating all 507 terms would be much too time consuming for an expert panel of curriculum and instruction professionals.

Purpose: To identify those terms that are identical or quite similar in nature and to consolidate them into a manageable amount for a rating of significance in a modified Delphi study.

Procedures:

1. Identify a pair or group of similar terms.

2. Determine the group's similar theme and designate that theme as the unique term.

3. State the new term and place the grouped terms in parenthesis.

4. If necessary, provide a definition of the new term.

Example:

Terms: personal objectives for teacher; personal teaching objectives; teacher performance objectives; teacher objectives.

New term: Personal teacher objectives

* Grouping of terms was done with consideration for each lesson plan's context when possible. Some terms, such as objectives and lesson focus, occur in more than one of the nine general categories and are therefore analyzed as such. Further consolidation may be warranted in a second round of consolidation. 


\section{Page 1 Background Information}

1-1. Teacher name (teacher name, student teacher, pre-professional teacher)

1-2. Lesson title (name of lesson, title, course, title of lesson)

1-3. Topic (subject, topic, major topic, instruction sub-topics, topic area, lesson topic, subject)

1-4. Lesson focus (lesson value, lesson focus, lesson summary, focus, subfocus, teacher focus, essential focus, concept)

1-5. Student questions (content (focus) questions, questions to be answered in lesson, essential/guiding questions)

1-6. Class skill level (skill level, class skill, student prerequisite skills, skills previously developed by students)

1-7. Development level (developmental characteristics of students, development level, generic level)

1-8. Cooperating teacher (mentor teacher, cooperating teacher, co-op initials)

1-9. Lesson number (number, day \# _ of _ days, lesson \#, lesson \# in block plan, lesson plan _ of __

1-10. Unit (unit, unit content, unit topic, unit focus, unit theme, \# lessons in unit)

1-11. Set-up (set-up needed, before class set-up)

1-12. Resources \& Materials (materials (by teacher, by students), lesson support material, printed materials, resources, internet resources, supplies, media, sources of information)

\section{Page 2 Background Information, cont}

2-1. Class length (length of class, lesson length, time begin: and end: , time) 2-2. Space (space, space/location, play space needed, special markings, layout or patterns)

2-3. Individual roles (roles, duties, responsibilities, your role)

2-4. Teaching style (type of method, instructional delivery, teaching style)

*I would like a drop-down menu for the terms on Pilot Categories file

\section{Page 3 Objectives/Outcomes/Domains}

3-1. Objectives (objectives, learner objectives, student performance outcome objectives, TSWBAT, goals, learning goals)

3-2. Behavioral objectives (behavioral objectives, student behavioral objectives,)

3-3. Psychomotor objective (psychomotor objective, terminal motor objective)

3-4. Fitness objectives (fitness objective, physical activity objectives, H-R fitness, health-related)

3-5. Teacher objectives (managerial objectives, personal objectives for teacher, personal teaching objectives, teacher performance objectives, teacher objectives)

\section{Page 3 Standards}

3-6. National standards (standards, NCATE, NASPE, NASPE beginning teacher standards, national)

\section{Page 3 Safety}

3-7. Safety considerations (safety considerations, safety statement, safety reminders, safety concerns, safety plan, safety factors to consider (facility, equipment, 
students), safety precautions, plan for safety, safety cues, safety issues)

\section{Page $4 \quad$ Content/Tasks/Activities}

4-1. Objective (objective, articulation of objectives, statement of objectives, purpose)

4-2. Introduction (opening, introduction, lesson opening)

4-3. Warm-up (introductory activity, warm-up, warm-up activity, instant activity, activating activity, introductory task)

4-4. Health-related fitness (health-related fitness, fitness concept (health-related), fitness component, fitness development activities, fitness activity, health related).

4-5. Content development (lesson content, content, content task development, teaching content, content information, content development, developmental analysis of content)

4-6. Lesson development (Instructional plan, body, lesson description, lesson development, lesson presentation, lesson detail, lesson organization, instruction)

4-7. Critical elements \& Cues (critical features, critical skill elements critical elements, cues, performance cues, instructional cues, key points/cues, key points, hints, teacher/skill cues)

4-8. Practice (practice, practice opportunities)

\section{Page 5 Content/Tasks/Activities, cont}

5-1. Instructional Tasks \& Methods (instructional strategies, instructional strategies \& methods, instructional activities, instructional tasks)

5-2. Activity development (activity/task, activities, activity/drill, student activities, pupil activity: what with, lesson activities, descriptions of activities, activity development, activity formation; learning experiences)

5-3. Task/Skill Development \& Progression (task construction, task presentation, task development, task progression, descriptions of skills, task/skill, skills \& activities, tasks)

5-4. Formation (formations, formation, formation sequence)

5-5. Game(s): (game, game activity)

5-6. Time (time; time line)

5-7. Managerial plan: managerial task, management arrangement, management tasks, management, management plan)

5-8. Organizational arrangements (organization, organizational patterns, organizational arrangements, grouping)

5-9. Equipment organization (equipment organization, equipment distribution/collection, organization equipment (where))

5-10. Adaptations for Student Diversity (individual student needs; adaptations; adaptations for students; adaptations for student diversity; adaptations for student needs; adaptations for gifted students; adaptations for students with special needs; differentiation/instructional needs; considerations for diversity in activity; _ulticultural for differential instruction: non-native English speaker, gifted student, resource student, learning styles, _ulticultural)

*I would like a drop-down menu for several of the above terms: gifted, special needs, etc.

5-11. Cross-curricular Integration (cross curricular opportunities; integration: math, language arts, science, technology, history) 
*I would like a drop-down menu for several of the above terms

5-12. Family/community extension (involving parents or families; family/community ext)

\section{Page 6 Content/Tasks/Activities, cont}

6-1. Teaching Methods (procedures, methods, teacher procedure, teacher instruction during lesson, teaching points, teaching methods \& strategies, teacher communication)

6-2. Teacher activity (teacher activity, teacher organization formations, activity of teacher)

6-3. Student Organization (student grouping, grouping procedures, student organization formations, student formation, student organization, class organization, student/ teacher organization, student/teacher organization formations)

6-4. Motivational Techniques (accountability/motivation, motivational techniques, motivation)

6-5. Behavioral Contingencies (behavioral management plan, behavioral contingencies, rules/consequences)

6-6. Extension tasks (extension; extension of content: up/down; extensions: precontrol, control, utilization, proficiency)

6-7. Goal Orientation (goal orientation, goal orientation of task)

6-8. Task Progressions (teaching progressions, progression)

6-9. Criteria for Progression (criteria to move on; criteria)

6-10. Refinement Tasks (refinement; refinement/feedback; refinement (cues))

6-11. Application Tasks (application; applications (challenges); challenges)

6-12. Concluding activity (culminating activity; wrap-up activity; concluding activity)

6-13. Closure (closure; closure activities; closure question; wrap-up)

6-14. Review (lesson summary; review; review questions; recap; questions to be answered)

6-15. Preview of Next Lesson (preview; next lesson)

6-16. Dismissal (organization for dismissal; dismissal)

\section{Page 7 Assessment}

7-1. Assessment Types (informal assessment; formal assessment; formative assessment; summative assessment)

* place all in drop down menu

7-2. Student Assessment (assessment; student assessment; evaluation; assessment of student achievement; assessment strategy; assessment of instructional objective; observation)

\section{Page $7 \quad$ Reflection}

7-3. Teacher Reflection (reflection; teacher reflection notes; teacher reflection points; teacher evaluation \& reflection questions; ideas for improvement) 
Appendix 6

Lesson Plan Terminology Reduction

Part I: Initial determination of terms occurring in at least 5\% (a minimum of 3 ) lesson plans. Total of 79 terms met criteria.

\section{Background Information}

1. Teacher name

2. Title

3. Grade

4. Subject

5. Topic

6. Lesson topic

7. Lesson focus

8. Focus

9. Activity

10. Lesson \#

11. Lesson plan __ of

12. Unit

13. Equipment

\section{Objectives/Outcomes/Domains}

26. Objectives

27. Psychomotor objective

28. Cognitive objective

29. Affective Objective

30. Fitness objective

31. NASPE standards

\section{Content/Tasks/Activities}

37. Introduction

38. Lesson focus

39. Introductory activity

40. Warm-up

41. Instant activity

42. Fitness activity

43. Lesson content

44. Content

45. Content development

46. Skill analysis

47. Instruction

48. Demonstration

49. Anticipatory set

50. Set induction
14. Materials

15. Resources

16. Technology

17. Date

18. Length of class

19. Time

20. Date taught

21. Class size

22. Class

23. School

24. Facility

25. Teaching style

32. National standards

33. State standards

34. Safety considerations

35. Safety

36. Safety concerns

57. Learning experiences

58. Formation

59. Time

60. Management

61. Organization

62. Organizational arrangements

63. Adaptations

64. Procedures

65. Motivation

66. Informing

67. Extension

68. Goal orientation

69. Transition

70. Progression 
51. Critical elements

52. Cues

53. Teaching by invitation

54. Intratask variation

55. CFU (check for understanding)

56. Activities

Assessment

77. Assessment

78. Evaluation

\section{Reflection}

79. Reflection

\section{Part II: Reduction}

The following paired items can be combined:

4, 5, \& 6; 7 \& 8; $10 \& 11 ; 31,32 \& 33 ; 34,35$, \& 36; 43, 44, \& 45; 56 \& 57; $61 \& 62 ; 74$ $\& 75$.

Result: 66 terms.
71. Modifications

72. Refinement

73. Application

74. Closure

75. Closure activities

76. Cool down 
Appendix 7

Prenotification E-mail for Modified Delphi Participant Recruitment

Dear (inset name here):

My name is Jack Sager and I am a doctoral student in physical education teacher education at West Virginia University.

I am writing to ask for your participation as an expert panel member for my dissertation research titled a Modified Delphi Investigation of Lesson Planning Concepts for Physical Education Teacher Education. The purpose of this study is to clarify the lesson planning process for PETE preservice teachers by determining the essential lesson planning concepts to be included in a lesson plan template. To date, there has been little consensus as to what should be included in a PETE undergraduate lesson plan.

You are being invited to participate because of your knowledge, expertise and experience in the areas of planning and/or curriculum and instruction. Your rating of lesson planning concepts previously accumulated from a study of all NCATE accredited PETE programs would benefit preservice teachers by providing consensus regarding the most pertinent planning concepts. You would simply need to rate 66 lesson planning concepts using a rating scale that will be employed to justify the validity of each concept for future use in a PETE curriculum.

In the next seven days, you will receive a follow-up e-mail that provides a more detailed description of the study.

Thank you for your time and consideration.

Jack W. Sager, MS

West Virginia University

College of Physical Activity \& Sport Sciences

PO Box 6116

Morgantown, WV 26506

304.685.3267 
Appendix 8

E-mail for Modified Delphi Round I Participant Recruitment ${ }^{1}$

Hello Dr. :

I am writing to request your participation as an expert panel member for my dissertation research titled a Modified Delphi Investigation of Lesson Planning Concepts for Physical Education Teacher Education. You have been selected to participate because of your scholarship and knowledge in the areas of planning and/or curriculum and instruction.

The purpose of this study is to clarify the lesson planning process for PETE preservice teachers by determining the essential lesson planning concepts to be included in a lesson plan template. To date, there has been little consensus as to what should be included in a PETE undergraduate lesson plan. In a pilot study, I surveyed all NCATE approved PETE undergraduate programs in the United States to determine any and all concepts that were included in PETE lesson plans. Those concepts found in at least 5\% of submitted lesson plans $(n=66)$ were included for rating for this study.

For your contribution to this research study, I simply need you to critique the survey items using a Likert scale (1-5) that will be used to justify the importance of each lesson plan concept for future use in a lesson plan template for preservice physical education teachers. The survey will include two rounds and will be conducted using an online survey engine. The survey should take no more than 10 minutes to complete.

For your contribution to this research study, I simply need you to rate the survey items that will in the future be employed in terms of importance and content validity.

- You must be 18 years of age or older to participate

- Your participation is entirely voluntary and you may choose to stop participation at any time. You are not required to answer any questions that you do not want to answer.

- Your responses will be kept as confidential as legally possible. Your name will never be revealed during the modified Delphi study or during reporting of data and results.

- Your job status will not be affected if you decide either not to participate or to withdraw from the study. 
West Virginia University's Institutional Review Board acknowledgement of this project is on file.

Would you be willing to participate in this study? Below is the tentative time line to determine whether or not this study fits into your schedule:

-September 29, 2011 - Round I survey sent to participants (will have two weeks to complete)

-October 20, 2011 - Round II survey sent to participants (will have two weeks to complete)

Following each round, you will receive a report detailing your ratings as well as the average ratings of your fellow panel members. Once Round II data have been analyzed, a copy of the completed survey will be sent to you. It is important for you to be able to participate in both rounds of the survey to ensure group consensus.

Please contact me at 304.685.3267 if you have any immediate questions regarding this email. Please reply by September 26, 2011.

Thank you for your time and consideration. I look forward to hearing from you soon.

Andrew H, Hawkins, $\mathrm{PhD}$

West Virginia University

Morgantown, WV 26506

304.293.0849

Jack Sager, MS

West Virginia University

1408 Bradford Lane

Morgantown, WV 26508

304.685.3267 
Appendix 9

E-mail to Provide Delphi Study Detailed Information

Dear Dr.

Thank you for agreeing to participate as an expert panel member for my dissertation titled: Modified Delphi Investigation of Lesson Planning Concepts for Physical Education Teacher Education. The results of this research will be used to fulfill the requirements for my doctoral dissertation at West Virginia University.

The purpose of this study is to clarify the lesson planning process for PETE preservice teachers by determining the essential lesson planning concepts to be included in a lesson plan template. As a panel member, I need you to rate the survey items using a Likert scale (1-5) that will be used to justify the importance of each lesson plan concept for future use in a lesson plan template for preservice physical education teachers.

Your participation in this phase of the research process is entirely voluntary and you do not need to respond to every item on the questionnaire. You can be assured of complete confidentiality regarding all your responses. Following each round, you will receive a report detailing your ratings as well as the average ratings of your fellow panel members. You will receive the final results upon completion of the study.

\section{If possible, I would greatly appreciate if you would complete Round I of the survey} by October 13, 2011. This will allow you two weeks to complete the survey. Instructions on completing the online survey will appear once you access the survey hyperlink below.

The following hyperlink will direct you to the online survey: https://www.surveymonkey.com/s/M95ZNRB

Thank you again for agreeing to participate in this study. Please contact me with any questions or concerns at 304.685.3267 or jsager@mix.wvu.edu

Sincerely, Jack W. Sager

West Virginia University Doctoral Candidate 
Appendix 10

Delphi Round I Survey Introduction

Welcome and thank you for agreeing to participate as an expert panel member in this Modified Delphi investigation!

As a panel member, you are asked to rate a list of lesson planning concepts in terms of their importance for use by preservice physical education teachers. These 66 survey items were taken directly from a study on PETE program lesson plans. You will also be asked to add additional lesson plan concepts for rating in Rounds II and III. The survey will be used to generate consensus of opinion regarding lesson planning concepts for addition in a future lesson planning template. Your professional experience and judgment are vital to the success of this project.

Please remember the final date for Round I survey completion is October 13, 2011. Round II will be sent out once all results are tabulated. I greatly appreciate your assistance in the completion of this project.

Thank you for your time and input. Please call or e-mail me with any questions you may have.

Jack Sager

West Virginia University

jsager@mix.wvu.edu

304.685 .326 
Appendix 11

Delphi Round I Survey Instructions

The following survey contains 66 lesson planning concepts you will need to judge in regard to their importance for placement into a lesson plan template for preservice teachers.

Please read the following:

-Rate each of the concepts separately in the area of importance. For the purpose of the study, IMPORTANCE will refer to the concept's value to the completion of a comprehensive lesson plan template for preservice teachers.

-A rating of (5) or (4) for IMPORTANCE means that you consider the item to be Essential for a preservice lesson plan.

-A rating of (3) means you are neutral regarding the IMPORTANCE of the item.

-A rating of (2) or (1) for IMPORTANCE means the item is Not essential for inclusion in a preservice teacher lesson plan.

-If you choose not to respond to an item, then please leave it blank.

A few reminders:

-You must enter your name on the first page of the survey in order to continue. This is the only question you must answer.

-You will not be allowed to go back into the survey once you have accessed the website link. Therefore, if you are reading this message then you are committed to completing the survey at this time.

-You may return to the instructions page at any time using the "Prev" button at the bottom of the survey pages. You have complete freedom (once you have entered your name) to go to any page within the survey and alter your responses if necessary.

-A survey completion bar will appear at the bottom of each page to show your progress through the survey. 
Appendix 12

Delphi Round I Questionnaire

Numbered pages 1 through 31 


\section{Planning Survey}

\section{Modified Delphi Round I Introduction}

Welcome and thank you for agreeing to participate as an expert panel member in this Modified Delphi investigation!

As a panel member, you are asked to rate a list of lesson planning concepts in terms of their importance for use by preservice physical education teachers. These 66 survey items were taken directly from a study on PETE program lesson plans. The survey will be used to generate consensus of opinion regarding lesson planning concepts for addition in a future lesson planning template. Your professional experience and judgment are vital to the success of this project.

Please remember the final date for Round I survey completion is October 13, 2011. Round II will be sent out once all results are tabulated. I greatly appreciate your assistance in the completion of this project.

Thank you for your time and input. Please call or e-mail me with any questions you may have.

Jack Sager

West Virginia University

jsager@mix.wvu.edu

304.685.3267 


\section{Planning Survey}

\section{Modiffed Delphi Round I Survey Instructions}

The following survey contains 66 lesson planning concepts you will need to judge in regard to their importance for placement into a lesson plan template for preservice teachers.

Please read the following:

-Rate each of the concepts separately in the area of importance. For the purpose of the study, IMPORTANCE will refer to the concept's value to the completion of a comprehensive lesson plan template for preservice teachers.

-A rating of (5) or (4) for IMPORTANCE means that you consider the item to be Essential for a preservice lesson plan.

-A rating of (3) means you are neutral regarding the IMPORTANCE of the item.

-A rating of (2) or (1) for IMPORTANCE means the item is Not essential for inclusion in a preservice teacher lesson plan.

-If you choose not to respond to an item, then please leave it blank.

A few reminders:

-You must enter your name on the first page of the survey in order to continue. This is the only question you must answer.

-You will not be allowed to go back into the survey once you have accessed the website link. Therefore, if you are reading this message then you are committed to completing the survey at this time.

-You may return to the instructions page at any time using the "Prev" button at the bottom of the survey pages. You have complete freedom (once you have entered your name) to go to any page within the survey and alter your responses if necessary.

-A survey completion bar will appear at the bottom of each page to show your progress through the survey. 


\section{Planning Survey}

\section{Modified Delphi Round I}

Table of Contents

Section 1: Participant Information (Question 1)

Section 2: Concepts - Contextual Information (Questions 2-22)

Section 3: Concepts - Pre-Instruction (Questions 23-29)

Section 4: Concepts - Instruction (Questions 30-64)

Section 5: Concepts - Post-Instruction (Questions 65-67) 


\section{Planning Survey}

Modified Delphi Round I

*1. Please enter your First and Last name:

Name: 


\section{Planning Survey}

\section{Modified Delphi Round I}

Please rate each lesson planning Concept below for IMPORTANCE using the 1-5 Likert Scale:

(5) or (4) - Concept is essential for a preservice lesson plan.

(3) You are neutral regarding the IMPORTANCE of the item.

(2) or (1) - Concept is NOT essential for inclusion in a preservice teacher lesson plan.

\section{CONTEXTUAL INFORMATION}

\section{2. .}

Teacher Name
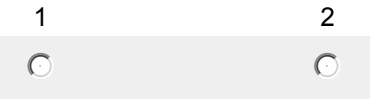

3

Comments regarding this concept?

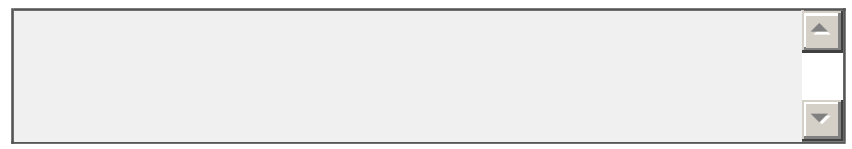

3. .

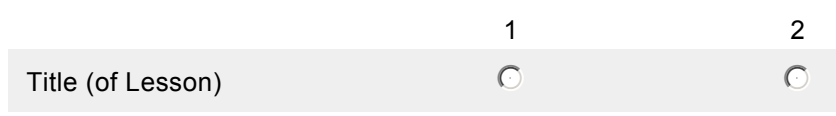

3

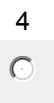

5

Comments regarding this concept?

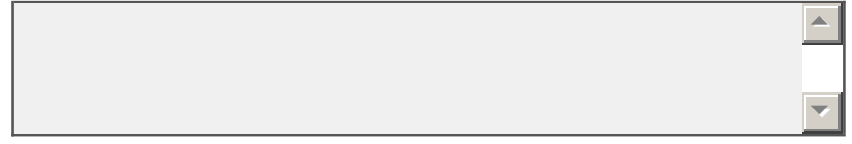

4. .

Grade (pre-K to 12 )
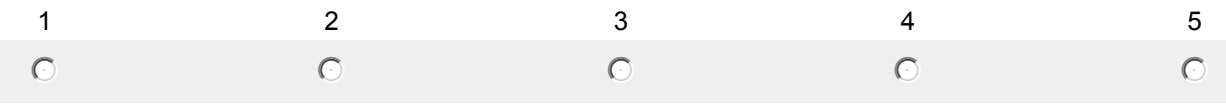

Comments regarding this concept?

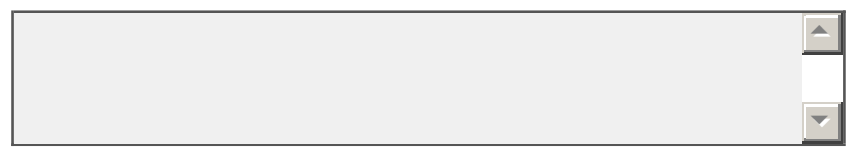

5. .
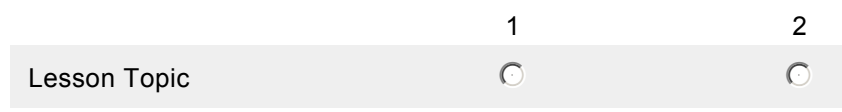

3

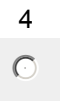

$\bigcirc$

Comments regarding this concept?

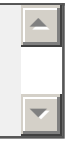




\section{Planning Survey}

\section{Modified Delphi Round I}

6. .

Focus

$\bigcirc^{1}$

$\bigcirc^{2}$

$0^{3}$

$0^{4}$

$\bigcirc^{5}$

Comments regarding this concept?

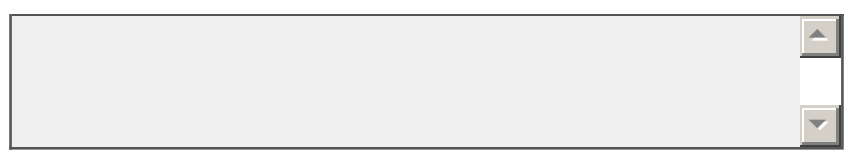




\section{Planning Survey}

\section{Modified Delphi Round I}

Please rate each lesson planning Concept below for IMPORTANCE using the 1-5 Likert Scale:

(5) or (4) - Concept is essential for a preservice lesson plan.

(3) You are neutral regarding the IMPORTANCE of the item.

(2) or (1) - Concept is NOT essential for inclusion in a preservice teacher lesson plan.

CONTEXTUAL INFORMATION - continued

7. .

Activity
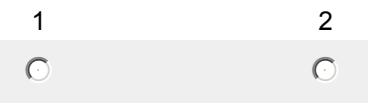

3

Comments regarding this concept?

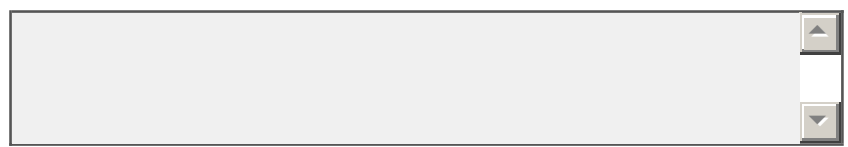

8. .

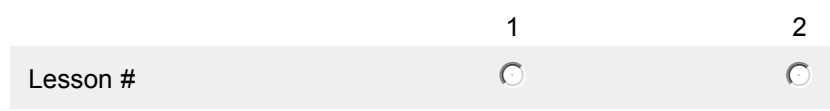

2

3

4

5

Comments regarding this concept?
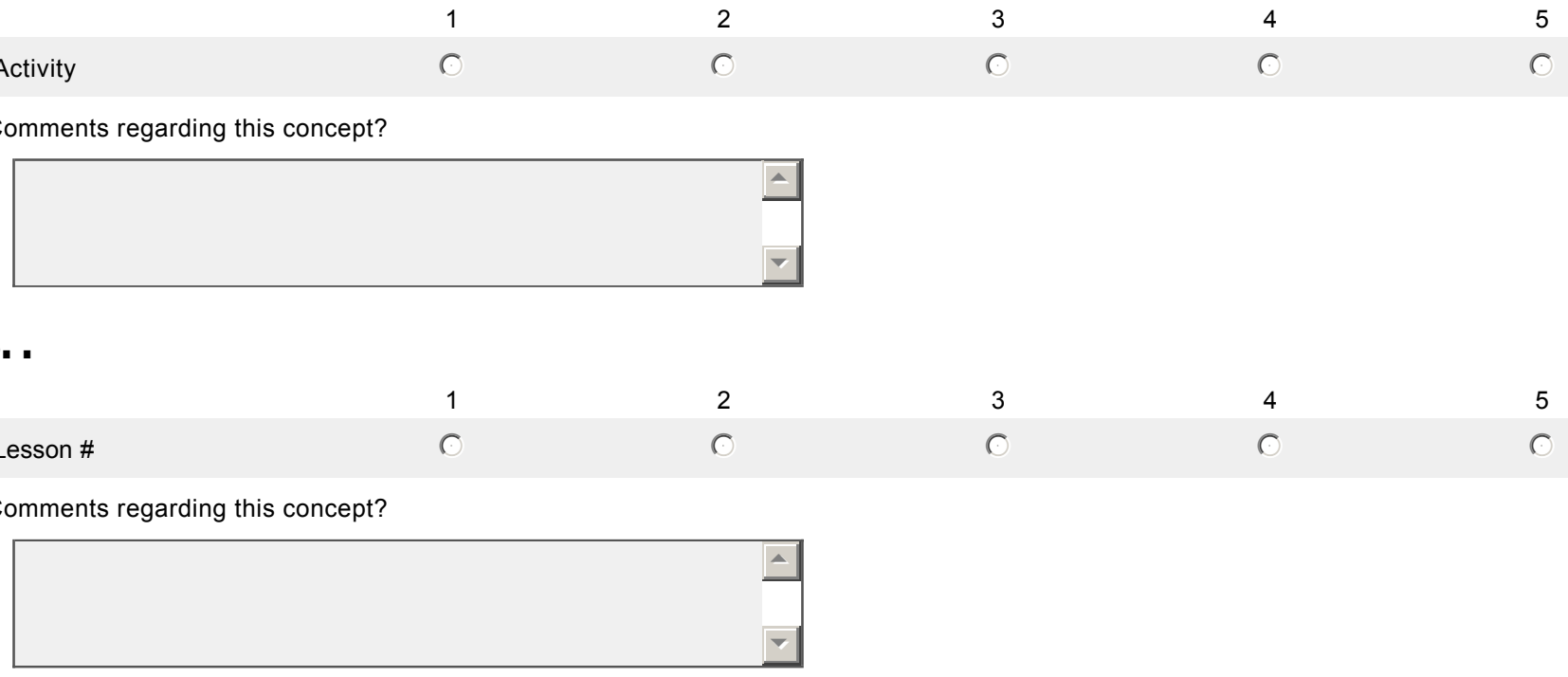

9. .
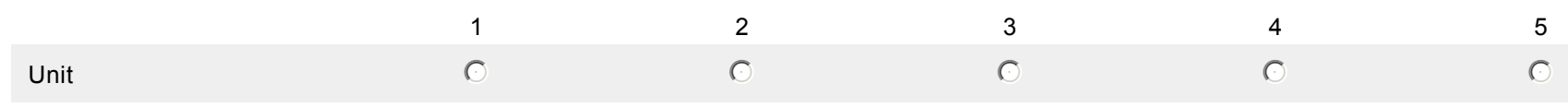

Comments regarding this concept?

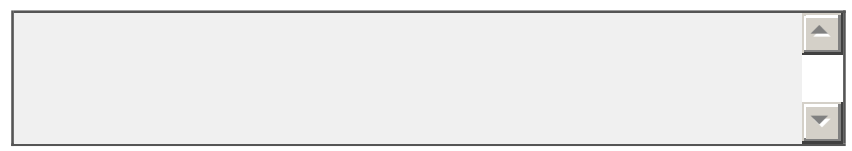

10. .
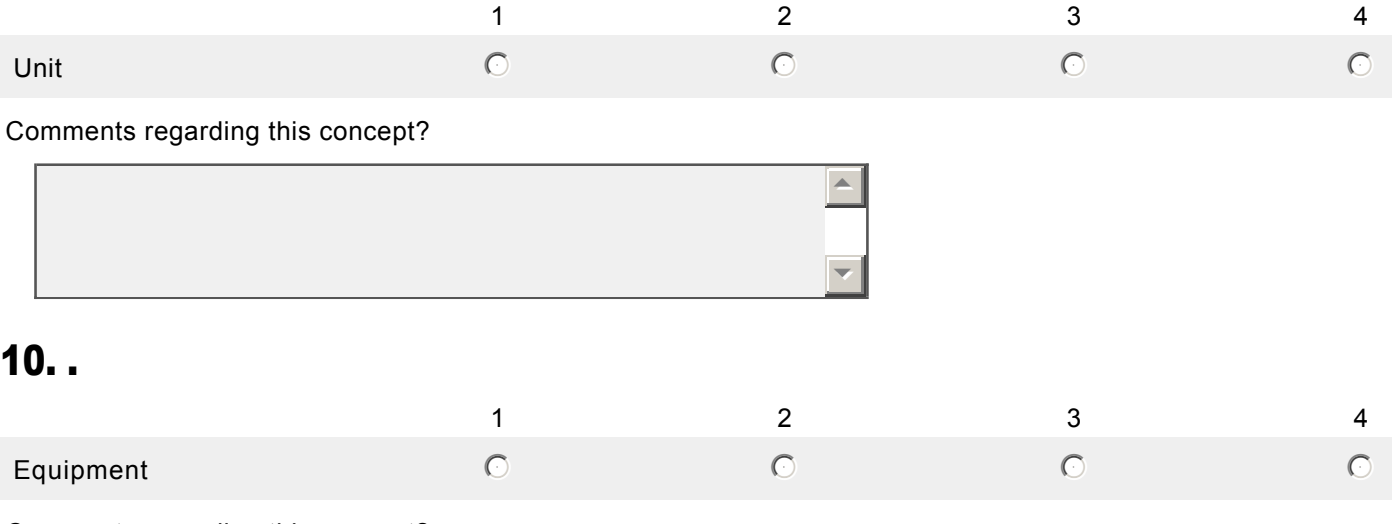

Comments regarding this concept?

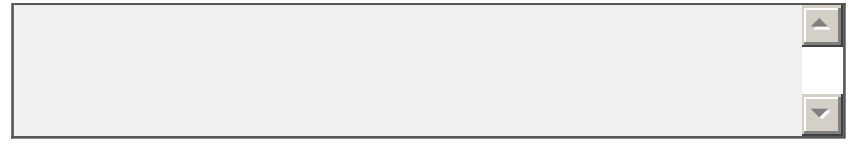




\section{Planning Survey}

11. .

Materials

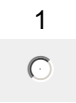

2

3

$0^{4}$

$\bigcirc^{5}$

Comments regarding this concept?

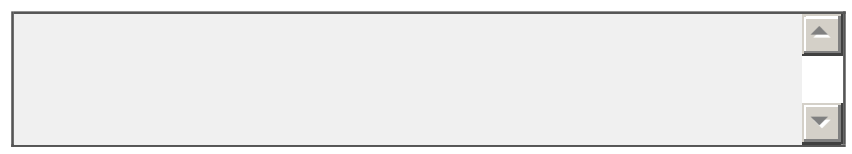




\section{Planning Survey}

\section{Modified Delphi Round I}

Please rate each lesson planning Concept below for IMPORTANCE using the 1-5 Likert Scale:

(5) or (4) - Concept is essential for a preservice lesson plan.

(3) You are neutral regarding the IMPORTANCE of the item.

(2) or (1) - Concept is NOT essential for inclusion in a preservice teacher lesson plan.

CONTEXTUAL INFORMATION - continued

\section{2.}

Resources
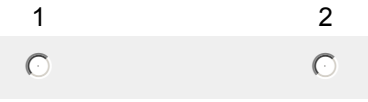

3

Comments regarding this concept?

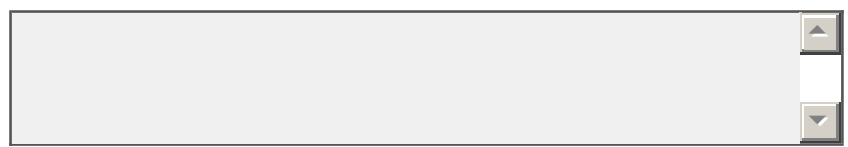

\section{3. .}

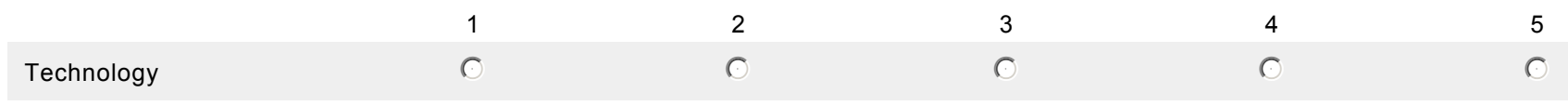

Comments regarding this concept?

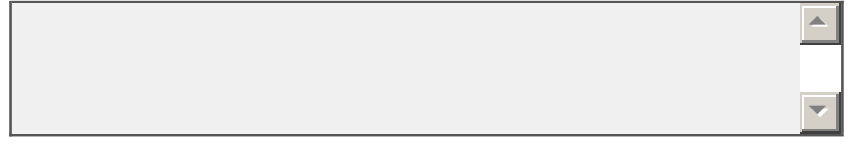

14.
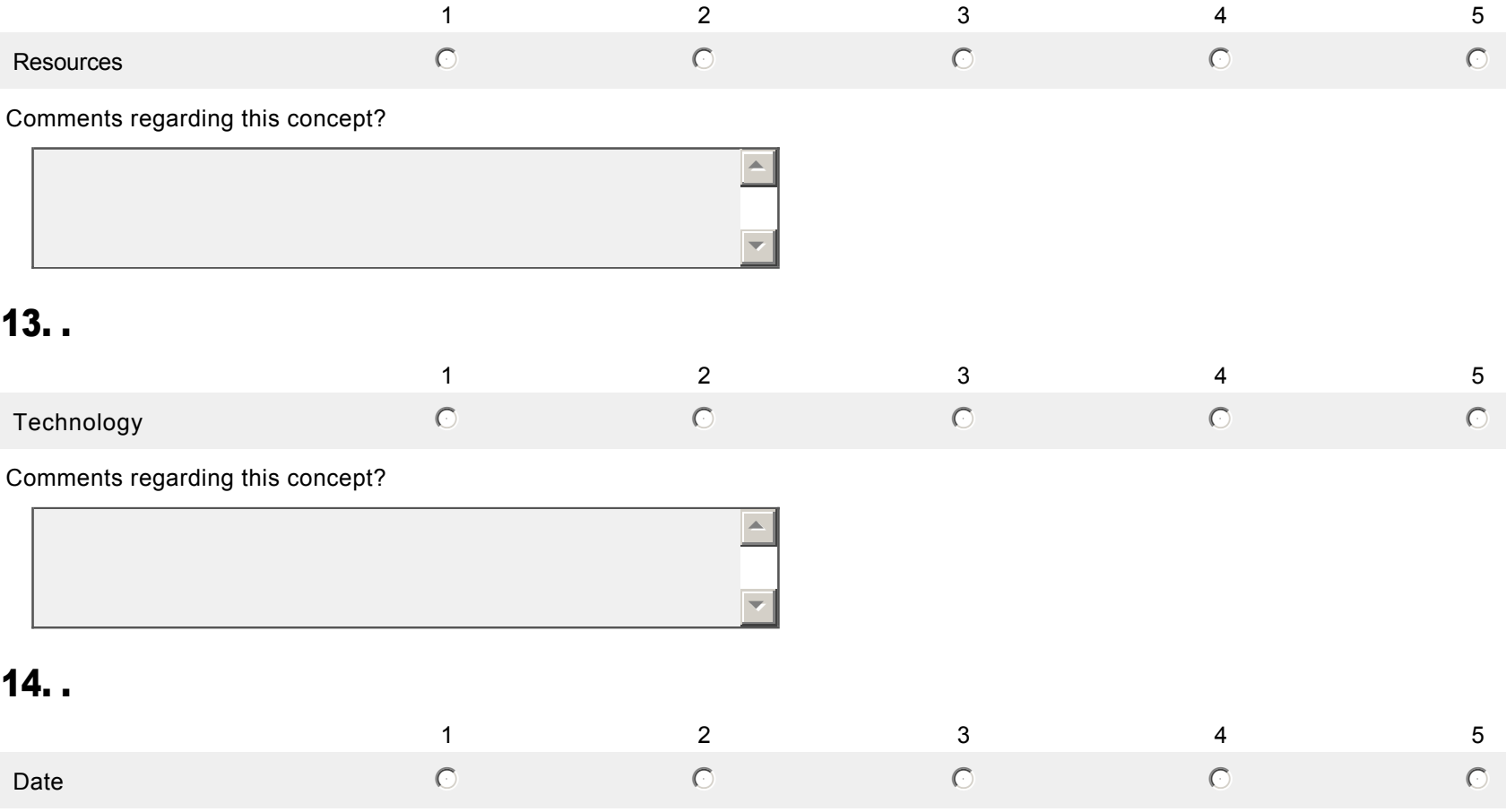

Comments regarding this concept?

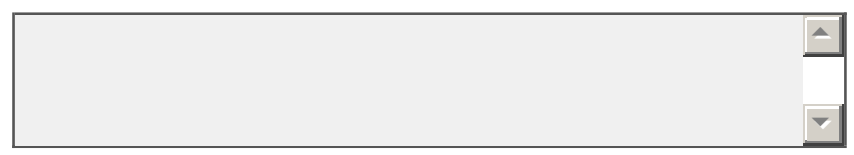

15.

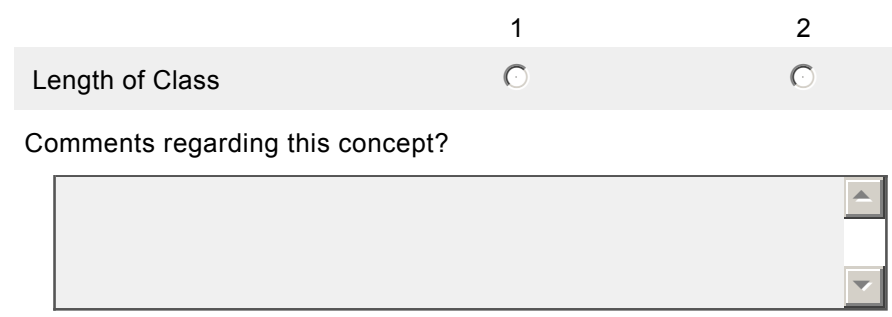

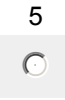

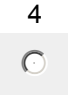

\section{.}

) 


\section{Planning Survey}

16. .

Time

1

$0^{2}$

3

$0^{4}$

$\bigcirc^{5}$

Comments regarding this concept?

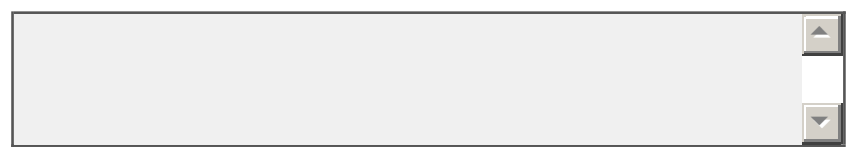




\section{Planning Survey}

\section{Modified Delphi Round I}

Please rate each lesson planning Concept below for IMPORTANCE using the 1-5 Likert Scale:

(5) or (4) - Concept is essential for a preservice lesson plan.

(3) You are neutral regarding the IMPORTANCE of the item.

(2) or (1) - Concept is NOT essential for inclusion in a preservice teacher lesson plan.

CONTEXTUAL INFORMATION - continued

\section{7. .}
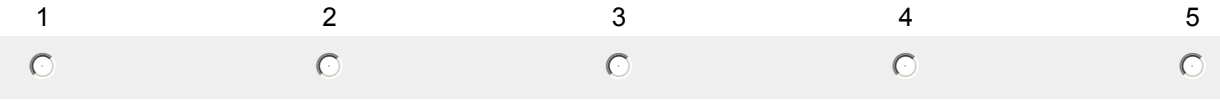

Comments regarding this concept?

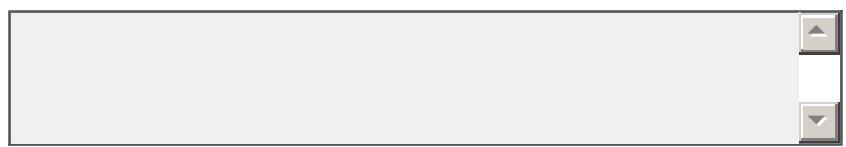

18. .

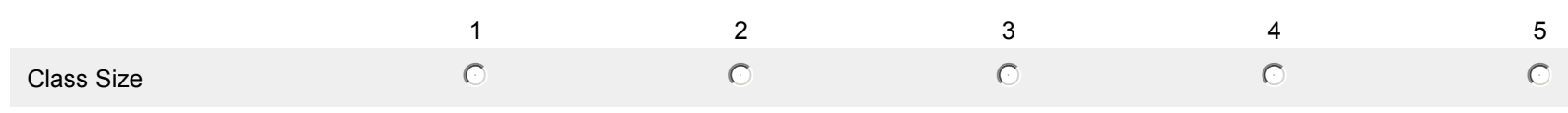

Comments regarding this concept?

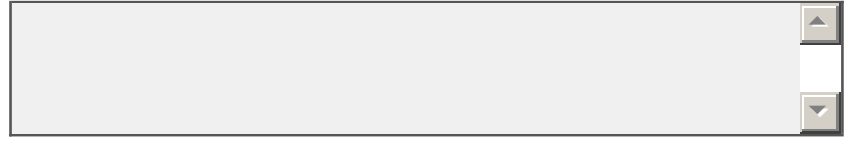

19. .
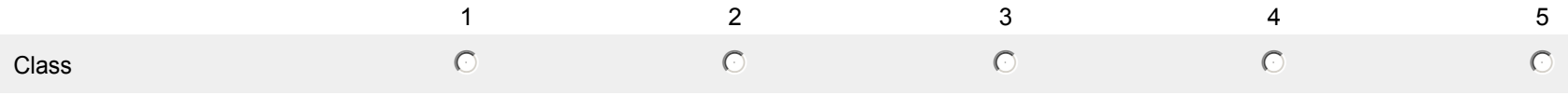

Comments regarding this concept?

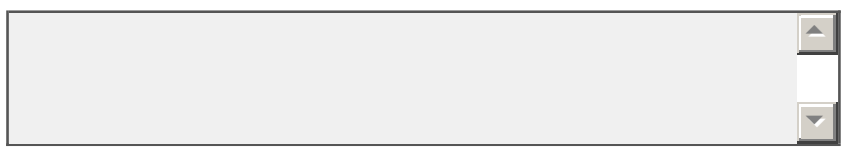

20. .
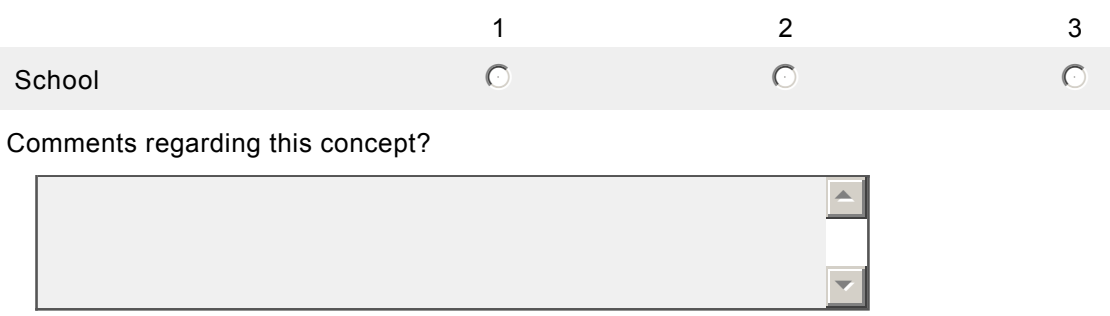


\section{Planning Survey}

21. .

Facility

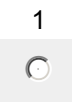

2

3

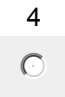

$\bigcirc$

Comments regarding this concept?

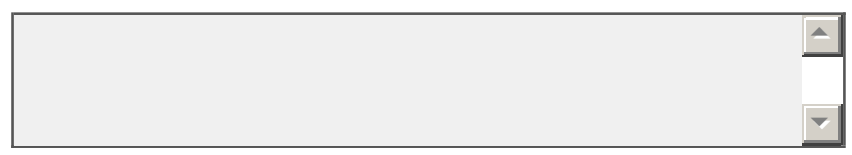

22. .

1

$0^{2}$

$0^{3}$

$\stackrel{4}{0}$

$0^{5}$

Comments regarding this concept?

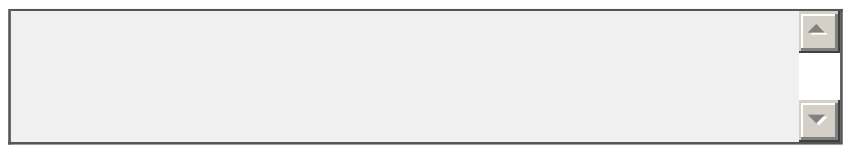




\section{Planning Survey}

\section{Modified Delphi Round I}

Please rate each lesson planning Concept below for IMPORTANCE using the 1-5 Likert Scale:

(5) or (4) - Concept is essential for a preservice lesson plan.

(3) You are neutral regarding the IMPORTANCE of the item.

(2) or (1) - Concept is NOT essential for inclusion in a preservice teacher lesson plan.

\section{PRE-INSTRUCTION}

\section{3. .}

Objectives
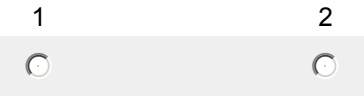

3

Comments regarding this concept?

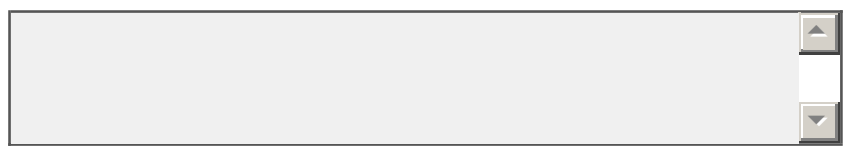

\section{4. .}

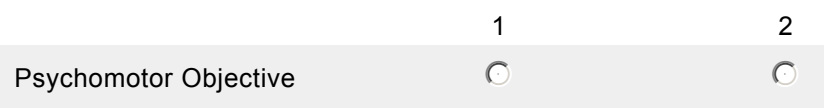

3

4

5

Comments regarding this concept?

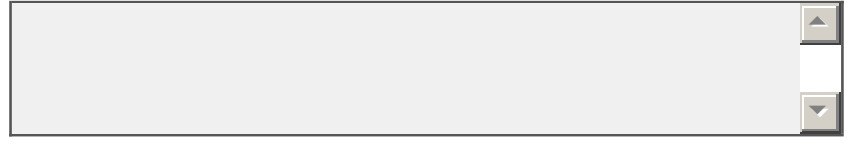

\section{5. .}

Cognitive Objective
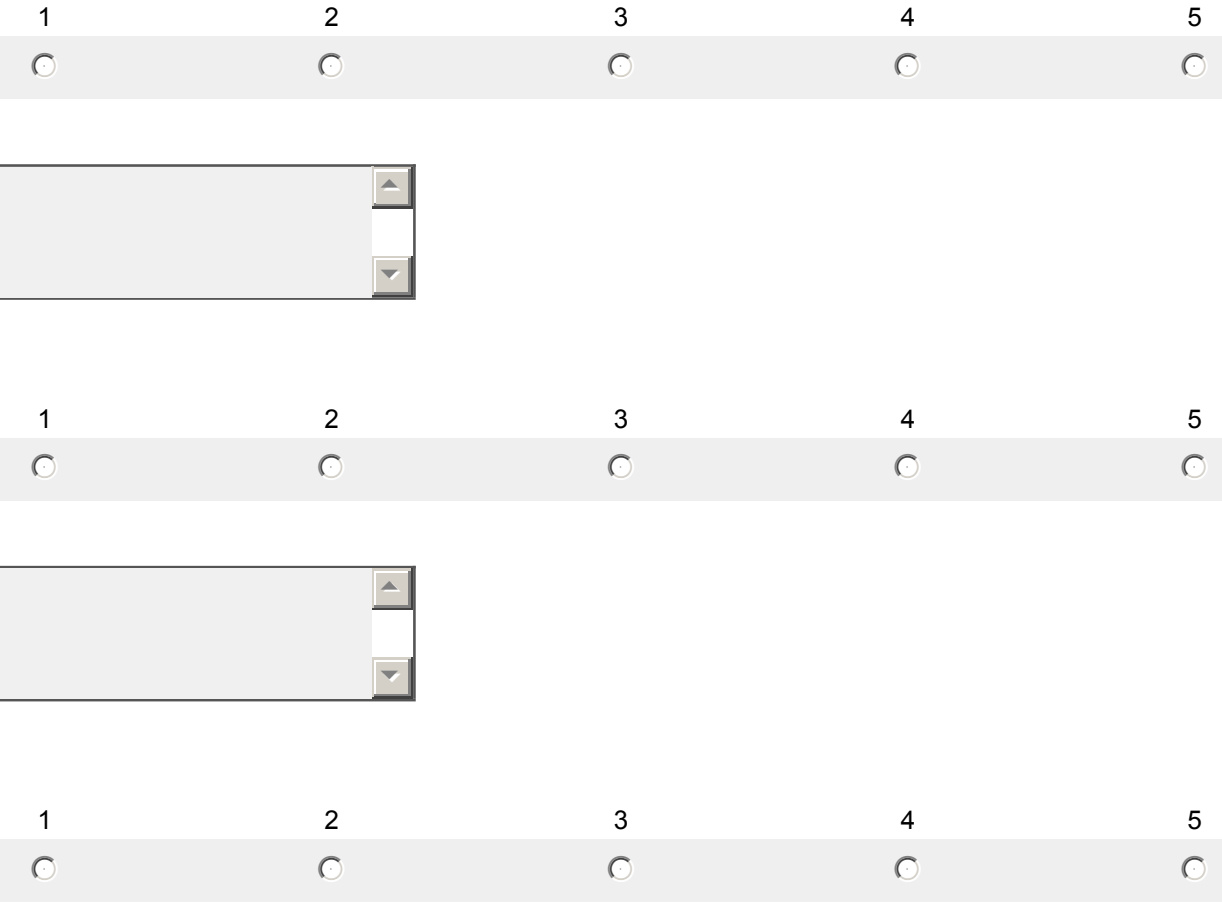

Comments regarding this concept?

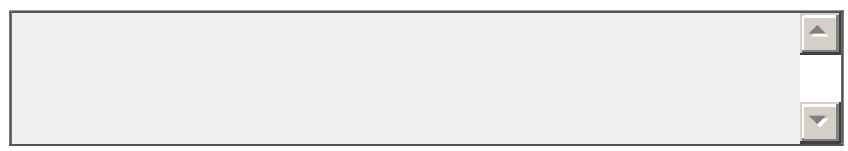

26. .

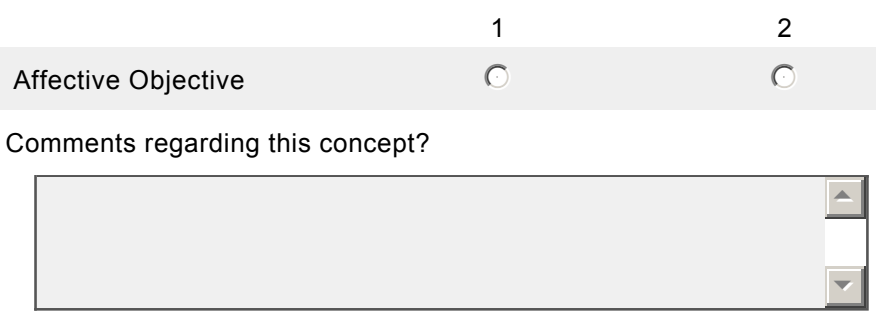

3

$\bigcirc$

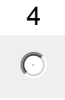

$\bigcirc$ . 


\section{Planning Survey}

27. .

Fitness Objective

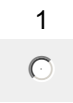

2

3

$0^{4}$

$\bigcirc^{5}$

Comments regarding this concept?

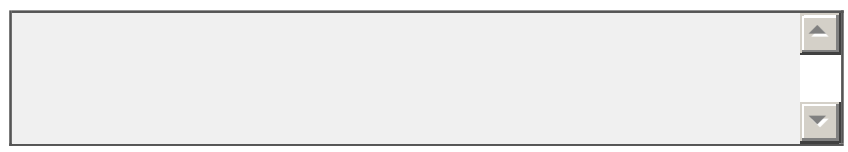




\section{Planning Survey}

\section{Modified Delphi Round I}

Please rate each lesson planning Concept below for IMPORTANCE using the 1-5 Likert Scale:

(5) or (4) - Concept is essential for a preservice lesson plan.

(3) You are neutral regarding the IMPORTANCE of the item.

(2) or (1) - Concept is NOT essential for inclusion in a preservice teacher lesson plan.

PRE-INSTRUCTION - continued

\section{8. .}

NASPE Standards
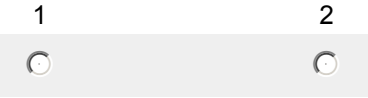

3

Comments regarding this concept?

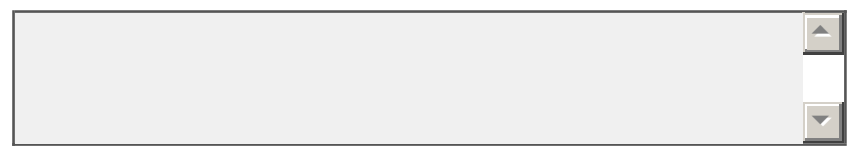

\section{9. .}
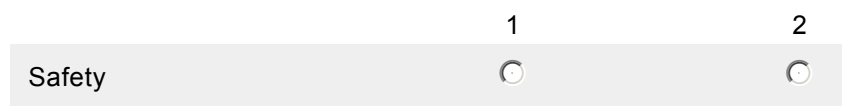

3
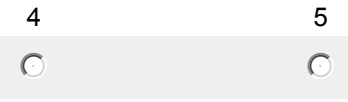

Comments regarding this concept?

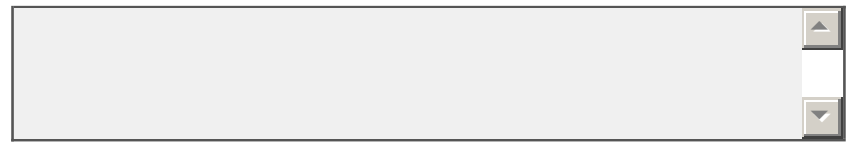




\section{Planning Survey}

\section{Modified Delphi Round I}

Please rate each lesson planning Concept below for IMPORTANCE using the 1-5 Likert Scale:

(5) or (4) - Concept is essential for a preservice lesson plan.

(3) You are neutral regarding the IMPORTANCE of the item.

(2) or (1) - Concept is NOT essential for inclusion in a preservice teacher lesson plan.

\section{INSTRUCTION}

\section{0. .}

Introduction
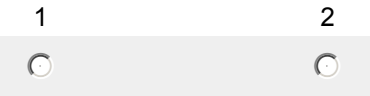

3

Comments regarding this concept?

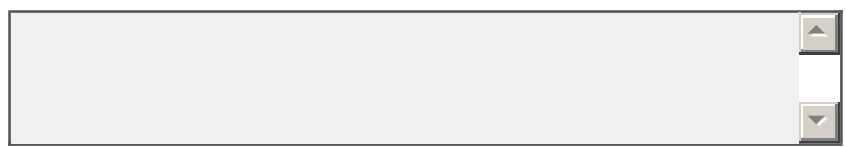

\section{1. .}

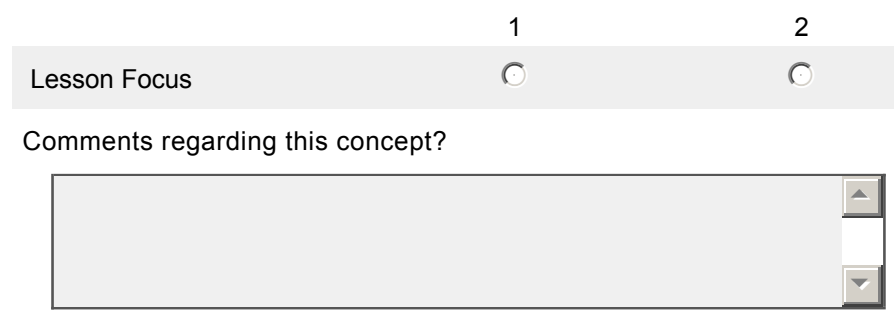

\section{2. .}

Introductory Activity
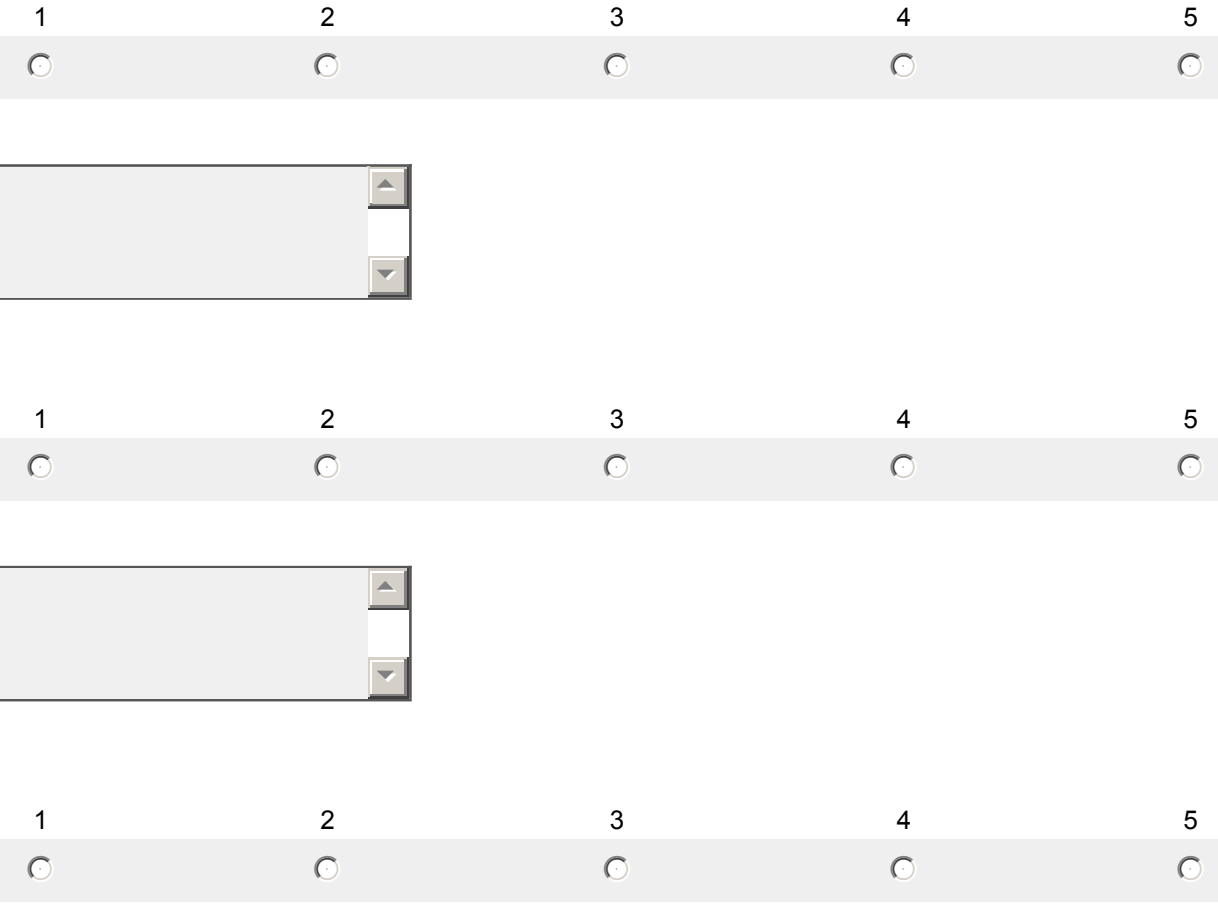

Comments regarding this concept?

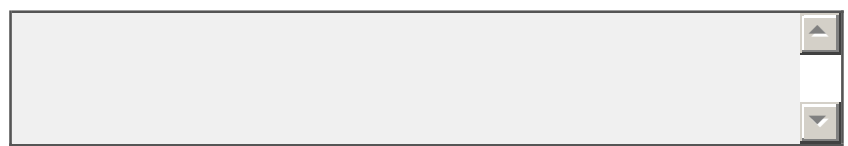

33.

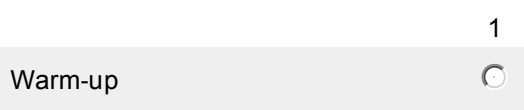

2

Comments regarding this concept?

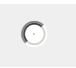

3

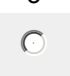

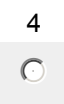

5

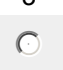

$\bigcirc$

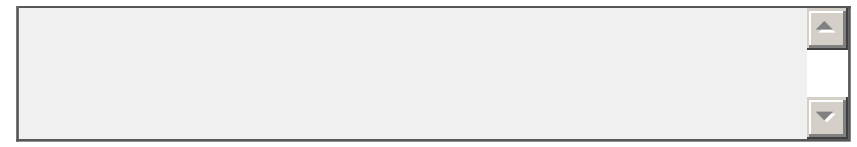




\section{Planning Survey}

34. .

Instant Activity

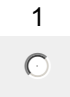

2

3

$0^{4}$

$\bigcirc^{5}$

Comments regarding this concept?

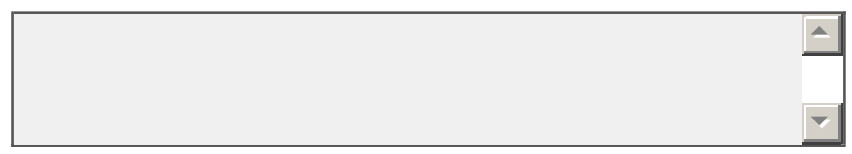




\section{Planning Survey}

\section{Modified Delphi Round I}

Please rate each lesson planning Concept below for IMPORTANCE using the 1-5 Likert Scale:

(5) or (4) - Concept is essential for a preservice lesson plan.

(3) You are neutral regarding the IMPORTANCE of the item.

(2) or (1) - Concept is NOT essential for inclusion in a preservice teacher lesson plan.

INSTRUCTION - continued

\section{5. .}

Fitness Activity
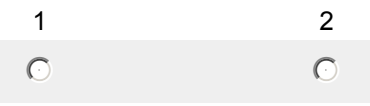

3

Comments regarding this concept?

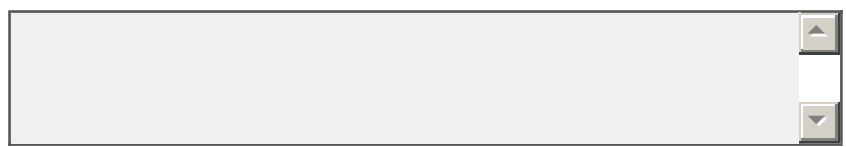

36. .

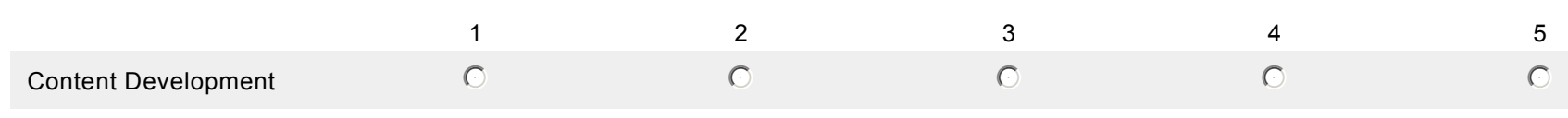

Comments regarding this concept?

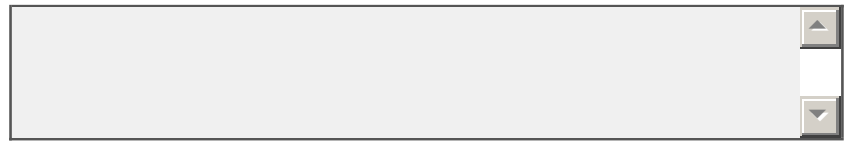

\section{7. .}

Skill Analysis
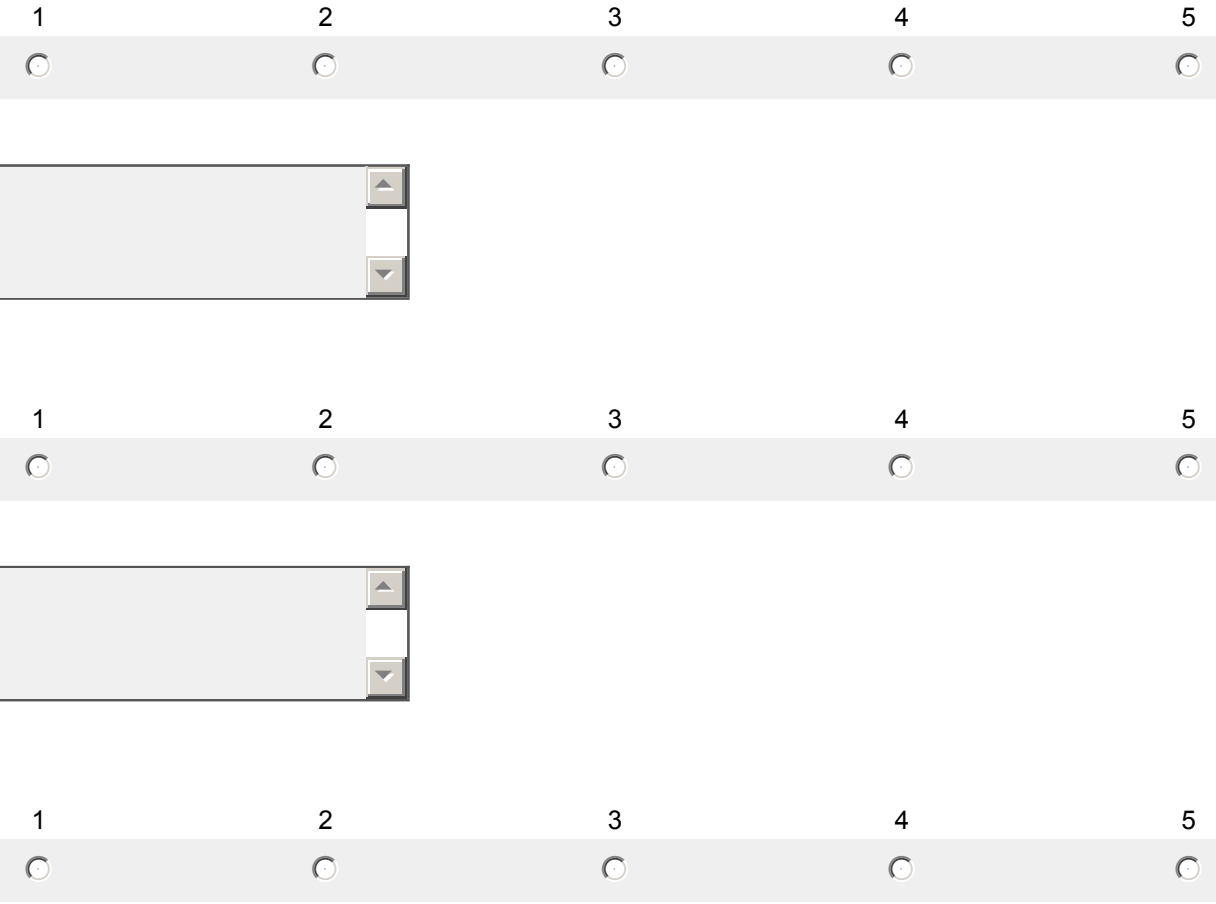

Comments regarding this concept?

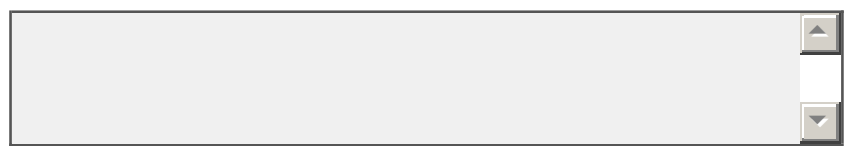

38.

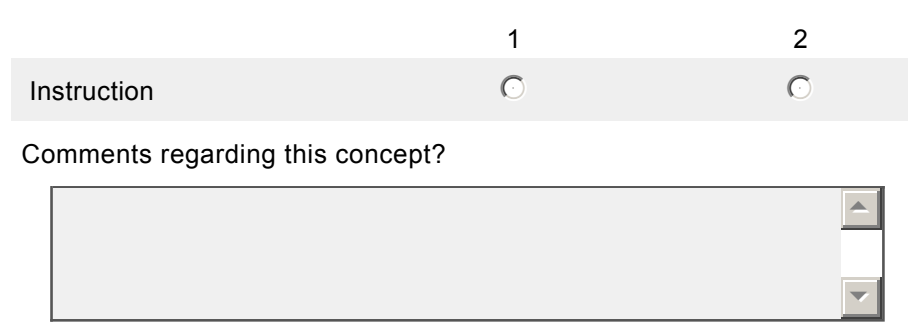




\section{Planning Survey}

39. .

Demonstration

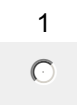

$\bigcirc^{2}$

$\bigcirc^{3}$

$\stackrel{4}{\circ}$

$\bigcirc^{5}$

Comments regarding this concept?

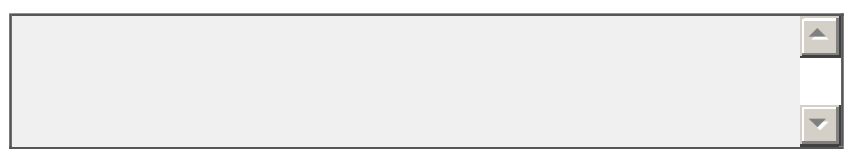




\section{Planning Survey}

\section{Modified Delphi Round I}

Please rate each lesson planning Concept below for IMPORTANCE using the 1-5 Likert Scale:

(5) or (4) - Concept is essential for a preservice lesson plan.

(3) You are neutral regarding the IMPORTANCE of the item.

(2) or (1) - Concept is NOT essential for inclusion in a preservice teacher lesson plan.

INSTRUCTION - continued

40. .

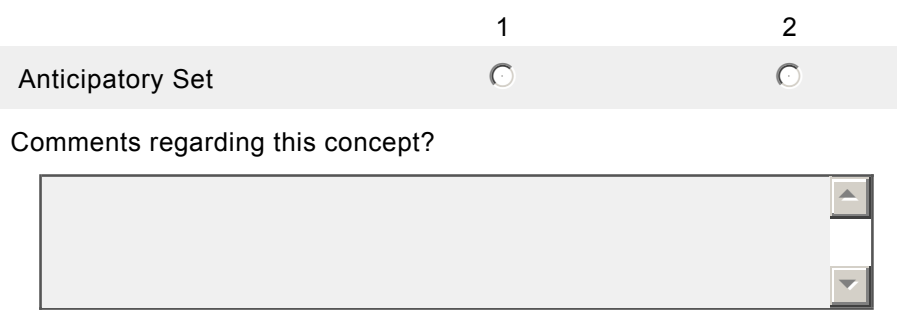

\section{1.}

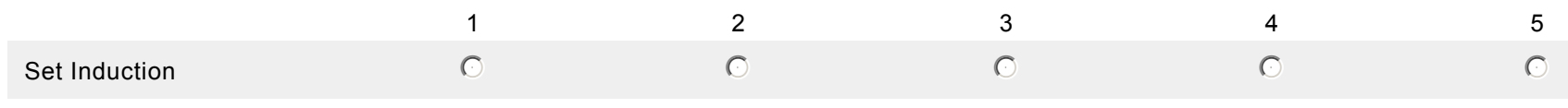

Comments regarding this concept?

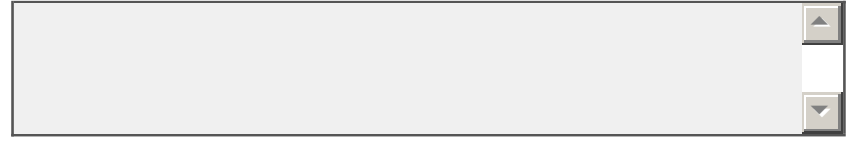

42. .

Critical Elements
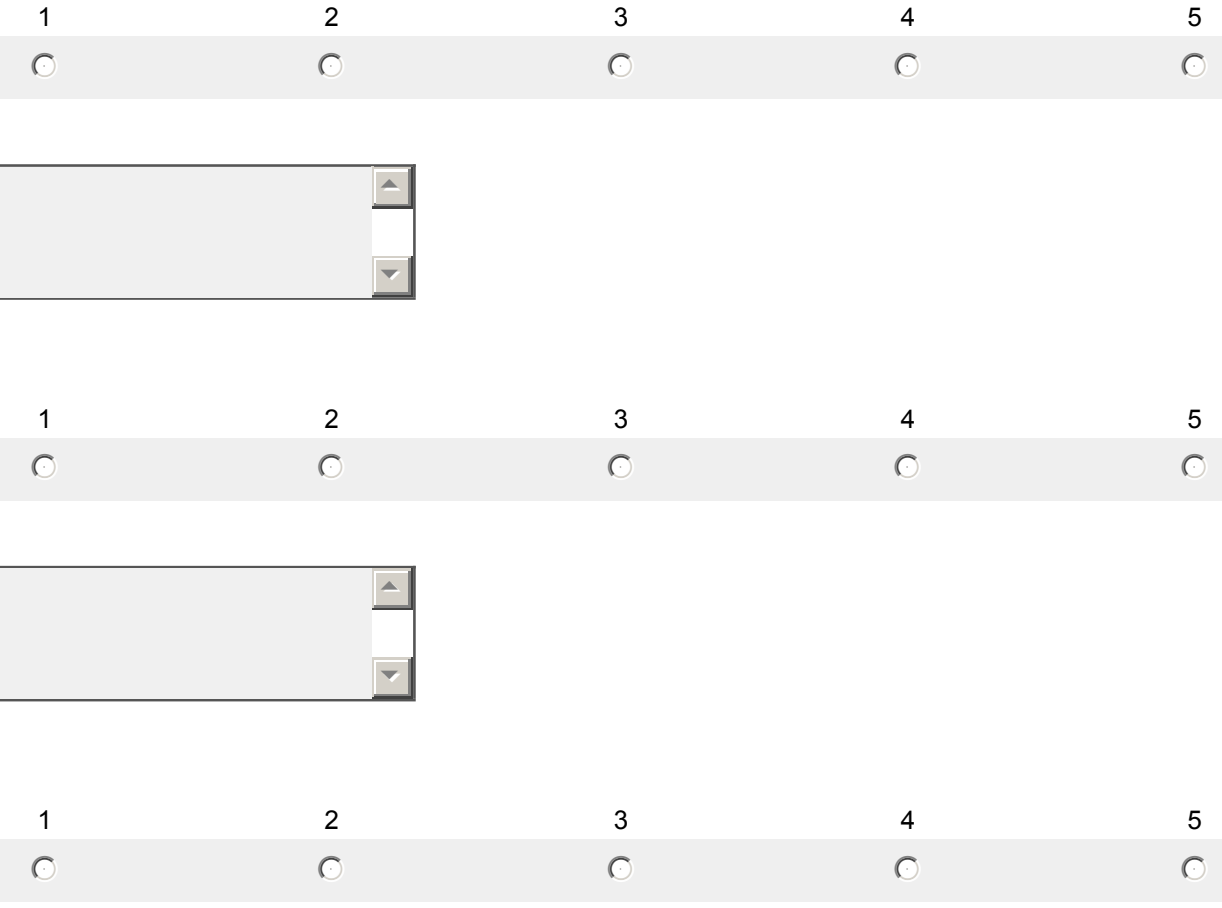

Comments regarding this concept?

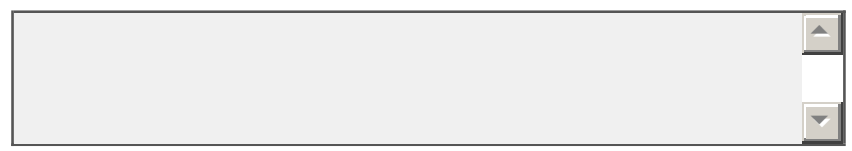

\section{3. .}

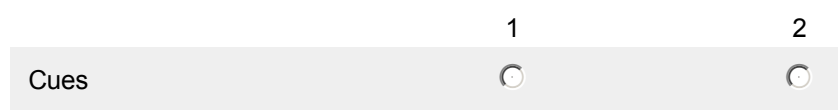

3

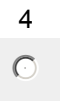

5

Comments regarding this concept?
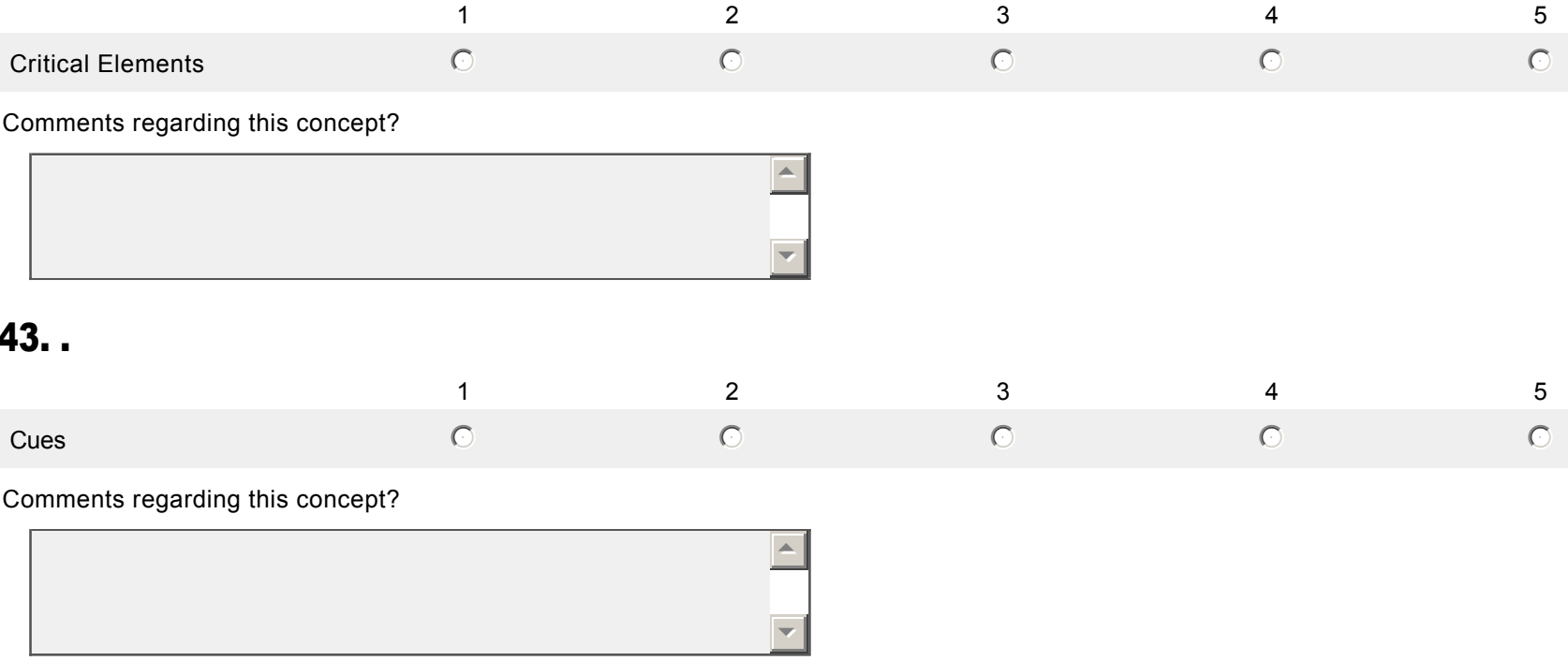


\section{Planning Survey}

44. .

Teaching by Invitation

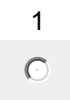

2

3

$0^{4}$

$\bigcirc^{5}$

Comments regarding this concept?

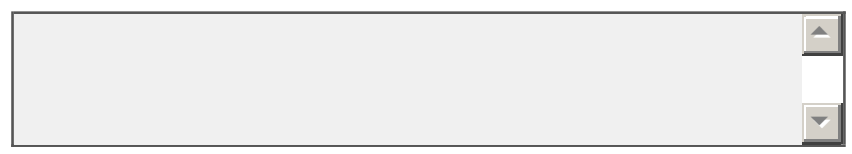




\section{Planning Survey}

\section{Modified Delphi Round I}

Please rate each lesson planning Concept below for IMPORTANCE using the 1-5 Likert Scale:

(5) or (4) - Concept is essential for a preservice lesson plan.

(3) You are neutral regarding the IMPORTANCE of the item.

(2) or (1) - Concept is NOT essential for inclusion in a preservice teacher lesson plan.

INSTRUCTION - continued

45. .

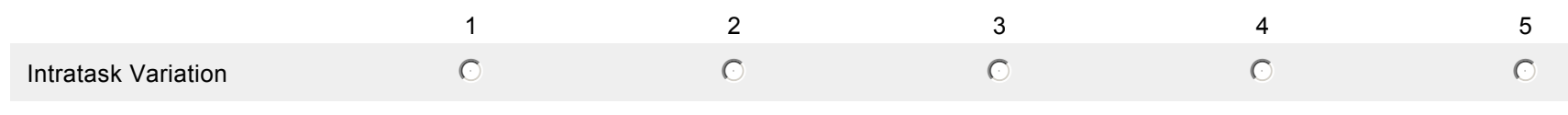

Comments regarding this concept?

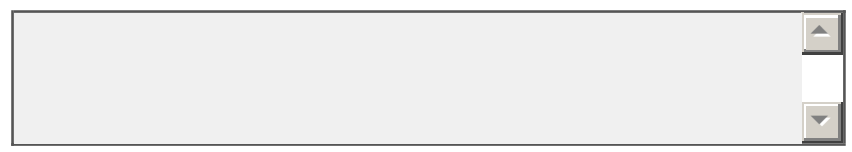

46. .

Checking for Understanding
$(\mathrm{CFU})$

Comments regarding this concept?

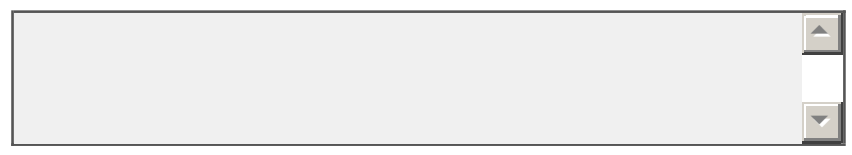

47. .

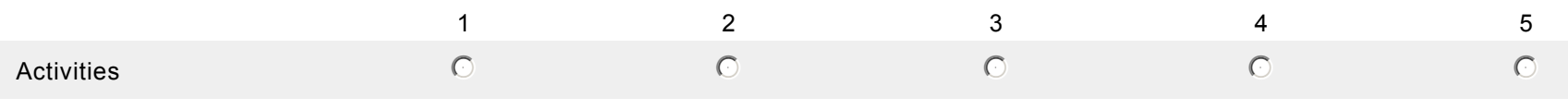

Comments regarding this concept?

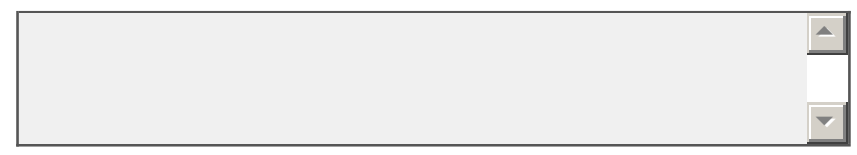

48. .

Formation

Comments regarding this concept?
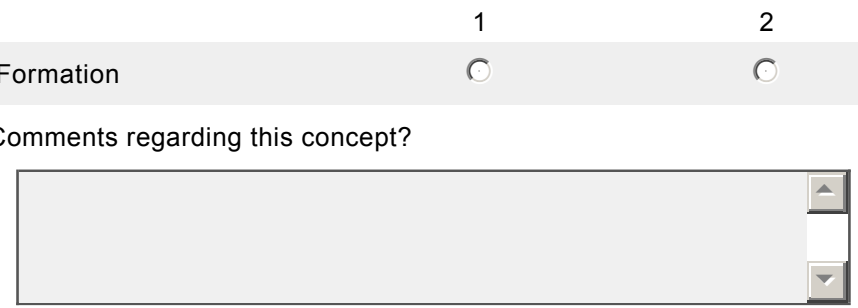


\section{Planning Survey}

49. .

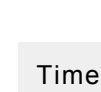

$0^{1}$

$0^{2}$

$0^{3}$

$0^{4}$

$\bigcirc^{5}$

Comments regarding this concept?

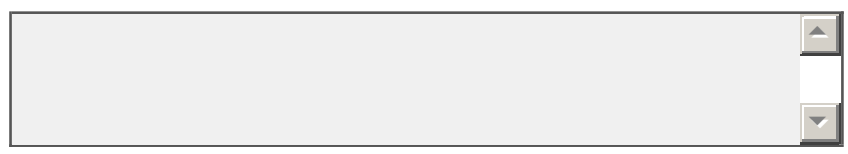




\section{Planning Survey}

\section{Modified Delphi Round I}

Please rate each lesson planning Concept below for IMPORTANCE using the 1-5 Likert Scale:

(5) or (4) - Concept is essential for a preservice lesson plan.

(3) You are neutral regarding the IMPORTANCE of the item.

(2) or (1) - Concept is NOT essential for inclusion in a preservice teacher lesson plan.

INSTRUCTION - continued

50. .

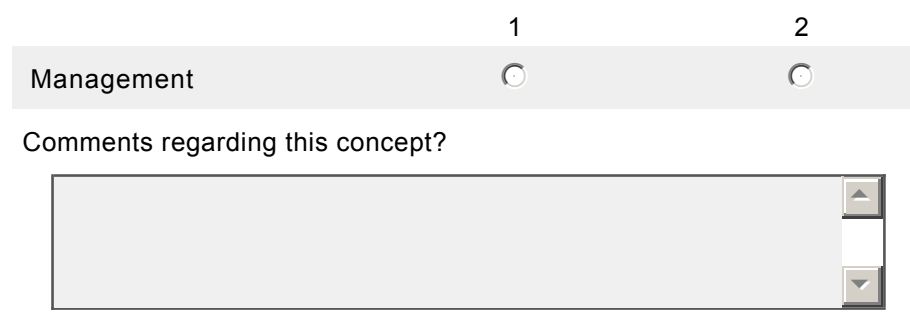

51. .

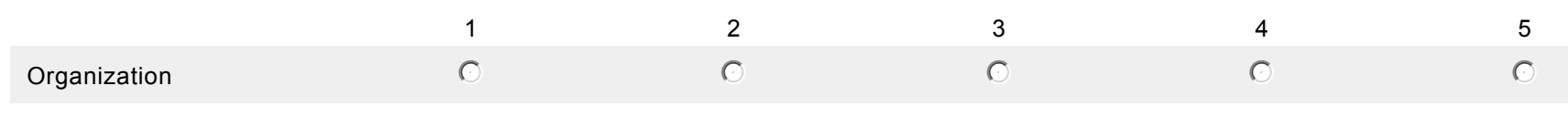

Comments regarding this concept?

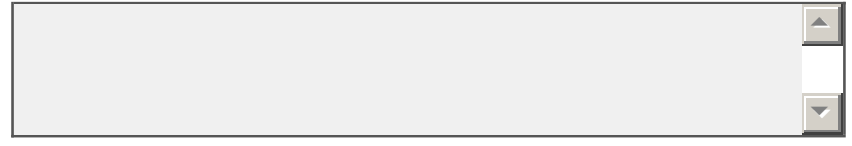

\section{2. .}

Adaptations
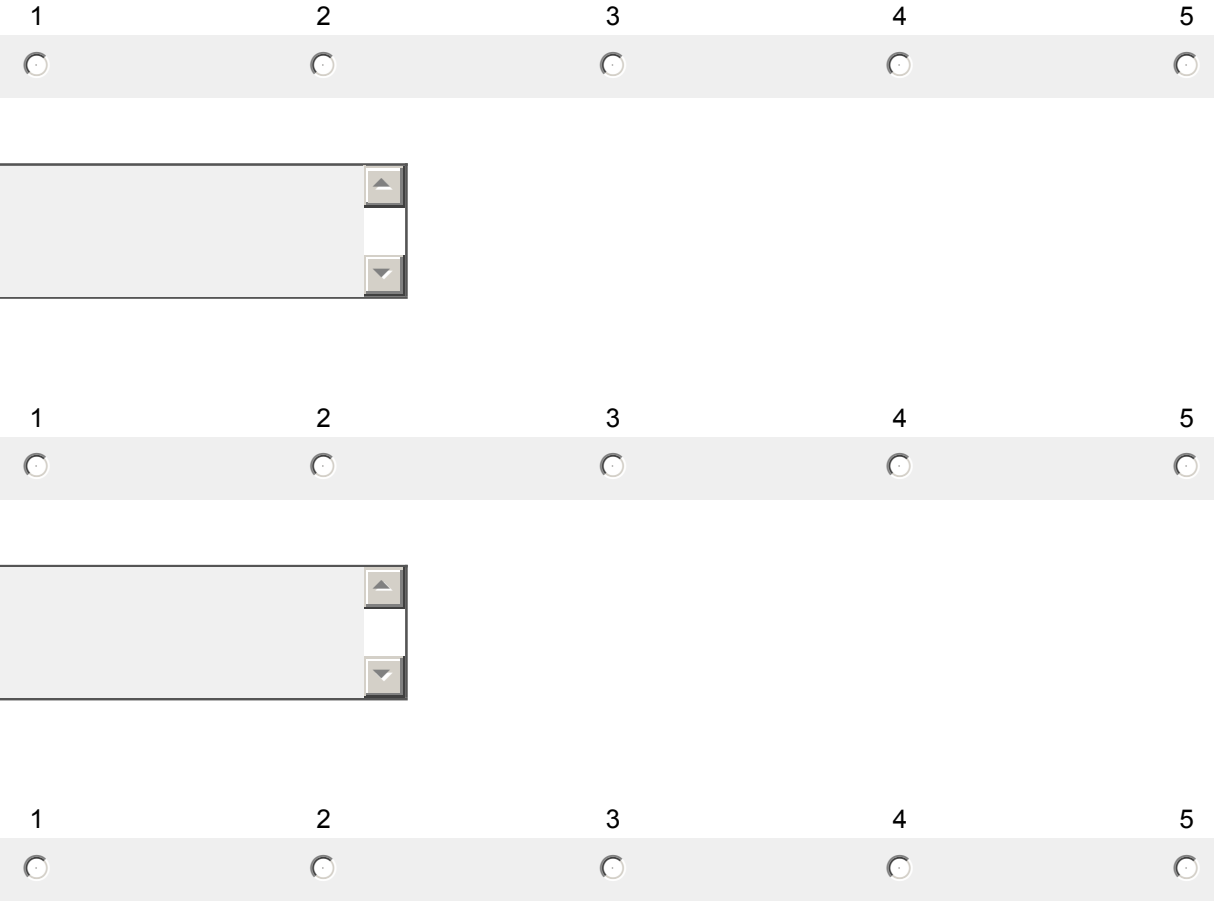

Comments regarding this concept?

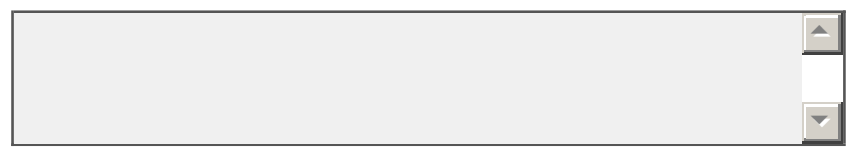

53. .

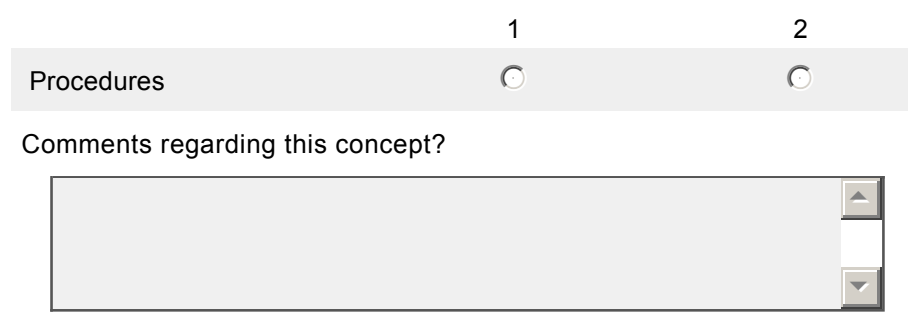

.




\section{Planning Survey}

54. .

Motivation

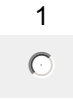

2

3

$0^{4}$

$\bigcirc^{5}$

Comments regarding this concept?

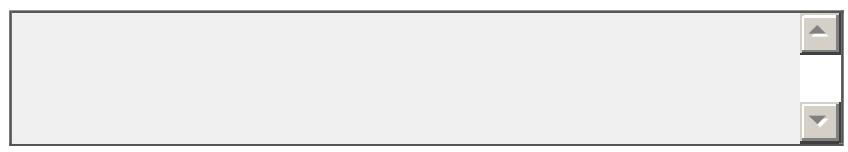




\section{Planning Survey}

\section{Modified Delphi Round I}

Please rate each lesson planning Concept below for IMPORTANCE using the 1-5 Likert Scale:

(5) or (4) - Concept is essential for a preservice lesson plan.

(3) You are neutral regarding the IMPORTANCE of the item.

(2) or (1) - Concept is NOT essential for inclusion in a preservice teacher lesson plan.

INSTRUCTION - continued

\section{5. .}

Informing
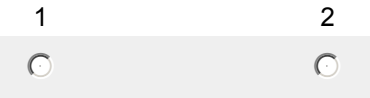

3

Comments regarding this concept?

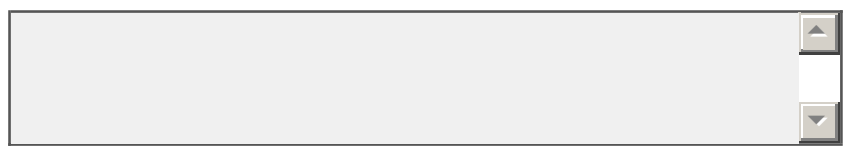

56.

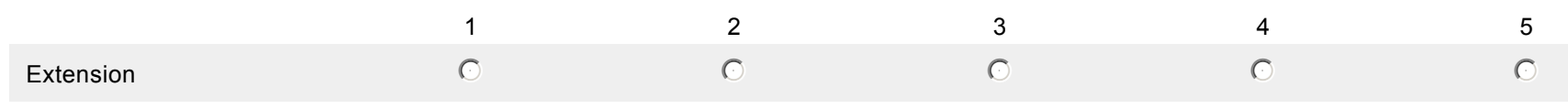

Comments regarding this concept?

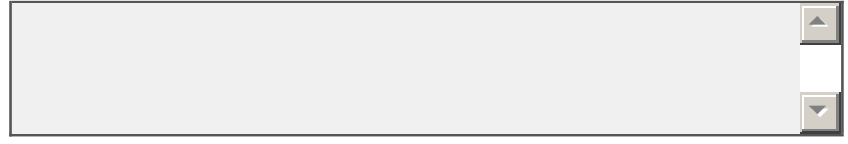

\section{7. .}

Goal Orientation
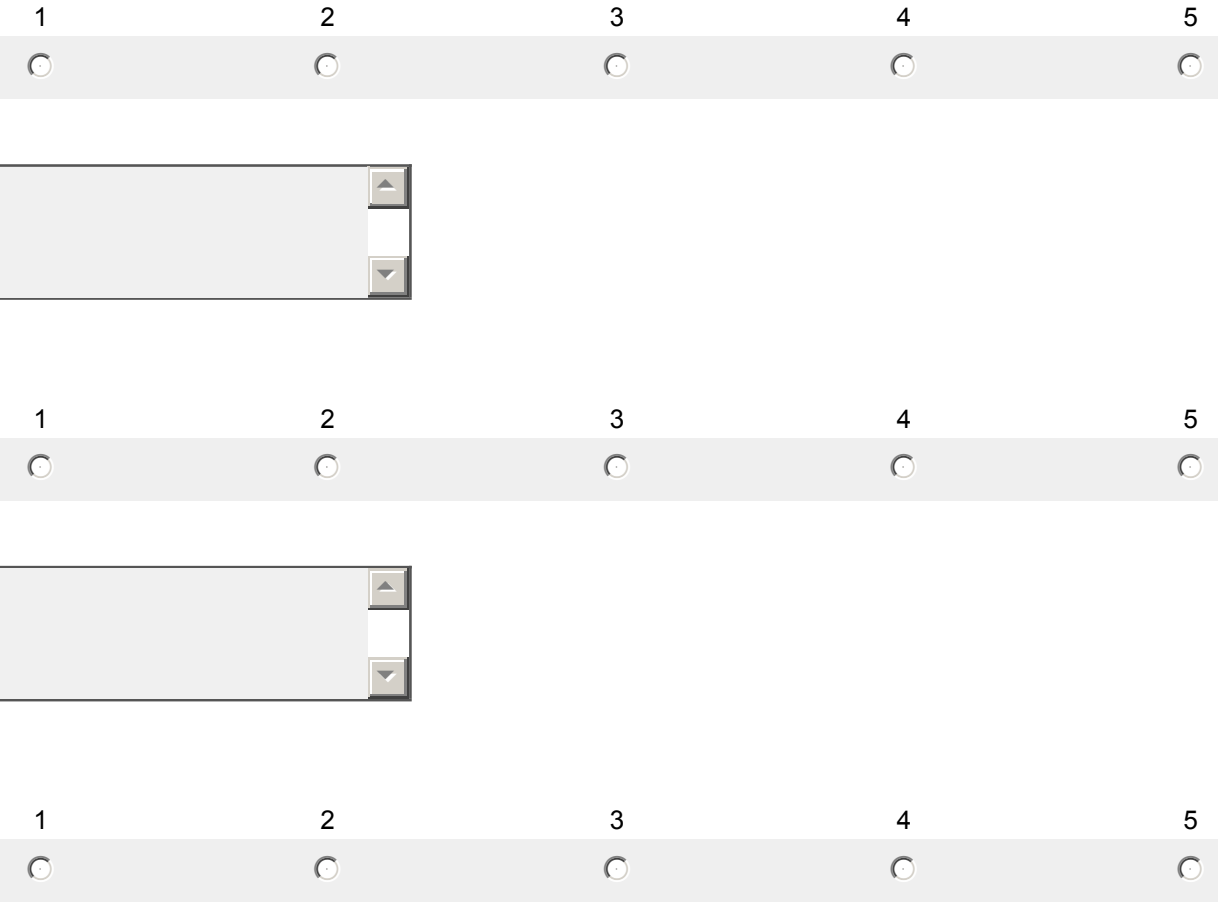

Comments regarding this concept?

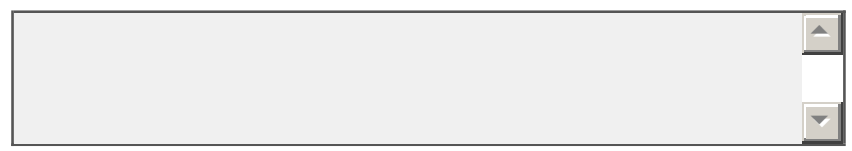

58.
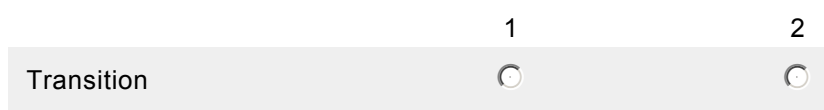

3

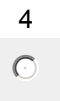

$\bigcirc$

Comments regarding this concept?

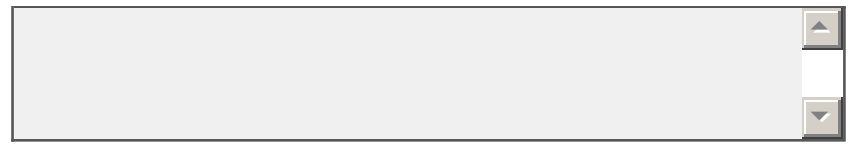




\section{Planning Survey}

59. .

Progression

1

$0^{2}$

3

$0^{4}$

$\bigcirc^{5}$

Comments regarding this concept?

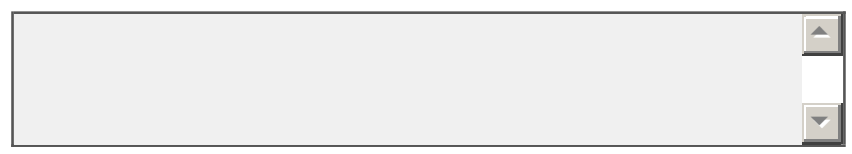




\section{Planning Survey}

\section{Modified Delphi Round I}

Please rate each lesson planning Concept below for IMPORTANCE using the 1-5 Likert Scale:

(5) or (4) - Concept is essential for a preservice lesson plan.

(3) You are neutral regarding the IMPORTANCE of the item.

(2) or (1) - Concept is NOT essential for inclusion in a preservice teacher lesson plan.

INSTRUCTION - continued

\section{0.}

Modifications
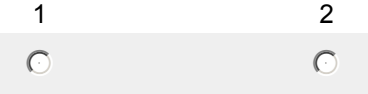

3

Comments regarding this concept?

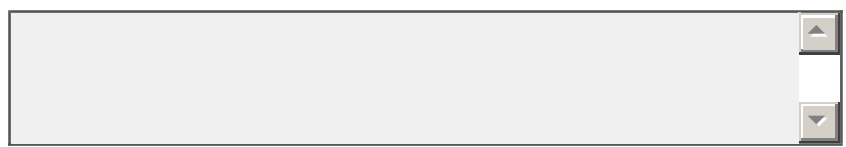

\section{1. .}

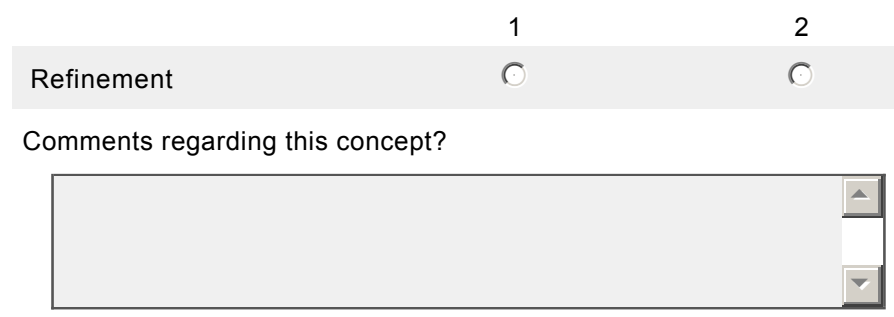

\section{2.}

Application
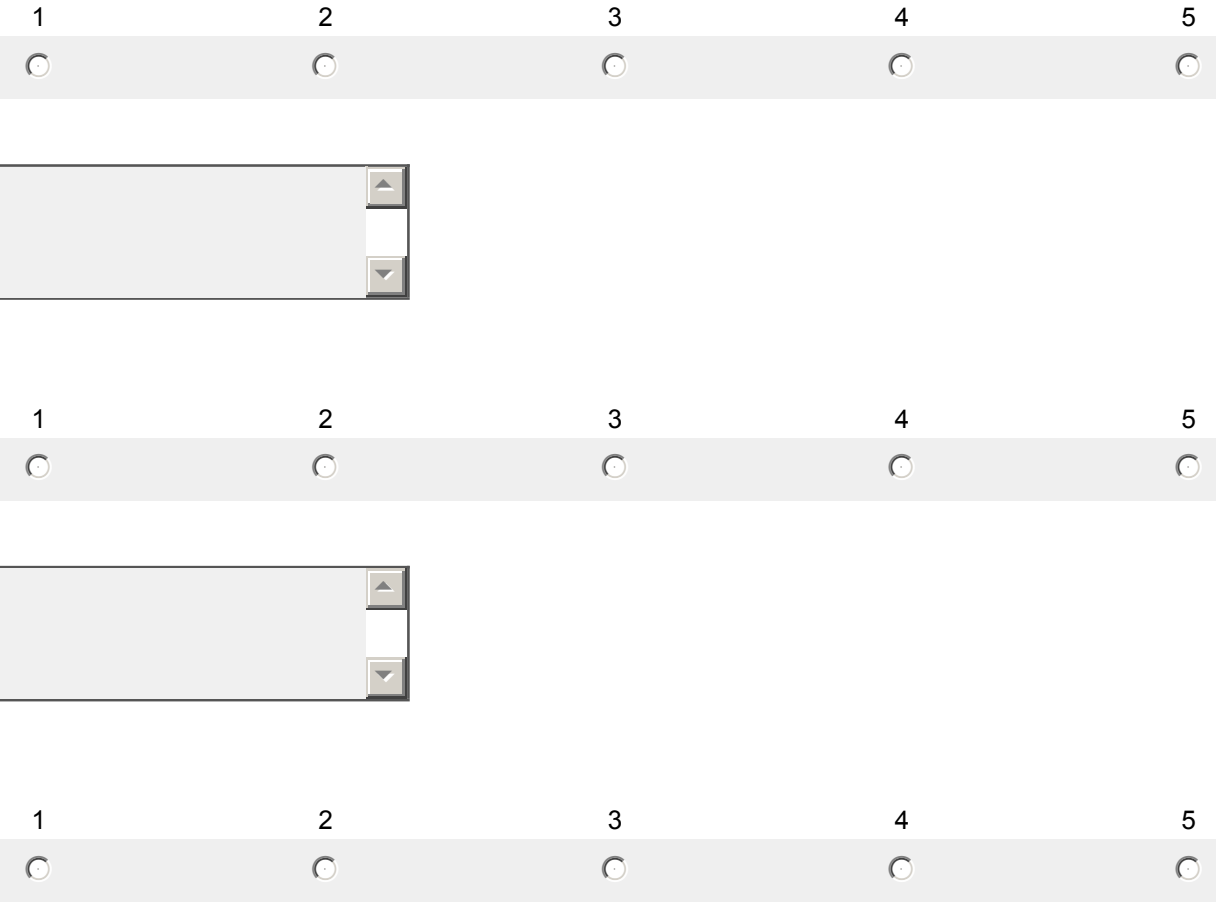

Comments regarding this concept?

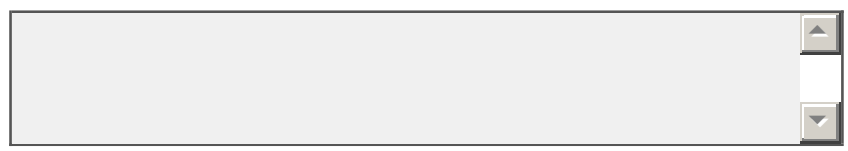

\section{3. .}
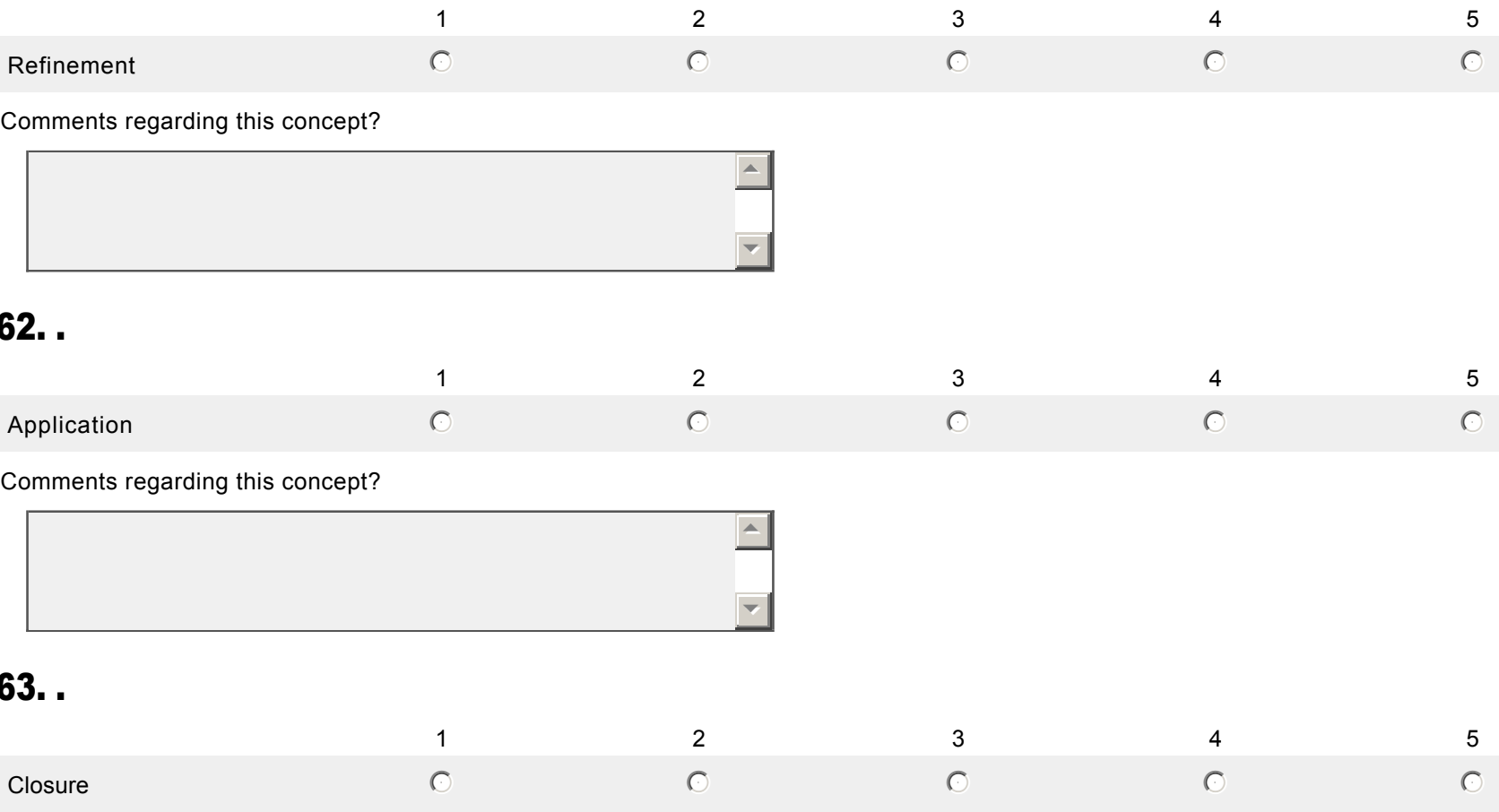

Comments regarding this concept?

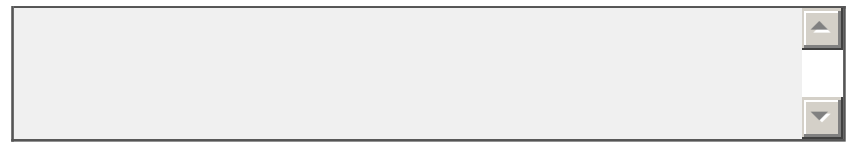




\section{Planning Survey}

64. .

Cool Down

1

$0^{2}$

3

$0^{4}$

$\bigcirc^{5}$

Comments regarding this concept?

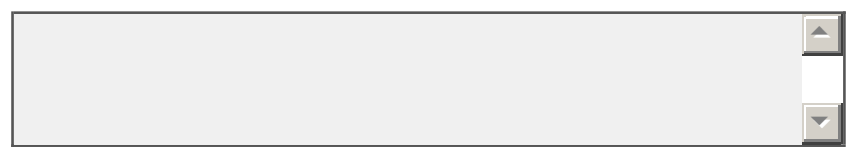




\section{Planning Survey}

\section{Modified Delphi Round I}

Please rate each lesson planning Concept below for IMPORTANCE using the 1-5 Likert Scale:

(5) or (4) - Concept is essential for a preservice lesson plan.

(3) You are neutral regarding the IMPORTANCE of the item.

(2) or (1) - Concept is NOT essential for inclusion in a preservice teacher lesson plan.

\section{POST-INSTRUCTION}

\section{5. .}
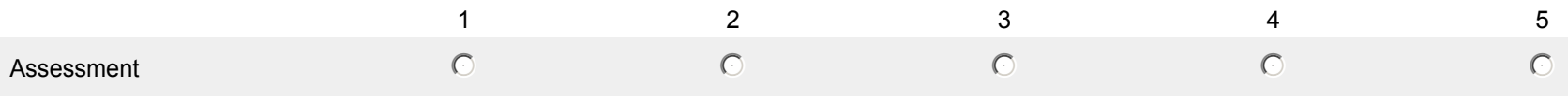

Comments regarding this concept?

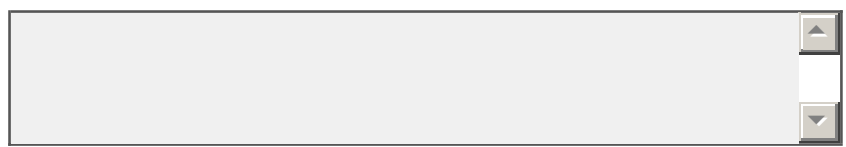

66. .

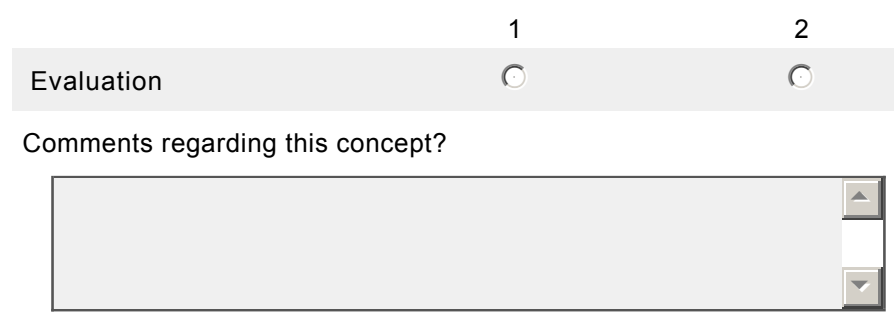

\section{7. .}

Reflection
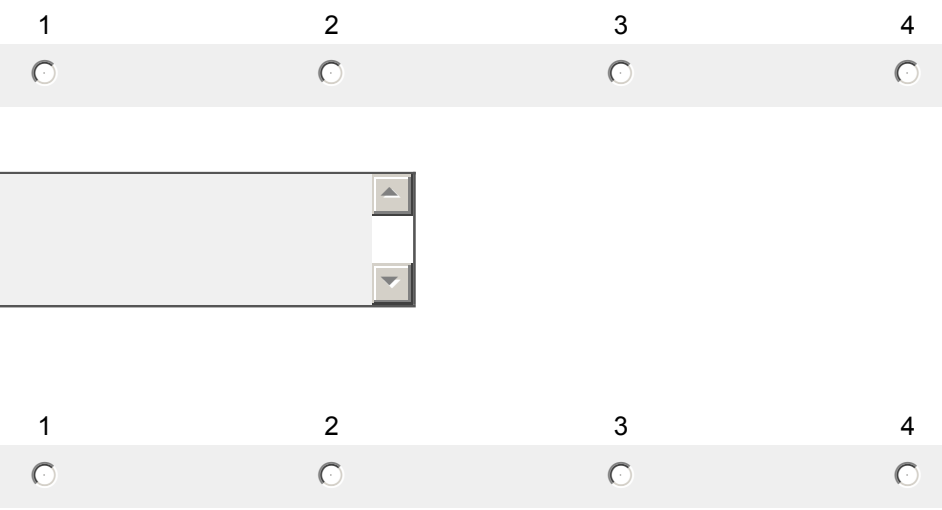

5

Comments regarding this concept?
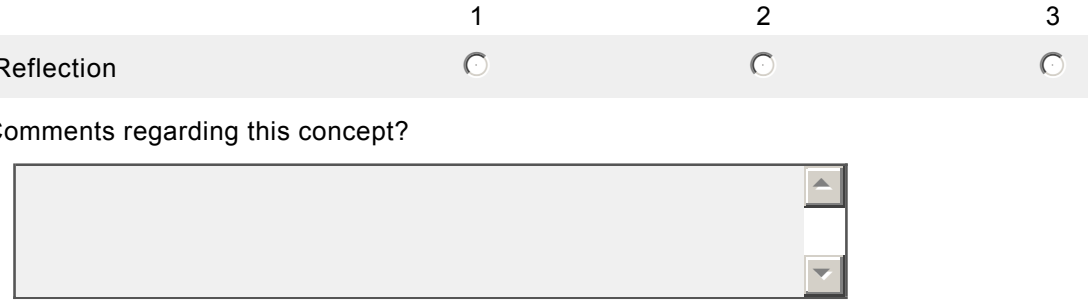


\section{Planning Survey}

\section{Modified Delphi Round I}

Thank you for completing the survey! Your input is greatly appreciated.

Once all Round I surveys have been completed and analyzed, I will e-mail you the website link to Round II of the study. I anticipate this taking place on October 20, 2011.

You will know you are completely finished with the survey once you are redirected to the West Virginia University CPASS website. This will occur once you click the "Done" button below.

\section{Jack Sager}

West Virginia University

jsager@mix.wvu.edu

304.685.3267 


\section{Appendix 13}

Round I Results Excel Spreadsheet

\begin{tabular}{|c|c|c|c|c|c|c|}
\hline \# & Concept & GM & $\mathrm{I}$ & Include? & Moderator Comments & $\begin{array}{l}\text { Summary Panel } \\
\text { Comments }\end{array}$ \\
\hline 2 & $\begin{array}{l}\text { Teacher } \\
\text { name }\end{array}$ & 4.04 & 3 & No & $\begin{array}{l}\text { 1. Only to successfully "turn in" } \\
\text { but for a portfolio or day to day } \\
\text { use, not essential }\end{array}$ & None \\
\hline 3 & Unit & 4 & 4 & No & None & $\begin{array}{l}\text { 1. Not sure it needs a } \\
\text { "unit" label - but the } \\
\text { content needs to be } \\
\text { progressive and have a } \\
\text { yearly plan that } \\
\text { articulates across the } \\
\text { grades }\end{array}$ \\
\hline 4 & $\begin{array}{l}\text { Title of } \\
\text { lesson }\end{array}$ & 3.71 & 5 & No & None & None \\
\hline 5 & $\begin{array}{l}\text { Lesson } \\
\text { Topic/ } \\
\text { Activity }\end{array}$ & - & - & - & $\begin{array}{l}\text { 1. Based on panel comments } \\
\text { and review of lesson plans } \\
\text { from pilot study, 'Lesson } \\
\text { Topic' and 'Activity' were } \\
\text { combined to form } 1 \text { concept. }\end{array}$ & $\begin{array}{l}\text { Lesson Topic } \\
\text { comment: } 1 . \text { I would } \\
\text { refer to this as "lesson } \\
\text { content" i.e., what is to } \\
\text { be taught. I suggest } \\
\text { replacing focus with this } \\
\text { section and adding the } \\
\text { following contextual } \\
\text { section: "Unit Context", } \\
\text { which would precede } \\
\text { this section }\end{array}$ \\
\hline 6 & $\begin{array}{l}\text { Focus or } \\
\text { Skill Theme }\end{array}$ & 4.19 & 5 & Yes & $\begin{array}{l}\text { 1. Based on panel comments, } \\
\text { the Focus concept needs } \\
\text { clarification. *If lesson Topic } \\
\text { is soccer passing, then Focus } \\
\text { is the push pass. }\end{array}$ & None \\
\hline 7 & Lesson \# & 4.04 & 4 & No & None & $\begin{array}{l}\text { 1. Important for } \\
\text { progressions }\end{array}$ \\
\hline 8 & Equipment & 4.79 & 4 & Yes & $\begin{array}{l}\text { 1. Equipment: items used by } \\
\text { students to practice skill, } \\
\text { including balls, mats, sticks, } \\
\text { poly spots and the like }\end{array}$ & $\begin{array}{l}\text { 1. specific types and } \\
\text { amounts needed }\end{array}$ \\
\hline 9 & $\begin{array}{l}\text { Materials/ } \\
\text { Resources }\end{array}$ & - & - & - & $\begin{array}{l}\text { 1. Based on panel member } \\
\text { comments and review of } \\
\text { lesson plans, 'Materials' and } \\
\text { 'Resources' were combined. }\end{array}$ & None \\
\hline \multicolumn{7}{|c|}{$\begin{array}{l}\text { Note. } \#=\text { concept number as per survey; GM = group mean; I = individual mean; Include? = Currently } \\
\text { meets criteria for inclusion as a lesson plan concept. }\end{array}$} \\
\hline
\end{tabular}




\begin{tabular}{|c|c|c|c|c|c|c|}
\hline \# & Concept & GM & I & Include? & Moderator Comments & $\begin{array}{l}\text { Summary Panel } \\
\text { Comments }\end{array}$ \\
\hline 9 & $\begin{array}{l}\text { Materials/ } \\
\text { Resources, } \\
\text { continued }\end{array}$ & - & - & - & $\begin{array}{l}\text { 2. This concept includes } \\
\text { materials like task cards, } \\
\text { handouts, pencils, as well as } \\
\text { resources, such as text books, } \\
\text { class notes, etc. used to prepare, } \\
\text { and implement lessons. } \\
\text { 3. Group means/Your } \\
\text { Individual score: } \text { Materials: } \\
\text { 4.27/4 Resources: } 4.11 / 4\end{array}$ & $\begin{array}{l}\text { Resources comments: } 1 . \\
\text { Need references to where } \\
\text { the lesson plan came } \\
\text { from/modified } \\
\text { from/textbooks for } \\
\text { liability purposes; } 2 \text {. - } \\
\text { providing due credit is } \\
\text { important--is not usually } \\
\text { included in in-service } \\
\text { plans that are just for the } \\
\text { teachers }\end{array}$ \\
\hline 10 & Technology & 3.75 & 3 & No & $\begin{array}{l}\text { Technology includes all } \\
\text { electronic media used to prepare } \\
\text { and implement lessons, } \\
\text { including computers, smart } \\
\text { boards, etc. }\end{array}$ & $\begin{array}{l}\text { 1. Would be a good } \\
\text { addition to a lesson plan } \\
\text { rubric, to think about } \\
\text { technology that may be } \\
\text { used in every lesson } \\
\text { 2. I don't think it is } \\
\text { practical to use } \\
\text { technology in every } \\
\text { lesson } \\
\text { 3. Only if used to } \\
\text { "adhere" to NASPE } \\
\text { Standards, no. Very few } \\
\text { will have the genuine } \\
\text { opportunity to use } \\
\text { technology, appropriately. } \\
\text { Including this just makes } \\
\text { PTs think they have to } \\
\text { incorporate it. } \\
\text { 4. Depends on the topic; } \\
\text { 5. Important for standards }\end{array}$ \\
\hline 11 & $\begin{array}{l}\text { Grade (pre- } \\
\text { K-12) }\end{array}$ & 4.79 & 5 & Yes & None & None \\
\hline 12 & Class & 3.35 & 4 & No & $\begin{array}{l}\text { Clarification: "Class" refers to } \\
\text { either a teacher name (Mr. } \\
\text { Fernandez) or a period ( } 5 \text { th } \\
\text { period). }\end{array}$ & $\begin{array}{l}\text { 1. For tracking-liability; } 2 \text {. } \\
\text { Depends on the setting; } 3 \text {. } \\
\text { I think that grade level is } \\
\text { more important than class. } \\
\text { Typically a plan will be } \\
\text { taught at a particular } \\
\text { grade level. }\end{array}$ \\
\hline 13 & Class size & 4.25 & 4 & Yes & & $\begin{array}{l}\text { 1. This should be taken } \\
\text { into account; however, } \\
\text { I'm not sure that it needs } \\
\text { to be recorded every time } \\
\text { if working with the same } \\
\text { class group. } \\
\text { 2. Although this may vary } \\
\text { with class period }\end{array}$ \\
\hline
\end{tabular}




\begin{tabular}{|c|c|c|c|c|c|c|}
\hline \# & Concept & GM & I & Include? & Moderator Comments & $\begin{array}{l}\text { Summary Panel } \\
\text { Comments }\end{array}$ \\
\hline 14 & $\begin{array}{l}\text { Date/Date } \\
\text { taught }\end{array}$ & - & - & - & $\begin{array}{l}\text { 1. Based on panel comments, } \\
\text { 'Date Taught' was combined } \\
\text { with 'Date'. }\end{array}$ & $\begin{array}{l}\text { Date comments: } 1 . \\
\text { liability: need a record }\end{array}$ \\
\hline 15 & Time & 3.59 & 3 & No & $\begin{array}{l}\text { Time in this pre-instruction } \\
\text { section refers to the actual time } \\
\text { the class is taught. It's time of } \\
\text { day, not script. }\end{array}$ & $\begin{array}{l}\text { 1. Time/date should be } \\
\text { recording for tracking } \\
\text { (liability). It would also } \\
\text { be great if time in MVPA } \\
\text { were considered and } \\
\text { measured using an } \\
\text { instrument such as } \\
\text { pedometers or sofit }\end{array}$ \\
\hline 16 & $\begin{array}{l}\text { Length of } \\
\text { class }\end{array}$ & 4.29 & 4 & Yes & None & $\begin{array}{l}\text { 1. This needs to be taken } \\
\text { into account in planning - } \\
\text { I'm not sure it needs to be } \\
\text { reported each time (e.g., } \\
\text { every lesson may be } 30 \\
\text { min) } \\
\text { 2. Usually part of the } \\
\text { assignment-minutes } \\
\text { allotted for each activity } \\
\text { is important; } 3 \text {. If } \\
\text { they outline time for } \\
\text { activities, then don't } \\
\text { need this }\end{array}$ \\
\hline 17 & School & 2.85 & 3 & No & None & 1. Tracking-liability \\
\hline 18 & Facility & 3.46 & 4 & No & $\begin{array}{l}\text { Facility refers to a gymnasium, } \\
\text { outside court, field,etc. }\end{array}$ & $\begin{array}{l}\text { 1. Needed for planning - } \\
\text { but not needed each time } \\
\text { if you are student } \\
\text { teaching at the same } \\
\text { facility each day; } \\
\text { 2. Facility description } \\
\text { should be part of the } \\
\text { assignment--not } \\
\text { necessarily part of lesson } \\
\text { plan; } \\
\text { 3. I think it is important to } \\
\text { indicate the intended } \\
\text { location for a lesson (e.g., } \\
\text { gym vs. outside court, } \\
\text { etc.) }\end{array}$ \\
\hline 19 & Safety & 4.37 & 4 & Yes & & $\begin{array}{l}\text { 1. PETE students need to } \\
\text { think through safety } \\
\text { issues, such as checking } \\
\text { the field in the morning; } \\
\text { 2. Include this as a section } \\
\text { to accompany the actual } \\
\text { activity section so } \\
\text { student's id the specific } \\
\text { safety considerations } \\
\text { assoc. with each } \\
\text { task/activity. }\end{array}$ \\
\hline
\end{tabular}




\begin{tabular}{|c|c|c|c|c|c|c|}
\hline \# & Concept & GM & $\mathrm{I}$ & Include? & Moderator Comments & $\begin{array}{c}\text { Summary Panel } \\
\text { Comments }\end{array}$ \\
\hline 20 & $\begin{array}{l}\text { NASPE } \\
\text { standards }\end{array}$ & 3.93 & 3 & No & None & $\begin{array}{l}\text { 1. Part of unit } \\
\text { planning:can be } \\
\text { designated on lesson plan, } \\
\text { sometimes gets too busy. } \\
\text { Often best place is in } \\
\text { closure; } \\
\text { 2. This should be evident } \\
\text { somewhere, but not } \\
\text { necessarily on the lesson } \\
\text { plan; } \\
\text { 3. Not all countries use } \\
\text { the NASPE standards but } \\
\text { lessons should indicate } \\
\text { the standards that fit the } \\
\text { context; } \\
\text { 4. This should simply be } \\
\text { referenced as an } \\
\text { alignment to each } \\
\text { objective; } \\
\text { 5. Four panel members } \\
\text { stated: state standards } \\
\text { trump NASPE standards }\end{array}$ \\
\hline 21 & Objectives & 4.61 & 4 & Yes & $\begin{array}{l}\text { 1. This concept, 'Objectives', } \\
\text { is/can be considered a heading } \\
\text { for psychomotor, cognitive, } \\
\text { affective, and fitness objectives }\end{array}$ & $\begin{array}{l}\text { 1. If we do not identify } \\
\text { the desired learning } \\
\text { outcome how will we } \\
\text { know which dir. to go?; } 3 \text {, } \\
\text { Not necessary if each } \\
\text { domain objective incl.; } \\
\text { 4.May include psych., } \\
\text { cog. or affective; it } \\
\text { depends on the lesson and } \\
\text { its intent; } 5 \text {. This should } \\
\text { be considered and the } \\
\text { lesson plan based it but it } \\
\text { seems not so useful on the } \\
\text { lesson plan; } 6 \text {. Do either } \\
\text { concept } 21 \text { or concepts } \\
22,23,24, \text { and } 25 . I f \text { you } \\
\text { do } 21, \text { you must specify } \\
\text { that the students include } \\
\text { all objectives under } 21 \\
\text { (which may/may not } \\
\text { include a psychomotor, } \\
\text { cognitive, affective, } \\
\text { and/or fitness); } 7 \text { objs. } \\
\text { yes as objectives aligned } \\
\text { with state standards, } \\
\text { written as behavioral } \\
\text { objectives from the } 70 \text { 's } \\
\text { not so much }\end{array}$ \\
\hline
\end{tabular}




\begin{tabular}{|c|c|c|c|c|c|c|}
\hline \# & Concept & GM & I & Include? & Moderator Comments & $\begin{array}{l}\text { Summary Panel } \\
\text { Comments }\end{array}$ \\
\hline 21 & $\begin{array}{l}\text { Objectives, } \\
\text { continued }\end{array}$ & & & & $\begin{array}{l}\text { 1. Not all lessons will have all } 4 \\
\text { objectives (concepts } 22-25 \text { ). The } \\
\text { goal is to provide preservice } \\
\text { teachers with a comprehensive } \\
\text { list of lesson plan concepts with } \\
\text { which they can choose from. }\end{array}$ & $\begin{array}{l}\text { Comment common to } \\
\text { Psychomotor, Cognitive, } \\
\text { Affective, \& Fitness } \\
\text { Objectives: } \\
\text { 1. Depends on the lesson } \\
\text { and its intent }\end{array}$ \\
\hline 22 & $\begin{array}{l}\text { Psycho- } \\
\text { motor. } \\
\text { Objective }\end{array}$ & 4.38 & 3 & Yes & None & $\begin{array}{l}\text { 1. The content of the } \\
\text { lesson should determine if } \\
\text { all three domains need to } \\
\text { be addressed. Again, } \\
\text { learning objectives are } \\
\text { one of the most essential } \\
\text { elements of a lesson plan; } \\
\text { 2. Should be in every } \\
\text { lesson; } \\
\text { 3. For each objective, to } \\
\text { ensure instructional } \\
\text { alignment template should } \\
\text { account for the objective, } \\
\text { associated naspe standard, } \\
\text { and assessment type } \\
\text { (rubric, peer observation, } \\
\text { etc.) and timing (activity } \\
\text { 1, task } 3 \text {, etc.). }\end{array}$ \\
\hline 23 & $\begin{array}{l}\text { Cognitive } \\
\text { objective }\end{array}$ & 4.36 & 3 & Yes & None & $\begin{array}{l}\text { 1. I think all lessons } \\
\text { should have a motor } \\
\text { objective but sometimes it } \\
\text { is hard to teach a motor, } \\
\text { cognitive and affective } \\
\text { objective within a } 30 \\
\text { minute lesson (which you } \\
\text { sometimes see in } \\
\text { elementary schools). I } \\
\text { beleive in holistic learning } \\
\text { over the course of the } \\
\text { entire curriulum but it } \\
\text { might be hard for new } \\
\text { teachers to teach three } \\
\text { objectives well in a single } \\
\text { lesson }\end{array}$ \\
\hline 24 & $\begin{array}{l}\text { Affective } \\
\text { objective }\end{array}$ & 4.31 & 3 & Yes & None & $\begin{array}{l}\text { 1. All lessons should have } \\
\text { a motor obj. but } \\
\text { sometimes it's hard to } \\
\text { teach a motor, cognitive } \\
\text { and affective objective } \\
\text { within a } 30 \text { minute lesson } \\
\text { (which you sometimes see } \\
\text { in elementary schools). I } \\
\text { believe in holistic learning } \\
\text { over the course of the } \\
\text { entire curriculum but it } \\
\text { may be hard for new } \\
\text { teachers to teach } 3 \text { objs } \\
\text { well in a single lesson. }\end{array}$ \\
\hline
\end{tabular}




\begin{tabular}{|c|c|c|c|c|c|c|}
\hline \# & Concept & GM & I & Include? & Moderator Comments & $\begin{array}{l}\text { Summary Panel } \\
\text { Comments }\end{array}$ \\
\hline 25 & $\begin{array}{l}\text { Fitness } \\
\text { objective }\end{array}$ & 3.72 & 3 & No & None & $\begin{array}{l}\text { 1. How is this different } \\
\text { than those identified } \\
\text { above?; } 2 \text {. We do not see } \\
\text { fitness objective as a } \\
\text { separate one; } 3 \text {. } \\
\text { Objectives should be } \\
\text { developed for the unit-- } \\
\text { lesson plans should move } \\
\text { students toward the unit } \\
\text { objectives--how they are } \\
\text { included in lesson plans } \\
\text { can vary; } \\
\text { 4. Fitness activities should } \\
\text { be part of the lesson:but } \\
\text { may or may not be a } \\
\text { specific lesson objective } \\
\text { depending the curricular } \\
\text { model used and lesson } \\
\text { objectives; } \\
\text { 5. Objectives under \#21 } \\
\text { (which may/may not } \\
\text { include a psychomotor, } \\
\text { cognitive, affective, } \\
\text { and/or fitness); } 6 \text {. Only if } \\
\text { time to actually achieve } \\
\text { something; } \\
\text { 7. This is a psychomotor } \\
\text { objective. }\end{array}$ \\
\hline 26 & $\begin{array}{c}\text { Introductory/ } \\
\text { instant/ } \\
\text { fitness } \\
\text { activity \& } \\
\text { warm-up }\end{array}$ & & & & $\begin{array}{l}\text { 1. Based on panel member } \\
\text { feedback, 'Introductory activity', } \\
\text { 'Instant activity', 'Fitness } \\
\text { activity', and 'Warm-up' were } \\
\text { collapsed to form } 1 \text { concept. } \\
\text { 2. Group means/Your } \\
\text { Individual scores } \\
\text { Introductory activity: } 3.88 / 5 \\
\text { Instant activity: } 4.00 / \text { no } \\
\text { Fitness activity: } 3.67 / 5 \\
\text { Warm-up: GM: } 3.19 / 5\end{array}$ & $\begin{array}{l}\text { Panel Comments } \\
\text { common to all } 4 \\
\text { concepts } \\
1 . \text { Not necessary to label } \\
\text { these things - IN the } \\
\text { progression, they should } \\
\text { be built in; } 2 \text {. If } \\
\text { appropriate for the lesson } \\
\text { and time permits } \\
\text { Warm-up comments: } 1 . \\
\text { must have it in lesson, } \\
\text { sometimes done by } \\
\text { starting slow in the } \\
\text { activity; } 2 \text {. Importance } \\
\text { of a warm-up depends } \\
\text { on grade level and } \\
\text { activity. I prefer a skill } \\
\text { related warm-up. } \\
\text { Fitness activity } \\
\text { comments: } 1 \text {. Can } \\
\text { happen in many ways } \\
\text { in lesson and should be } \\
\text { integrated throughout } \\
\text { the lesson. Should be } \\
\text { identified, but not }\end{array}$ \\
\hline
\end{tabular}




\begin{tabular}{|c|c|c|c|c|c|c|}
\hline \# & Concept & GM & $\mathrm{I}$ & Include? & Moderator Comments & $\begin{array}{l}\text { Summary Panel } \\
\text { Comments }\end{array}$ \\
\hline 26 & $\begin{array}{l}\text { Introductory/ } \\
\text { instant/ } \\
\text { fitness } \\
\text { activity \& } \\
\text { warm-up } \\
\text { continued }\end{array}$ & & & & None & $\begin{array}{l}\text { 2. Depends alot on } \\
\text { grade level, what is } \\
\text { being taught and the } \\
\text { length of class. At the } \\
\text { HS level a fitness } \\
\text { activity that is more } \\
\text { "stand alone" might be } \\
\text { appropriate when the } \\
\text { class is block } \\
\text { scheduled and there is } \\
\text { time. If the class is not } \\
\text { block scheduled or the } \\
\text { class time is short, I } \\
\text { would embed fitness } \\
\text { into skills teaching. } \\
3 . \text { Necessary if it's a } \\
\text { DPE lesson but as a } \\
\text { generic lesson not } \\
\text { really }\end{array}$ \\
\hline 27 & Introduction & 4.27 & 3 & Yes & $\begin{array}{l}\text { 1. Definition: Explains to } \\
\text { students what will be learned } \\
\text { by stating the objective(s) of } \\
\text { the lesson. Provides a } \\
\text { connection between prior } \\
\text { learning experiences and the } \\
\text { current lesson. } \\
\text { 2. Several panel members } \\
\text { stated that the Introduction } \\
\text { refers to Set Induction or } \\
\text { Anticipatory Set. However, } \\
\text { based on a review of pilot } \\
\text { study lesson plans, the } \\
\text { Introduction is a separate } \\
\text { concept from anticipatory set } \\
\text { and set induction. }\end{array}$ & $\begin{array}{l}\text { 1. I suggest a template } \\
\text { that simply asks the } \\
\text { teacher to sequence } \\
\text { instructional events, } \\
\text { giving each event a } \\
\text { name and highlighting } \\
\text { critical instructional info } \\
\text { for each. For example, } \\
\text { activity } 1=\text { =warm up } \\
\text { (aka, instant activity, } \\
\text { ASAP, etc.). } \\
\text { Presentation = Verbal. } \\
\text { Equipment = jump } \\
\text { ropes. Safety } \\
\text { considerations = } \\
\text { Personal Space. Time } \\
=4 \text { min }\end{array}$ \\
\hline 28 & $\begin{array}{l}\text { Anticipatory } \\
\text { set/Set } \\
\text { induction }\end{array}$ & & & & $\begin{array}{l}\text { 1. Based on panel member } \\
\text { feedback and review of pilot } \\
\text { study lesson plans, these } 2 \\
\text { concepts were collapsed to } \\
\text { form } 1 \text { concept. } 2 \text {. Definition: } \\
\text { Explains to students how they } \\
\text { will complete the lesson and } \\
\text { why it is important to them. } \\
\text { 3. Group means/Your } \\
\text { Individual score: } \\
\text { Anticipatory set: GM: } 3.88, \mathrm{I} \text { : } \\
2 \text { Set induction: GM: } 3.92, \text { I: } 2\end{array}$ & $\begin{array}{l}\text { Panel Comments } \\
\text { common to both } \\
\text { concepts } \\
\text { 1. Not necessary to } \\
\text { label these things - IN } \\
\text { the progression they } \\
\text { should be built in; } \\
\text { Anticipatory Set } \\
\text { comment: } \\
\text { 1. Tough to have good } \\
\text { anticipatory sets in all } \\
\text { lessons--particularly in } \\
\text { a series, but are great } \\
\text { to prompt them also }\end{array}$ \\
\hline
\end{tabular}




\begin{tabular}{|c|c|c|c|c|c|c|}
\hline \# & Concept & GM & I & Include? & Moderator Comments & $\begin{array}{c}\text { Summary Panel } \\
\text { Comments }\end{array}$ \\
\hline 29 & Instruction & 4.17 & 3 & Yes & $\begin{array}{l}\text { Definition: In reviewing the } \\
\text { pilot study lesson plans, this } \\
\text { concept serves as a heading } \\
\text { in the design of the main } \\
\text { portion of the lesson. In round } \\
\text { Il of survey, the concepts } \\
\text { under this heading are } \\
\text { shown. }\end{array}$ & None \\
\hline 30 & $\begin{array}{l}\text { Teaching } \\
\text { style }\end{array}$ & 3.44 & 1 & No & None & $\begin{array}{l}\text { 1. Organization is } \\
\text { needed - which may or } \\
\text { may not be defined as } \\
\text { the teaching style; } \\
\text { 2. Relevant as a } \\
\text { knowing the teaching } \\
\text { style help evaluate the } \\
\text { appropriateness of the } \\
\text { task progression ; } \\
\text { 3. Multiple teaching } \\
\text { styles may be } \\
\text { employed: not just } 1 . \\
\text { 4. We go by } \\
\text { instructional model... So } \\
\text { we view Instructional } \\
\text { model as } 5 . . . \text { the } 5 \\
\text { does not reflect the } \\
\text { importance of teaching } \\
\text { style... which will be (1); } \\
5 \text {. Depends on the } \\
\text { assignment; } 6 \text {. No: Can } \\
\text { see in the lesson } \\
\text { activities; } \\
\text { 7. Maybe change to } \\
\text { "Teaching Style or } \\
\text { Model" }\end{array}$ \\
\hline 31 & $\begin{array}{c}\text { Skill } \\
\text { Analysis }\end{array}$ & 3.88 & 2 & No & $\begin{array}{l}\text { 1. Based on pilot study lesson } \\
\text { plans, this concept refers to } \\
\text { how a skill will be developed } \\
\text { in terms of its mechanics }\end{array}$ & $\begin{array}{l}\text { 1. Students should } \\
\text { identify "modification } \\
\text { variables" that they will } \\
\text { use to individualize } \\
\text { instruction such as } \\
\text { space, number of } \\
\text { people, type of } \\
\text { equipment. Also, } \\
\text { refinement cues should } \\
\text { be developed in this } \\
\text { section. } 2 \text {. Cues } \\
\text { identified as skill focus } \\
\text { for each task; } 3 . \text { For the } \\
\text { purpose of designing } \\
\text { cues and directing the } \\
\text { observation of the } \\
\text { teacher; } 4 \text {. Certainly } \\
\text { important, part of every } \\
\text { lesson? }\end{array}$ \\
\hline
\end{tabular}




\begin{tabular}{|c|c|c|c|c|c|c|}
\hline \# & Concept & GM & I & Include? & Moderator Comments & $\begin{array}{l}\text { Summary Panel } \\
\text { Comments }\end{array}$ \\
\hline 32 & $\begin{array}{l}\text { Critical } \\
\text { elements }\end{array}$ & 3.85 & 2 & No & $\begin{array}{l}\text { Definition: "The components } \\
\text { determined to be the most } \\
\text { critical pieces for attainment } \\
\text { of the performance outcomes } \\
\text { and mastery of the skill."1 } \\
{ }^{1} \text { Lund, J., \& Tannehill, D. } \\
\text { (Eds.) (2010). Standards- } \\
\text { based physical education } \\
\text { curriculum development (2nd } \\
\text { ed.) (p. 406). Sudbury, MA: } \\
\text { Jones and Bartlett. }\end{array}$ & $\begin{array}{l}\text { 1. Critical elements } \\
\text { should be considered in } \\
\text { the pre-planning stage. } \\
\text { In the instructional part } \\
\text { of the plan, critical } \\
\text { elements are reduced } \\
\text { to cues; } 2 \text {. Not } \\
\text { necessary to label } \\
\text { these things: IN the } \\
\text { progression they should } \\
\text { be built in as the } \\
\text { refinement of the task; } \\
3 \text {. Just use the term } \\
\text { cues; } \\
4 \text {. Students should } \\
\text { identify "modification } \\
\text { variables" that they will } \\
\text { use to individualize } \\
\text { instruction such as } \\
\text { space, number of } \\
\text { people, type of } \\
\text { equipment. Also, } \\
\text { refinement cues should } \\
\text { be developed in this } \\
\text { section. }\end{array}$ \\
\hline 33 & Cues & 4.85 & 5 & Yes & $\begin{array}{l}\text { Definition: "The simple } \\
\text { phrases-the } 2 \text { to } 3 \text { words that } \\
\text { give children the cognitive } \\
\text { reminder of what is needed to } \\
\text { perform the skill correctly" } \\
\text { 'Lund, J., \& Tannehill, D. } \\
\text { (Eds.) (2010). Standards- } \\
\text { based physical education } \\
\text { curriculum development (2nd } \\
\text { ed.) (p. 406). Sudbury, MA: } \\
\text { Jones and Bartlett. }\end{array}$ & $\begin{array}{l}\text { 1. I prefer this } \\
\text { language. Cues are } \\
\text { matched with tasks to } \\
\text { identify the focus of } \\
\text { instruction and teacher } \\
\text { observation and } \\
\text { feedback; } 2 \text {. Students } \\
\text { should identify } \\
\text { "modification variables" } \\
\text { that they will use to } \\
\text { individualize instruction } \\
\text { such as space, number } \\
\text { of people, type of } \\
\text { equipment. Also, } \\
\text { refinement cues should } \\
\text { be developed in this } \\
\text { section; } 3 \text {. Not } \\
\text { necessary to label } \\
\text { these things - IN the } \\
\text { progression they should } \\
\text { be built in as the } \\
\text { refinement of the task; } \\
4 . \text { Some teaching cues } \\
\text { should be written into } \\
\text { the lesson plan - I'm not } \\
\text { sure it is desirable to } \\
\text { have every teaching } \\
\text { cue }\end{array}$ \\
\hline
\end{tabular}




\begin{tabular}{|c|c|c|c|c|c|c|}
\hline \# & Concept & GM & I & Include? & Moderator Comments & $\begin{array}{c}\text { Summary Panel } \\
\text { Comments }\end{array}$ \\
\hline 34 & $\begin{array}{l}\text { Teaching by } \\
\text { invitation }\end{array}$ & 3 & 3 & No & $\begin{array}{l}\text { Definition: Used for } \\
\text { individualized instruction; } \\
\text { Teacher structures the task } \\
\text { so that students can } \\
\text { manipulate the dimensions of } \\
\text { that task }{ }^{2} \\
{ }^{2} \text { Griffey, D. C., \& Housner, L. } \\
\text { D. (2007). Designing effective } \\
\text { instructional tasks for physical } \\
\text { education and sports. } \\
\text { Champaign, IL: Human } \\
\text { Kinetics. }\end{array}$ & $\begin{array}{l}\text { 1. Important that they } \\
\text { know this teaching } \\
\text { strategy and how to use } \\
\text { it as they present task } \\
\text { (would perhaps show } \\
\text { up in their scripting of } \\
\text { tasks), but not a } \\
\text { separate category; } 2 \text {. In } \\
\text { some cases this } \\
\text { concept should be } \\
\text { used. }\end{array}$ \\
\hline 35 & CFU & 4.54 & 3 & Yes & $\begin{array}{l}\text { "CFU" means checking for } \\
\text { understanding }\end{array}$ & $\begin{array}{l}\text { 1. Ask questions to } \\
\text { students, not if students } \\
\text { have any questions }\end{array}$ \\
\hline 36 & & & & & $\begin{array}{l}\text { 1. Based upon review of } \\
\text { panel member comments and } \\
\text { pilot study lesson plans, } \\
\text { 'Content development', } \\
\text { 'Activities', and 'Lesson focus' } \\
\text { were collapsed to form } 1 \\
\text { concept.; } 2 \text {. This collapsed } \\
\text { concept of 'Content } \\
\text { Development' is considered a } \\
\text { heading, with several } \\
\text { planning concepts contained } \\
\text { within it.; } \\
\text { Group means/Your } \\
\text { Individual score: } \\
\text { Content development: } 4.52 / 3 \\
\text { Activities: } 4.6 / 4 \\
\text { Lesson focus: } 4.2 / 4\end{array}$ & $\begin{array}{l}\text { 1. If the tasks are } \\
\text { properly sequenced } \\
\text { and include extensions, } \\
\text { refinement, and } \\
\text { applications, then this is } \\
\text { inferred and does not } \\
\text { need to be listed as a } \\
\text { separate element. }\end{array}$ \\
\hline 37 & Organ/Form & & & & $\begin{array}{l}\text { 1. Based upon panel member } \\
\text { comments and pilot study } \\
\text { lesson plans, these } 2 \\
\text { concepts were collapsed. } \\
\text { 2. This collapsed comment } \\
\text { refers to the organization and } \\
\text { position of students and } \\
\text { equipment for each task. } \\
\text { Group means/Your } \\
\text { Individual score: } \\
\text { Organization: } 4.54 / 5 \\
\text { Formation: } 4.41 / 4 \\
\end{array}$ & None \\
\hline 38 & Transition & 4.07 & 5 & No & $\begin{array}{l}\text { 1. Based on panel member } \\
\text { comments, this Concept } \\
\text { would be contained within (as } \\
\text { a subheading of) both the } \\
\text { Organization/Formation } \\
\text { concept and the } \\
\text { Management/Procedures } \\
\text { concept. }\end{array}$ & $\begin{array}{l}\text { 1. Definitely need to } \\
\text { consider. Sometimes } \\
\text { use protocols instead }\end{array}$ \\
\hline
\end{tabular}




\begin{tabular}{|c|c|c|c|c|c|c|}
\hline \# & Concept & GM & I & Include? & Moderator Comments & $\begin{array}{c}\text { Summary Panel } \\
\text { Comments }\end{array}$ \\
\hline 39 & Time & 2.23 & 3 & Yes & None & $\begin{array}{l}\text { 1. Four panel members } \\
\text { state: Estimated time } \\
\text { for each portion of the } \\
\text { lesson and activity.; } \\
\text { 2. Students may guess } \\
\text { at time estimation, but } \\
\text { it's not necessary }\end{array}$ \\
\hline 40 & $\begin{array}{l}\text { Management } \\
\text { /Procedures }\end{array}$ & & & & $\begin{array}{l}\text { 1. Based on panel member } \\
\text { comments, these two } \\
\text { concepts were collapsed to } \\
\text { form one concept.; } \\
\text { 2. Refers to instructional } \\
\text { behaviors relating to } \\
\text { structuring, directing and } \\
\text { reinforcing appropriate } \\
\text { conduct. }^{3} \\
{ }^{3} \text { Rink, J. E. (2006). Teaching } \\
\text { physical education for } \\
\text { learning (5th ed.). New York, } \\
\text { NY: McGraw-Hill. } \\
\text { Group means/Your } \\
\text { Individual score: } \\
\text { Management: } 4.44 / 5 \\
\text { Procedures: } 3.96 / 5\end{array}$ & None \\
\hline 41 & Progression & 4.33 & 4 & Yes & $\begin{array}{l}\text { 1. Based on panel member } \\
\text { comments and a review of } \\
\text { pilot study lesson plans, } \\
\text { 'Progression' is contained } \\
\text { within the 'Content } \\
\text { Development' concept. }\end{array}$ & $\begin{array}{l}\text { 1. Climate being set; } \\
\text { 2. Helps keep tasks } \\
\text { focused on objective(s). }\end{array}$ \\
\hline 42 & $\begin{array}{c}\text { Goal } \\
\text { orientation }\end{array}$ & 3.44 & 3 & No & None & $\begin{array}{l}\text { 1. Climate being set - } \\
\text { also discussed under } \\
\text { motivation; } 2 \text {. Helps to } \\
\text { keep tasks focused on } \\
\text { the objective(s) being } \\
\text { taught }\end{array}$ \\
\hline 43 & $\begin{array}{l}\text { Informing } \\
\text { task }\end{array}$ & 3.93 & 3 & No & None & $\begin{array}{l}\text { 1. When appropriate; } \\
\text { depends on the content } \\
\text { being taught and the } \\
\text { instructional strategies } \\
\text { used. }\end{array}$ \\
\hline 44 & $\begin{array}{l}\text { Demon- } \\
\text { stration }\end{array}$ & 4.28 & 3 & Yes & $\begin{array}{l}\text { 1. Demonstrating to students } \\
\text { how to perform skill. }\end{array}$ & $\begin{array}{l}\text { 1. Essential to effective } \\
\text { task presentation; } 2 \text {. In } \\
\text { problem solving lessons } \\
\text { it's not always approp., } \\
\text { but should be prompted } \\
\text { in most instruction; } \\
\text { 3. Assuming it applies. } \\
\text { You don't have demo } \\
\text { when indirect teaching } \\
\text { styles are being used } \\
\text { (styles F, G, H). You } \\
\text { have something else }\end{array}$ \\
\hline
\end{tabular}




\begin{tabular}{|c|c|c|c|c|c|c|}
\hline \# & Concept & GM & I & Include? & Moderator Comments & $\begin{array}{l}\text { Summary Panel } \\
\text { Comments }\end{array}$ \\
\hline 45 & $\begin{array}{c}\text { Extension } \\
\text { task }\end{array}$ & 4.3 & 3 & Yes & & $\begin{array}{l}\text { 1. Teach students this } \\
\text { term--they use in lesson } \\
\text { plan as appropriate; } 2 \text {. } \\
\text { When appropriate; } \\
\text { Depends on content } \\
\text { and instructional } \\
\text { strategies. }\end{array}$ \\
\hline 46 & $\begin{array}{l}\text { Refinement } \\
\text { task }\end{array}$ & 4.3 & 4 & Yes & & $\begin{array}{l}\text { 1. Depends on the } \\
\text { lesson and the } \\
\text { instructional strategies } \\
\text { chosen; } 2 \text {. Would not } \\
\text { use TGfU. }\end{array}$ \\
\hline 47 & $\begin{array}{l}\text { Application } \\
\text { task }\end{array}$ & 4.27 & 3 & Yes & None & $\begin{array}{l}\text { 1. With TGfU model, } \\
\text { would not use in these } \\
\text { terms; } 2 \text {. Accounted for } \\
\text { in Content Develop.; } \\
\text { 3. Use challenges } \\
\text { rather than application; } \\
\text { 4. Depends on the } \\
\text { lesson and the instruct. } \\
\text { strategies chosen; } \\
\text { 5. Application of task - } \\
\text { or the lesson activity - } \\
\text { real world meaning for } \\
\text { students is critical }\end{array}$ \\
\hline 48 & $\begin{array}{l}\text { Adaptation/ } \\
\text { Modification/ }\end{array}$ & & & & $\begin{array}{l}\text { 1. Based on panel member } \\
\text { comments and a review of } \\
\text { pilot study lesson plans, } \\
\text { these three concepts were } \\
\text { collapsed.; } 2 \text {. Definition: How } \\
\text { teachers adapt tasks to meet } \\
\text { individual student needs. } \\
\text { Group means/Your } \\
\text { individual score: } \\
\text { Adaptation: } 4.19 / 3 \\
\text { Modifications: } 4.12 / 4 \\
\text { Intratask variation: } 3.67 / 3\end{array}$ & $\begin{array}{l}\text { Adaptation comments: } \\
\text { 1. Already accounted } \\
\text { for under Content } \\
\text { Development. } \\
\text { Modification comments: } \\
\text { 1. Many choices at the } \\
\text { individual and class } \\
\text { level should be } \\
\text { prepared } \\
\text { 2. Already accounted } \\
\text { for under Content } \\
\text { Development. } \\
\text { Intratask variation } \\
\text { comments: } \\
\text { 1. Choice will allow } \\
\text { students to meet their } \\
\text { own abilities } \\
\text { 2. Should be built in as } \\
\text { the extension of the } \\
\text { task } \\
\text { 3. Three panel } \\
\text { members' comment: } \\
\text { Students should know } \\
\text { this as a teaching } \\
\text { method, but not } \\
\text { necessary to include as } \\
\text { a stand alone concept. } \\
\text { 4. Not necessity to label } \\
\text { these things. }\end{array}$ \\
\hline
\end{tabular}




\begin{tabular}{|c|c|c|c|c|c|c|}
\hline \# & Concept & GM & I & Include? & Moderator Comments & $\begin{array}{l}\text { Summary Panel } \\
\text { Comments }\end{array}$ \\
\hline 49 & Motivation & 3.14 & 5 & No & None & $\begin{array}{l}\text { 1. Three panel } \\
\text { members: Should be } \\
\text { inherent; } 2 \text {. I would } \\
\text { identify this as } \\
\text { motivational goals; } \\
\text { 3. This is part of what } \\
\text { you have developed } \\
\text { with choice of content, } \\
\text { objectives and } \\
\text { instructional strategies; } \\
\text { knowing your pupils } \\
\text { guides this. }\end{array}$ \\
\hline 50 & Closure & 4.75 & 4 & Yes & None & $\begin{array}{l}\text { 1. Review and closure } \\
\text { are both critical. }\end{array}$ \\
\hline 51 & Cool down & 3.22 & 3 & No & None & $\begin{array}{l}\text { 1. Cool down after } \\
\text { aerobic activities is } \\
\text { needed to slowly lower } \\
\text { heart rate and reduce } \\
\text { blood flow to avoid } \\
\text { blood pooling; } 2 \text {. Only if } \\
\text { the level of activity } \\
\text { warrants this } 3 \text {. } \\
\text { Depends on grade level } \\
\text { and what is being } \\
\text { taught } 4 \text {. As is warm- } \\
\text { up, cool down is an } \\
\text { antiquated part of a } \\
\text { lesson. }\end{array}$ \\
\hline 52 & Assess/Eval & & & & $\begin{array}{l}\text { Based on a review of pilot study } \\
\text { lesson plans, these } 2 \text { concepts } \\
\text { were collapsed; } 2 \text {. This concept } \\
\text { refers to the assessment/eval. of } \\
\text { K-12 students by the teacher. } \\
\text { Group means/Your } \\
\text { Individual score: } \\
\text { Assessment: } 4.54 / 3 \\
\text { Evaluation: } 3.71 / 3\end{array}$ & $\begin{array}{l}\text { Assessment comments: } \\
\text { 1. Where are they now- } \\
\text {-what next--concept } \\
\text { needs to be included } \\
\text { 2. Yes, include, but it is } \\
\text { a part of instruction and } \\
\text { post-instruction } \\
\text { 3. Should be accounted } \\
\text { for in pre-instruction } \\
\text { and aligned with } \\
\text { objective(s); } 4 \text {. Must be } \\
\text { a regular part of } \\
\text { instruction and students } \\
\text { held accountable for } \\
\text { learning; } \\
\text { Evaluation comments: } \\
\text { 1. Evaluation is } \\
\text { technically part of } \\
\text { assessment - test or } \\
\text { measure first, make a } \\
\text { decision about what it } \\
\text { means is evaluation } \\
\text { and then assessment is } \\
\text { the combination of both } \\
\text { 2. Depends on activity }\end{array}$ \\
\hline
\end{tabular}




\begin{tabular}{|l|l|l|l|l|l|l|}
\hline$\#$ & Concept & GM & I & Include? & Moderator Comments & $\begin{array}{l}\text { Summary Panel } \\
\text { Comments }\end{array}$ \\
\hline 53 & Reflection & 4.39 & $\mathbf{5}$ & Yes & & $\begin{array}{l}\text { 1. Reflection improves } \\
\text { instruction at all levels; } \\
\text { 2. Two panel members: } \\
\text { Important, but does not } \\
\text { belong on plan. }\end{array}$ \\
& & & & & & \\
\hline
\end{tabular}


Appendix 14

Round II Survey E-mail

Hello

Welcome to the second round of this modified Delphi investigation!

The Delphi panel members provided an unexpectedly large number of comments during

Round I of the survey. These comments provided the basis for organizing the lesson planning concepts into a coherent framework for the second Round survey, as well as providing expert feedback to fellow panel members. In addition, several concepts were collapsed/combined based on panel member feedback and a review of the lesson concepts within the pilot study lesson plans.

I have attached an Excel spreadsheet document that includes the following: (a) your individual rating (I) of each concept; (b) the group mean rating (GM) for each concept; (c) a column stating whether the Concept currently meets the criteria for inclusion in a planning template (Include?); (d) the Moderator comments, and; (e) a summary of Panel Member comments for each survey item. Please refer to this document when making your selection for this second round. Feel free to select either your Round I score or make a different selection based on the group mean and comments.

In order for the item to be included and group consensus achieved, the following criteria must be met: (a) The item needs to have a mean rating of at least four or higher in the area of importance; and (b) the item needs to receive at least $75 \%$ of all individual ratings at level four or higher.

The following hyperlink will take you to Round II of the survey: http://www.surveymonkey.com/f'kkvnfkvnfrv;jfhvafv;fvf;vbhnf;vbfvvvnfvnnvbjrfovbfb

If possible, please complete the online survey prior to midnight on Monday, January 30, 2012.

Thank you once again for your assistance!

Jack

Jack Sager, MS

West Virginia University

304.685 .3267 
Appendix 15

Round II Survey Introduction

Welcome back! Thank you for agreeing to participate in Round II as an expert panel member in this Modified Delphi investigation!

As a panel member, you are asked to rate a list of lesson planning concepts in terms of their importance for use by preservice physical education teachers. Several concepts were combined/collapsed based upon panel member feedback and a review of the pilot study lesson plans. As a result, 52 survey items will need to be rated during Round II. The survey will be used to generate consensus of opinion regarding lesson planning concepts for addition in a future lesson planning template. Your professional experience and judgment are vital to the success of this project.

Please remember the final date for Round II survey completion is Monday, January 30, 2012. Round II results will be emailed once all data are tabulated. I greatly appreciate your assistance in the completion of this project.

Thank you for your time and input. Please call or e-mail me with any questions you may have.

Jack Sager

West Virginia University

jsager@mix.wvu.edu

304.685.3267 
Appendix 16

Round II Survey Instructions

The following survey contains 52 lesson planning concepts you will need to judge in regard to their importance for placement into a lesson plan template for preservice teachers.

Please read the following:

-Rate each of the concepts separately in the area of importance. For the purpose of the study, IMPORTANCE will refer to the concept's value to the completion of a comprehensive lesson plan template for preservice teachers.

-A rating of (5) or (4) for IMPORTANCE means that you consider the item to be Essential for a preservice lesson plan.

-A rating of (3) means you are neutral regarding the IMPORTANCE of the item.

-A rating of (2) or (1) for IMPORTANCE means the item is Not essential for inclusion in a preservice teacher lesson plan.

-If you choose not to respond to an item, then please leave it blank.

A few reminders:

-You must enter your name on the first page of the survey in order to continue. This is the only question you must answer.

-You will not be allowed to go back into the survey once you have accessed the website link. Therefore, if you are reading this message then you are committed to completing the survey at this time.

-You may return to the instructions page at any time using the "Prev" button at the bottom of the survey pages. You have complete freedom (once you have entered your name) to go to any page within the survey and alter your responses if necessary.

-A survey completion bar will appear at the bottom of each page to show your progress through the survey. 
Appendix 17

Delphi Round I Concept Outline

\section{Contextual Information}

2. Teacher name 3. Unit 4. Title of lesson 5. Lesson topic/Activity

6. Focus or skill theme 7. Lesson \# 8. Equipment 9. Materials/Resources

10. Technology 11. Grade:Pre-K to 12 12. Class 13. Class size 14. Date/Date taught 15. Time 16. Length of class 17 . School 18 . Facility 19. Safety 20. NASPE standards

Pre-Instruction Concepts

21. Objectives

22. Psychomotor 23. Cognitive 24. Affective 25. Fitness

\section{Instruction Concepts}

26. Introductory/Instant/Fitness activity \& Warm-up

27. Introduction

28. Anticipatory set/Set induction

29. Instruction

30. Teaching style

31. Skill analysis

32. Critical elements

33. Cues

34. Teaching by invitation

35. $\mathrm{CFU}$

36. Content development/Activities/Lesson focus

37. Organization/Formation

38. Time

39. Management/Procedures

40. Transition

41. Progression

42. Goal orientation

43. Informing task

44. Demonstration

45. Extension task

46. Refinement task

47. Application task

48. Adaptation/Modification/Intratask variation

49. Motivation

50. Closure

51. Cool down

Post-Instruction Concepts

52. Assessment/Evaluation

53. Reflection 
Appendix 18

Delphi Round II Survey

Non-numbered pages 1 through 24 


\section{Planning Delphi Round II}

\section{Modified Delphi Round II Introduction}

Welcome back! Thank you for agreeing to participate in Round II as an expert panel member in this Modified Delphi investigation!

As a panel member, you are asked to rate a list of lesson planning concepts in terms of their importance for use by preservice physical education teachers. Several concepts were combined/collapsed based upon panel member feedback and a review of the pilot study lesson plans. As a result, 53 survey items will need to be rated during Round II. The survey will be used to generate consensus of opinion regarding lesson planning concepts for addition in a future lesson planning template. Your professional experience and judgment are vital to the success of this project.

Please remember the final date for Round II survey completion is Monday, January 30, 2012. Round II results will be emailed once all data are tabulated. I greatly appreciate your assistance in the completion of this project.

Thank you for your time and input. Please call or e-mail me with any questions you may have.

Jack Sager

West Virginia University

jsager@mix.wvu.edu

304.685.3267 


\section{Planning Delphi Round II}

\section{Modified Delphi Round II Survey Instructions}

The following survey contains 53 lesson planning concepts you will need to judge in regard to their importance for placement into a lesson plan template for preservice teachers.

Please read the following:

-Rate each of the concepts separately in the area of importance. For the purpose of the study, IMPORTANCE will refer to the concept's value to the completion of a comprehensive lesson plan template for preservice teachers.

-A rating of (5) or (4) for IMPORTANCE means that you consider the item to be Essential for a preservice lesson plan.

-A rating of (3) means you are neutral regarding the IMPORTANCE of the item.

-A rating of (2) or (1) for IMPORTANCE means the item is Not essential for inclusion in a preservice teacher lesson plan.

-If you choose not to respond to an item, then please leave it blank.

A few reminders:

-You must enter your name on the first page of the survey in order to continue. This is the only question you must answer.

-You will not be allowed to go back into the survey once you have accessed the website link. Therefore, if you are reading this message then you are committed to completing the survey at this time.

-You may return to the instructions page at any time using the "Prev" button at the bottom of the survey pages. You have complete freedom (once you have entered your name) to go to any page within the survey and alter your responses if necessary.

-A survey completion bar will appear at the bottom of each page to show your progress through the survey. 


\section{Planning Delphi Round II}

\section{Modified Delphi Round II}

\section{TABLE OF CONTENTS}

Section 1: Participant Information (Question 1)

Section 2: Concepts - Contextual Information (Questions 2-20)

Section 3: Concepts - Pre-Instruction (Questions 21-25)

Section 4: Concepts - Instruction (Questions 26-51)

Section 5: Concepts - Post-Instruction (Questions 52-53)

\section{OUTLINE}

Contextual Information

2. Teacher name

3. Unit

4. Title of lesson

5. Lesson topic/Activity

6. Focus or skill theme

7. Lesson \#

8. Equipment

9. Materials/Resources

10. Technology

11. Grade:Pre-K to 12

12. Class

13. Class size

14. Date/Date taught

15. Time

16. Length of class

17. School

18. Facility

19. Safety

20. NASPE standards

Pre-Instruction Concepts

21. Objectives

$\rightarrow 22$. Psychomotor objective

$\rightarrow 23$. Cognitive objective

$\rightarrow 24$. Affective objective

$\rightarrow 25$. Fitness objective

\section{Instruction Concepts}

26. Introductory/Instant/Fitness activity \& Warm-up

27. Introduction

28. Anticipatory set/Set induction

29. Instruction

$\rightarrow 30$. Teaching style

$\rightarrow 31$. Skill analysis

$\rightarrow 32$. Critical elements

$\rightarrow 33$. Cues

$\rightarrow 34$. Teaching by invitation

$\rightarrow 35$. CFU

36. Content development/Activities/Lesson focus

$\rightarrow 37$. Organization/Formation

$\rightarrow 38$. Transition

$\rightarrow 39$. Time

$\rightarrow 40$. Management/Procedures 


\section{Planning Delphi Round II}

$\rightarrow 41$. Progression

$\rightarrow \rightarrow 42$. Goal orientation

$\rightarrow \rightarrow 43$. Informing task

$\rightarrow \rightarrow 44$. Demonstration

$\rightarrow \rightarrow 45$. Extension task

$\rightarrow \rightarrow 46$. Refinement task

$\rightarrow \rightarrow 47$. Application task

$\rightarrow \rightarrow 48$. Adaptation/Modification/Intratask variation

$\rightarrow \rightarrow 49$. Motivation

50. Closure

51. Cool down

Post-Instruction Concepts

52. Assessment/Evaluation

53. Reflection 


\section{Planning Delphi Round II}

\section{Modified Delphi Round II}

*1. Please enter your First and Last name:

Name: 


\section{Planning Delphi Round II}

\section{Modified Delphi Round II}

Please rate each lesson planning Concept below for IMPORTANCE using the 1-5 Likert Scale:

(5) or (4) - Concept is essential for a preservice lesson plan.

(3) You are neutral regarding the IMPORTANCE of the item.

(2) or (1) - Concept is NOT essential for inclusion in a preservice teacher lesson plan.

\section{CONTEXTUAL INFORMATION}

\section{2. .}

Teacher Name
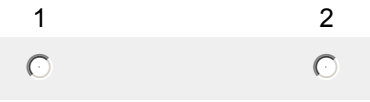

3

Comments regarding this concept?

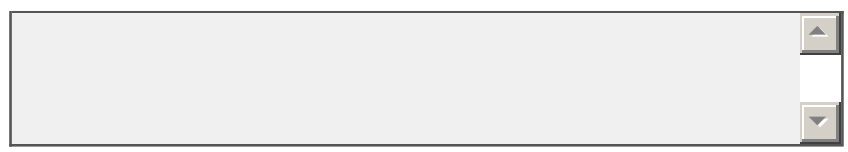

3. .

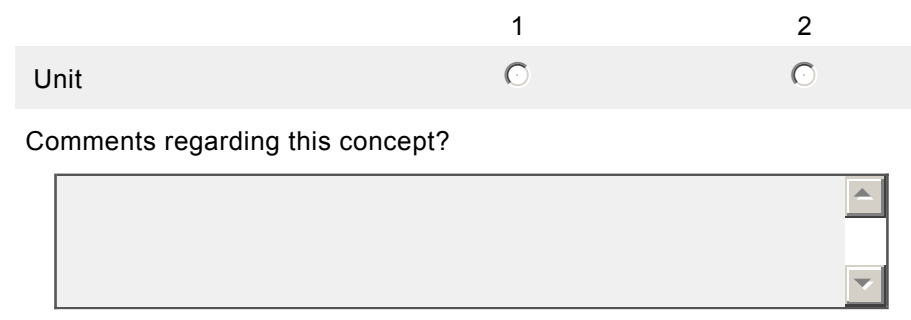

4. .

Title of lesson
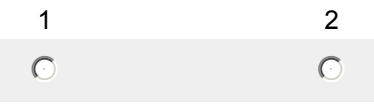

3

Comments regarding this concept?

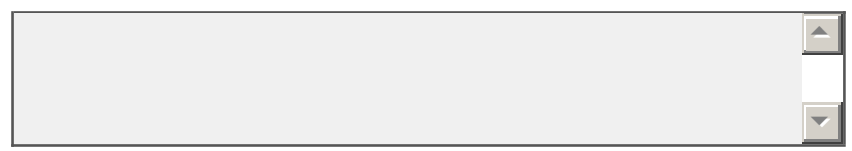

5. .

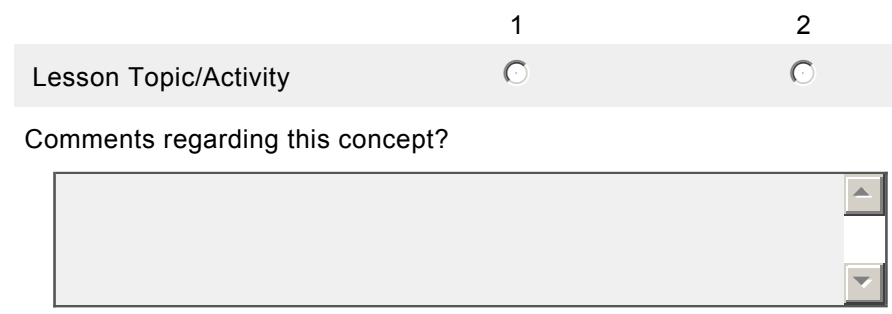

3

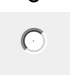

4

$\bigcirc$

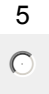

$\overbrace{}^{5}$

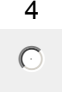

0

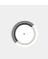




\section{Planning Delphi Round II}

6.

Focus or skill theme

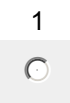

2

3

$0^{4}$

$\bigcirc^{5}$

Comments regarding this concept?

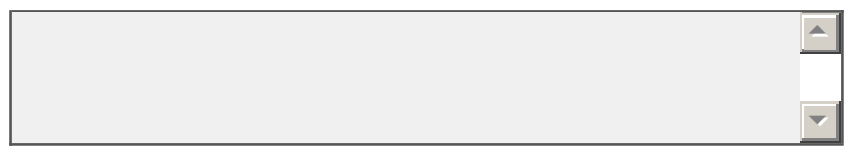




\section{Planning Delphi Round II}

\section{Modified Delphi Round II}

Please rate each lesson planning Concept below for IMPORTANCE using the 1-5 Likert Scale:

(5) or (4) - Concept is essential for a preservice lesson plan.

(3) You are neutral regarding the IMPORTANCE of the item.

(2) or (1) - Concept is NOT essential for inclusion in a preservice teacher lesson plan.

CONTEXTUAL INFORMATION - continued

7.
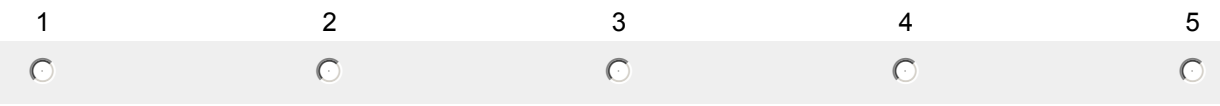

Comments regarding this concept?

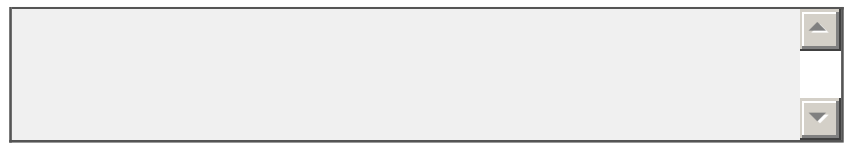

8. .

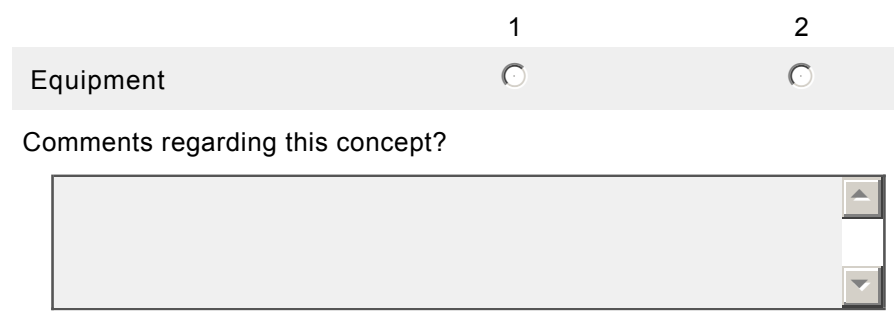

9. .

Materials/Resources
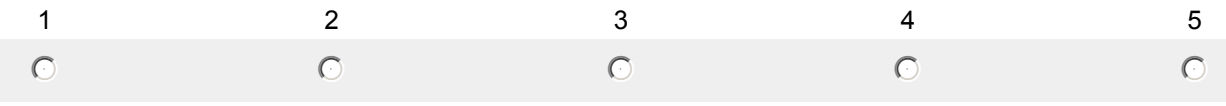

Comments regarding this concept?

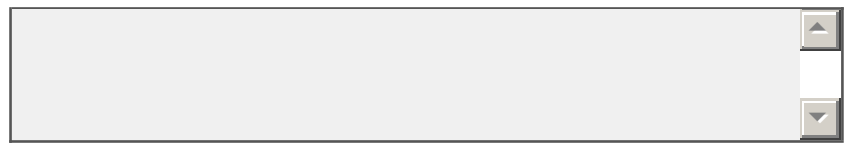

10. .

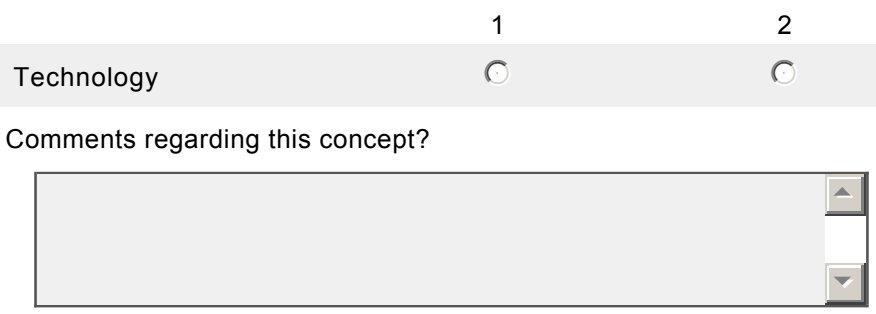

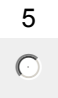

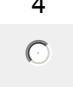

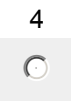

\section{)}

\section{)}

\section{(1)}




\section{Planning Delphi Round II}

\section{Modified Delphi Round II}

Please rate each lesson planning Concept below for IMPORTANCE using the 1-5 Likert Scale:

(5) or (4) - Concept is essential for a preservice lesson plan.

(3) You are neutral regarding the IMPORTANCE of the item.

(2) or (1) - Concept is NOT essential for inclusion in a preservice teacher lesson plan.

CONTEXTUAL INFORMATION - continued

\section{1. .}

Grade (pre-K to 12 )
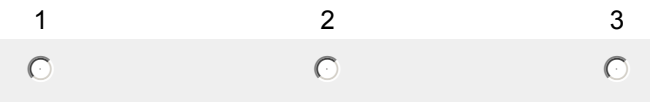

5

Comments regarding this concept?

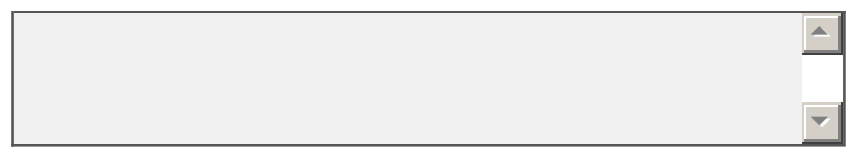

12.

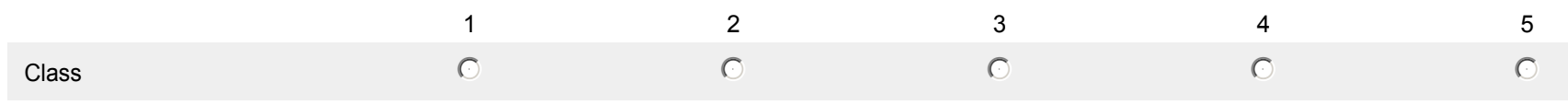

Comments regarding this concept?

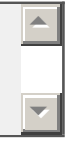

13.

Class size
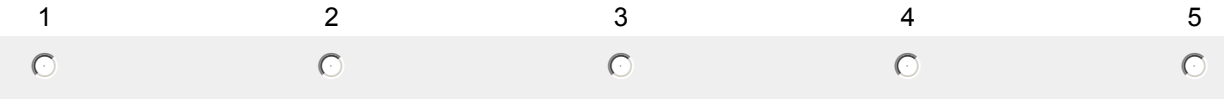

Comments regarding this concept?

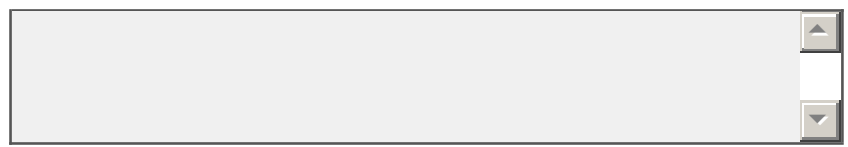

14. .
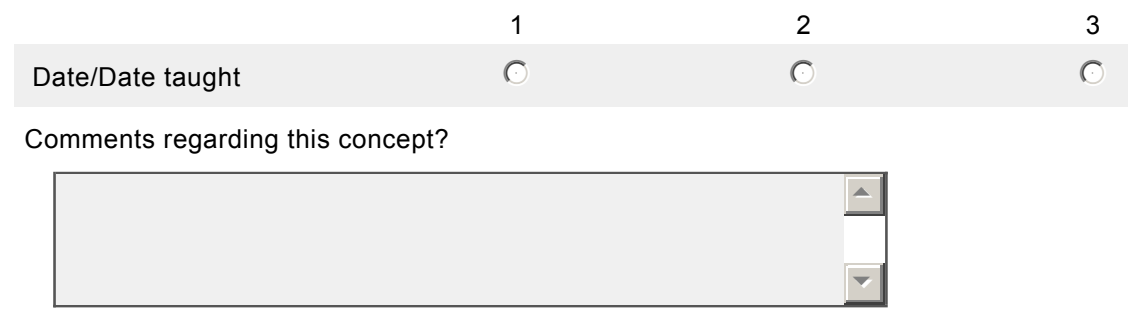


\section{Planning Delphi Round II}

15.

Time

$0^{2}$

3

$0^{4}$

$\bigcirc^{5}$

Comments regarding this concept?

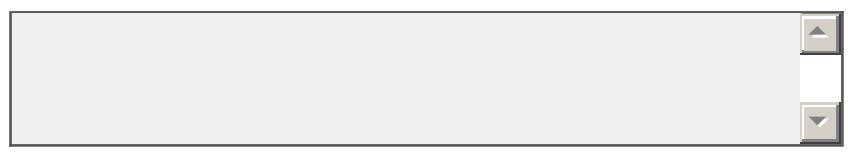




\section{Planning Delphi Round II}

\section{Modified Delphi Round II}

Please rate each lesson planning Concept below for IMPORTANCE using the 1-5 Likert Scale:

(5) or (4) - Concept is essential for a preservice lesson plan.

(3) You are neutral regarding the IMPORTANCE of the item.

(2) or (1) - Concept is NOT essential for inclusion in a preservice teacher lesson plan.

CONTEXTUAL INFORMATION - continued

16. .

Length of class
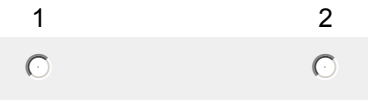

3

Comments regarding this concept?

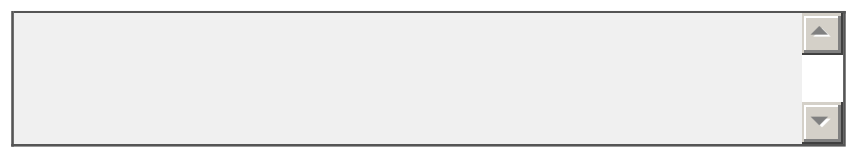

\section{7. .}
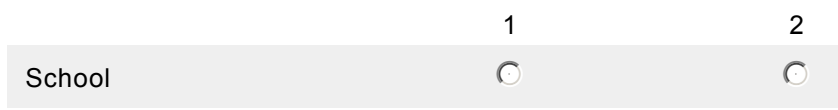

3

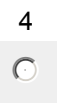

5

Comments regarding this concept?

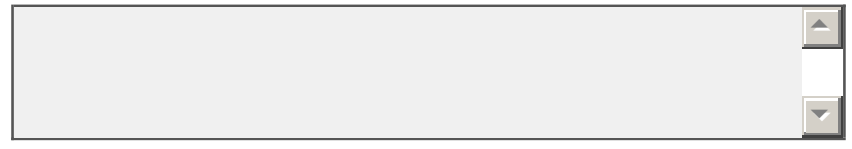

18.

Facility
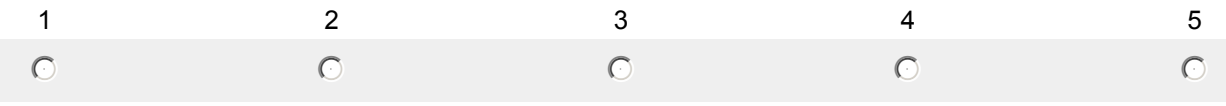

Comments regarding this concept?

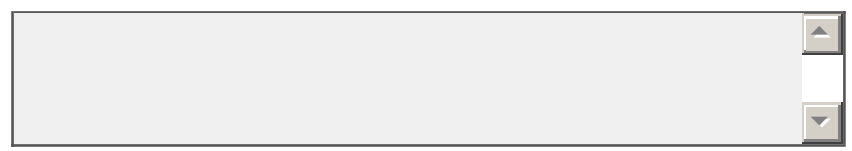

19. .
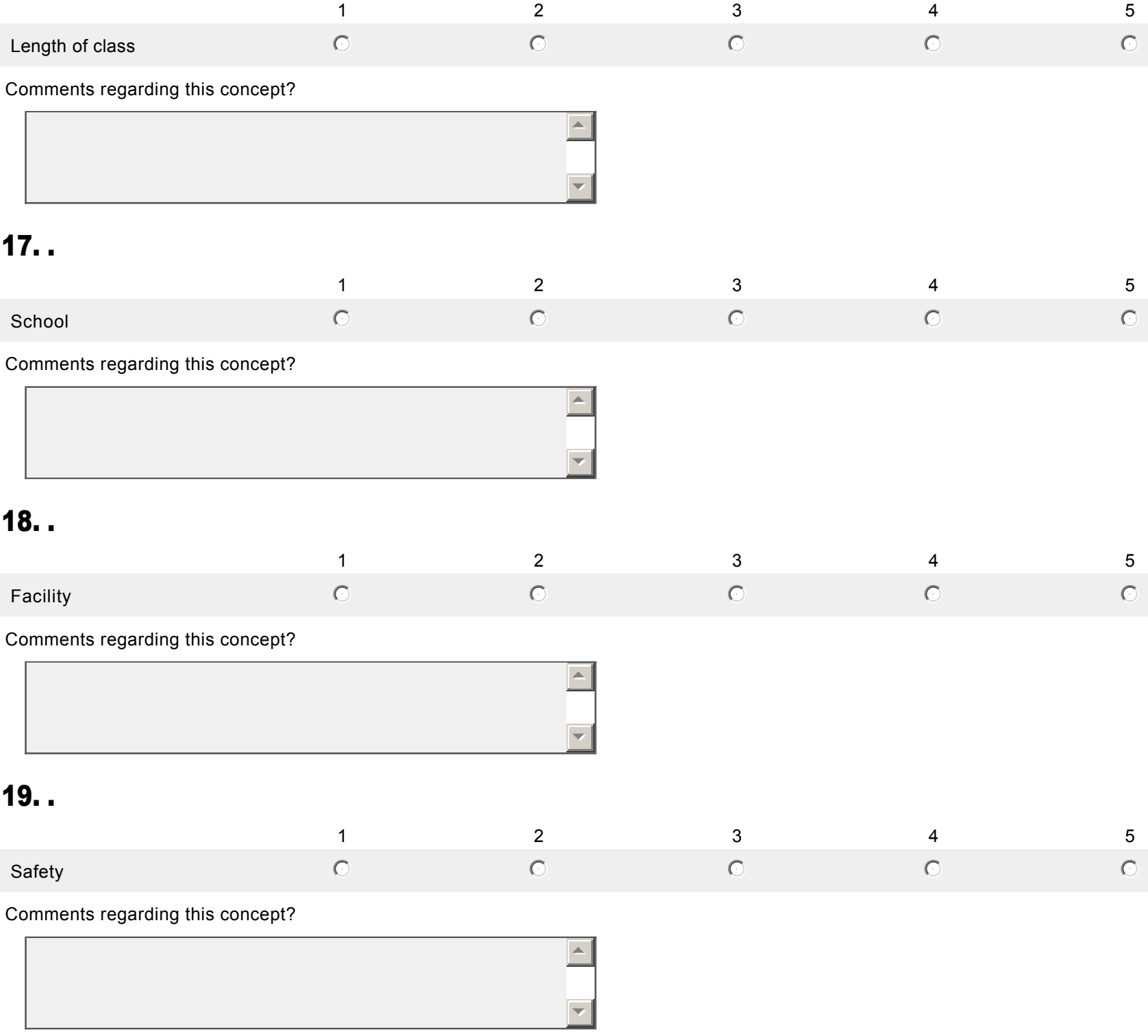

)

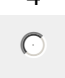

$\bigcirc$

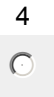

\section{S}
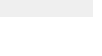


\section{Planning Delphi Round II}

20.

NASPE standards

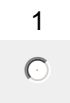

○

$0^{3}$

$0^{4}$

$\bigcirc^{5}$

Comments regarding this concept?

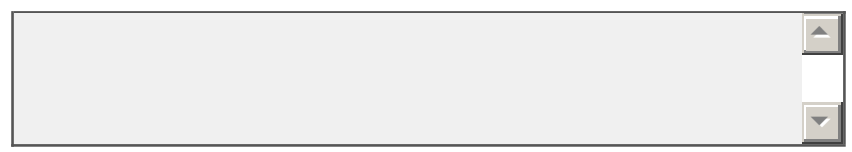




\section{Planning Delphi Round II}

\section{Modified Delphi Round II}

Please rate each lesson planning Concept below for IMPORTANCE using the 1-5 Likert Scale:

(5) or (4) - Concept is essential for a preservice lesson plan.

(3) You are neutral regarding the IMPORTANCE of the item.

(2) or (1) - Concept is NOT essential for inclusion in a preservice teacher lesson plan.

\section{PRE-INSTRUCTION}

\section{1. .}

\section{OBJECTIVES}
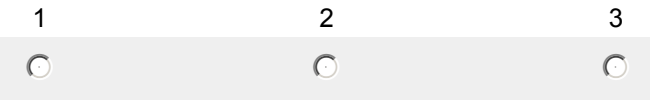

Comments regarding this concept?

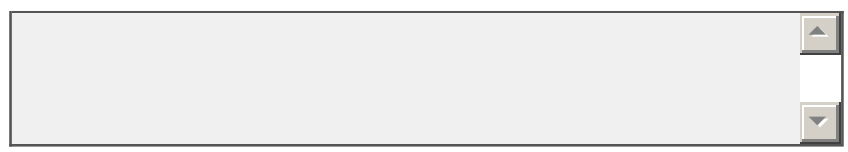

22. .

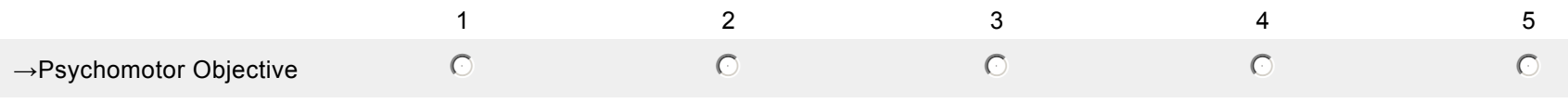

Comments regarding this concept?

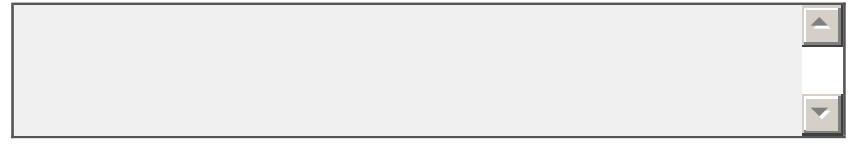

23.

$\rightarrow$ Cognitive Objective
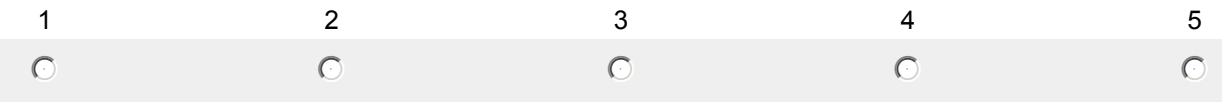

Comments regarding this concept?

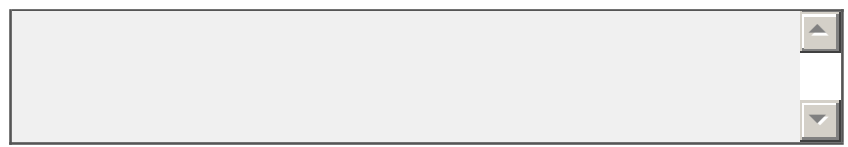

24. .

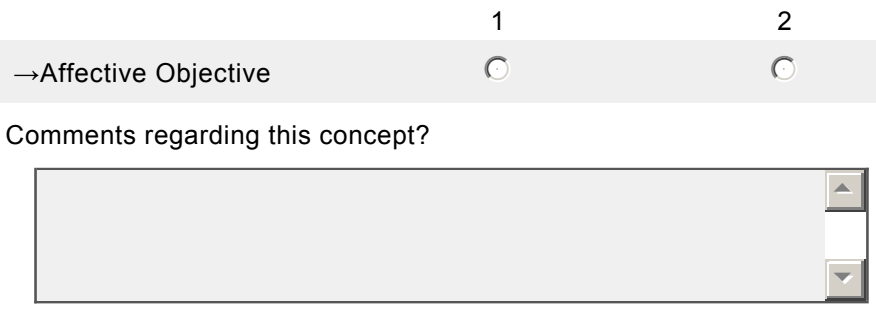




\section{Planning Delphi Round II}

25. .

$\rightarrow$ Fitness Objective

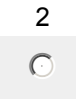

3

$0^{4}$

$\bigcirc^{5}$

Comments regarding this concept?

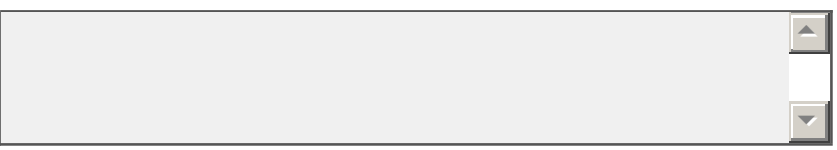




\section{Planning Delphi Round II}

\section{Modified Delphi Round II}

Please rate each lesson planning Concept below for IMPORTANCE using the 1-5 Likert Scale:

(5) or (4) - Concept is essential for a preservice lesson plan.

(3) You are neutral regarding the IMPORTANCE of the item.

(2) or (1) - Concept is NOT essential for inclusion in a preservice teacher lesson plan.

\section{INSTRUCTION}

\section{6. .}

Introductory/Instant/Fitness

activity \& Warm-up
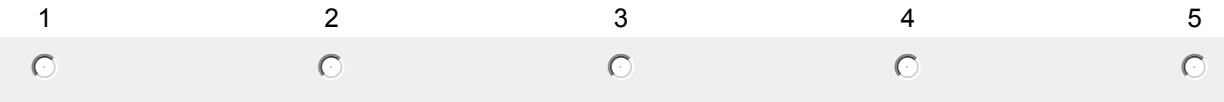

Comments regarding this concept?

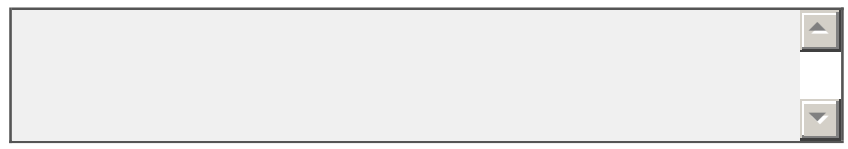

\section{7. .}

Introduction

Comments regarding this concept?
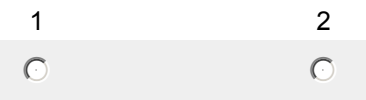

3
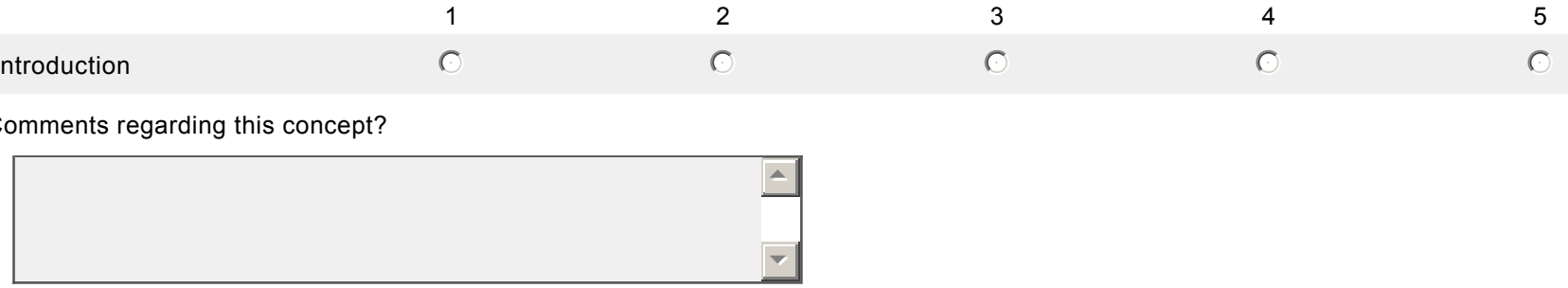

28. .

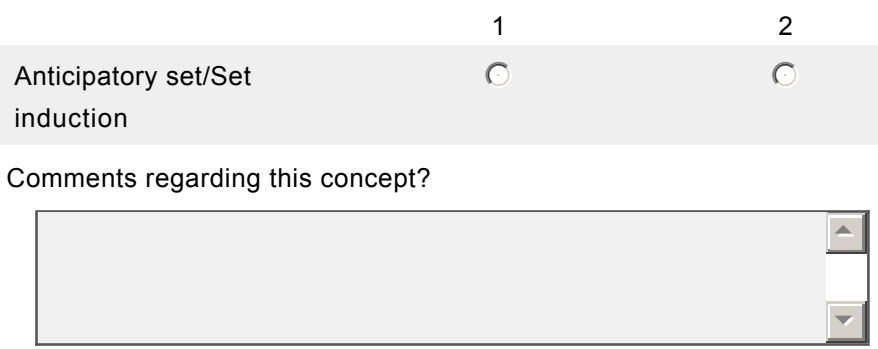




\section{Planning Delphi Round II}

\section{Modified Delphi Round II}

Please rate each lesson planning Concept below for IMPORTANCE using the 1-5 Likert Scale:

(5) or (4) - Concept is essential for a preservice lesson plan.

(3) You are neutral regarding the IMPORTANCE of the item.

(2) or (1) - Concept is NOT essential for inclusion in a preservice teacher lesson plan.

\section{INSTRUCTION}

\section{9. .}
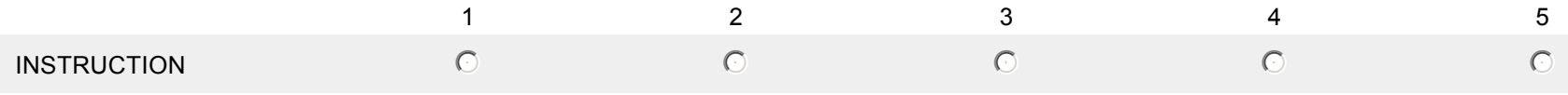

Comments regarding this concept?

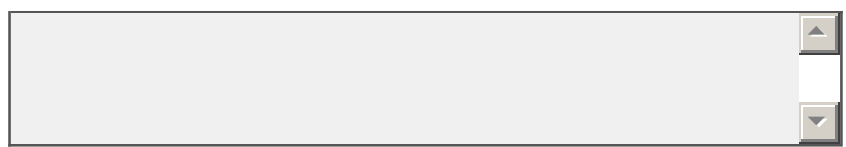

30. .

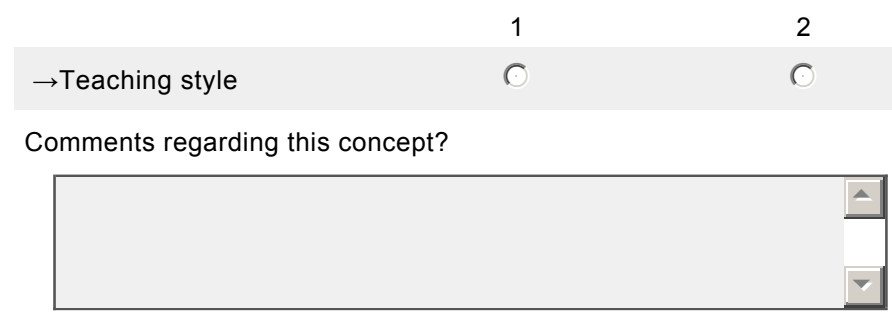

\section{1. .}

$\rightarrow$ Skill analysis
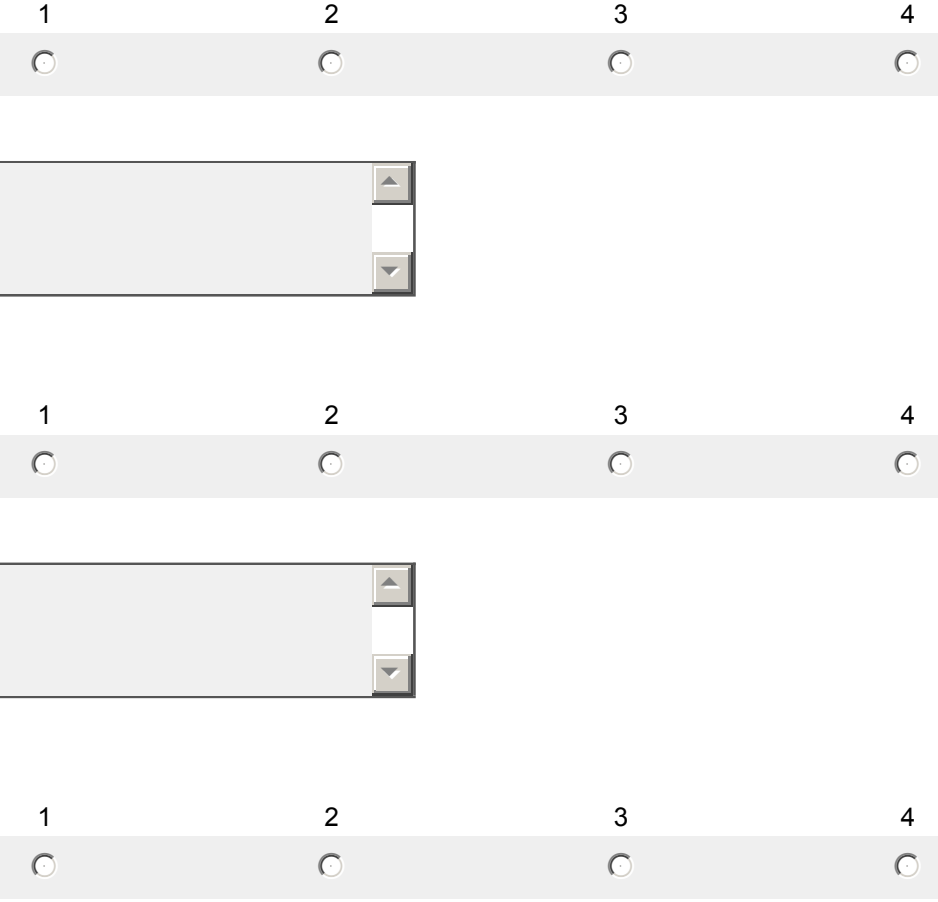

Comments regarding this concept?

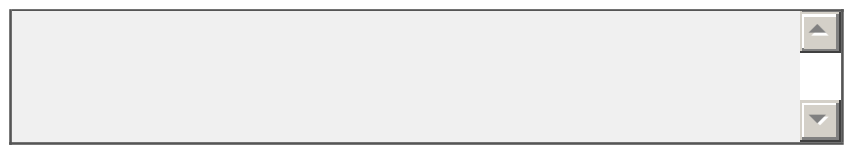

32. .

$\rightarrow$ Critical elements
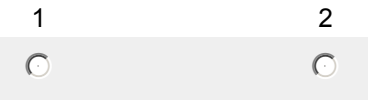

3
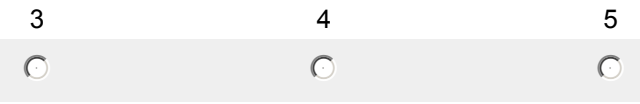

Comments regarding this concept?

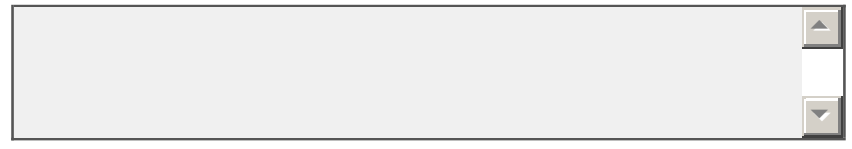




\section{Planning Delphi Round II}

33.

$\rightarrow$ Cues

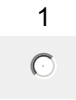

2

$0^{3}$

$0^{4}$

$0^{5}$

Comments regarding this concept?

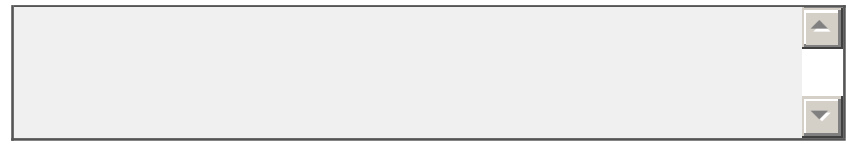

34. .

1

$0^{2}$

$\stackrel{4}{0}$

$\bigcirc^{5}$

Comments regarding this concept?

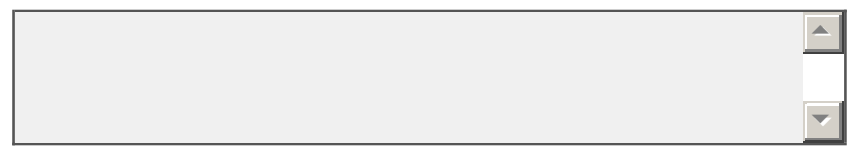

35. .

$\rightarrow$ CFU (checking for

understanding)

$0^{3}$

Comments regarding this concept?

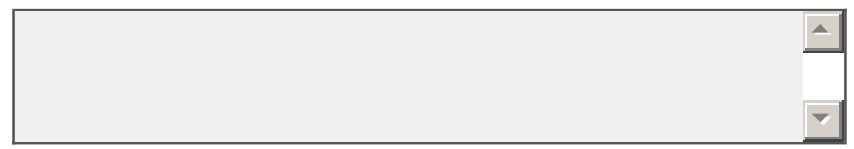




\section{Planning Delphi Round II}

\section{Modified Delphi Round II}

Please rate each lesson planning Concept below for IMPORTANCE using the 1-5 Likert Scale:

(5) or (4) - Concept is essential for a preservice lesson plan.

(3) You are neutral regarding the IMPORTANCE of the item.

(2) or (1) - Concept is NOT essential for inclusion in a preservice teacher lesson plan.

INSTRUCTION - continued

36. .

CONTENT

DEVELOPMENT/ACTIVITIES/LESSON
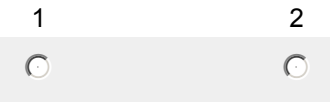

3

5

FOCUS

Comments regarding this concept?

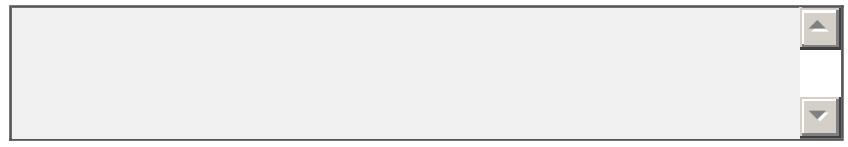

37. .

$\rightarrow$ Organization/Formation
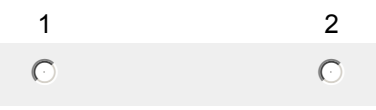

$\bigcirc^{3}$

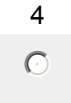

Comments regarding this concept?

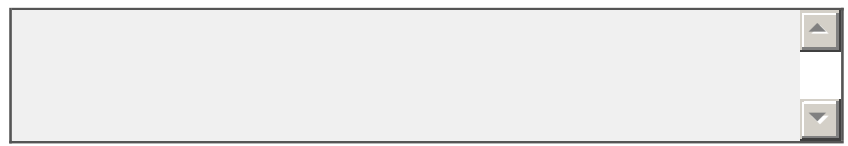

38. .

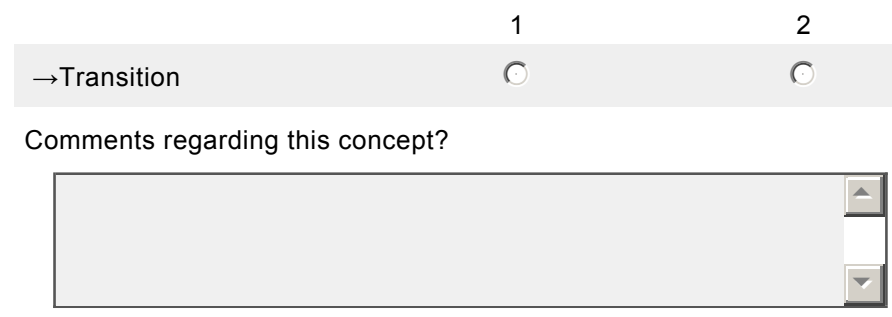

39. .

$\rightarrow$ Time

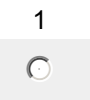

$0^{2}$

3

4

$\bigcirc^{5}$

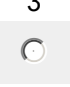

$\bigcirc$

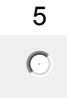

5

Comments regarding this concept?

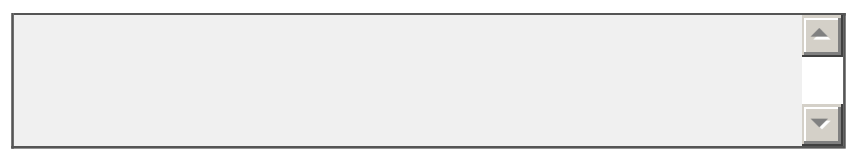




\section{Planning Delphi Round II}

40.

$\rightarrow$ Management/Procedures

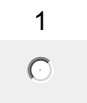

$0^{2}$

3

$0^{4}$

$\bigcirc^{5}$

Comments regarding this concept?

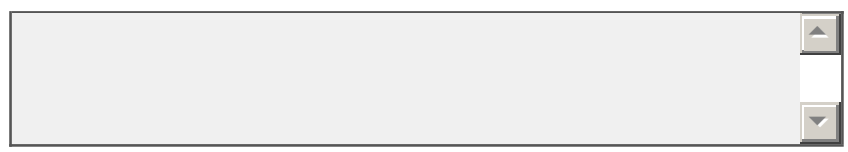




\section{Planning Delphi Round II}

\section{Modified Delphi Round II}

Please rate each lesson planning Concept below for IMPORTANCE using the 1-5 Likert Scale:

(5) or (4) - Concept is essential for a preservice lesson plan.

(3) You are neutral regarding the IMPORTANCE of the item.

(2) or (1) - Concept is NOT essential for inclusion in a preservice teacher lesson plan.

INSTRUCTION - continued

\section{1. .}

$\rightarrow$ Progression
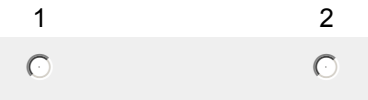

3

Comments regarding this concept?

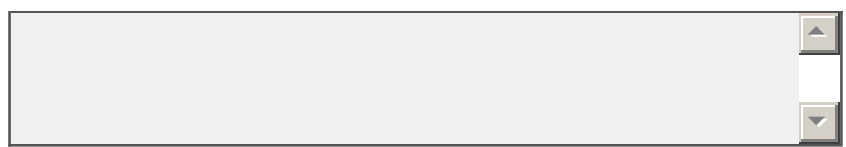

42. .

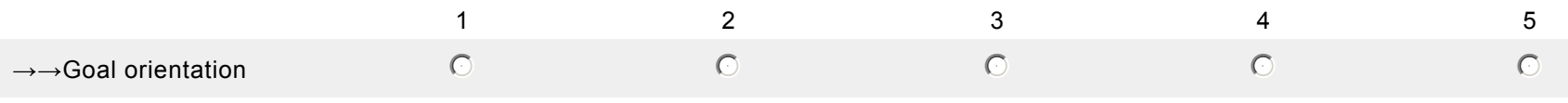

Comments regarding this concept?

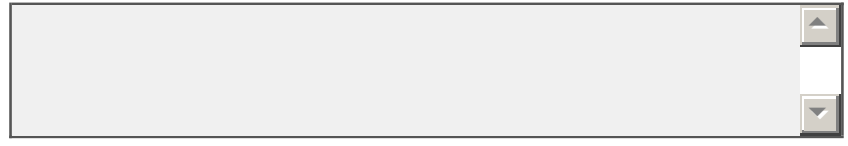

43. .

$\rightarrow \rightarrow$ Informing task
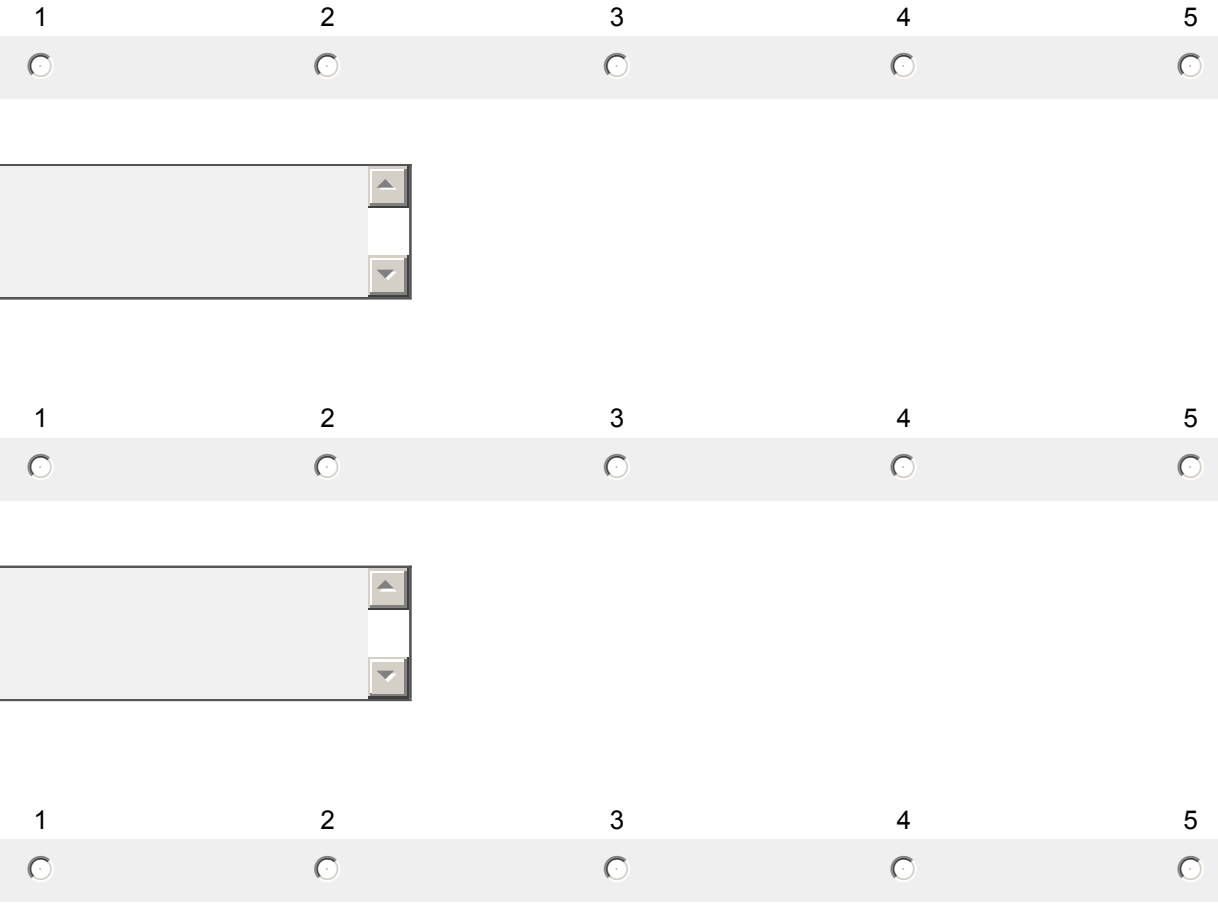

Comments regarding this concept?

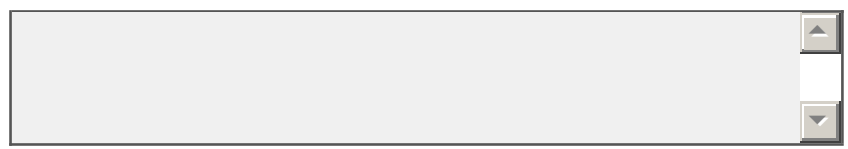

44. .

$\rightarrow \rightarrow$ Demonstration
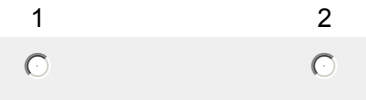

3

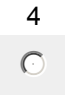

Comments regarding this concept? 


\section{Planning Delphi Round II}

45. .

$\rightarrow \rightarrow$ Extension task
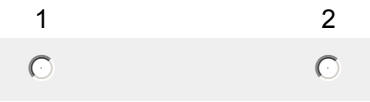

3

0

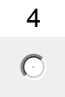

$0^{5}$

Comments regarding this concept?

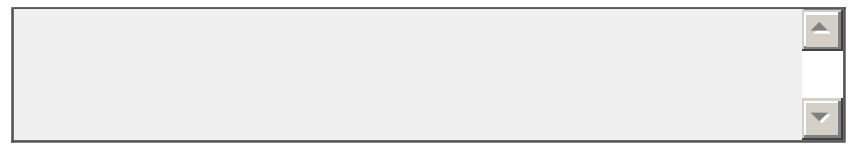

46. .

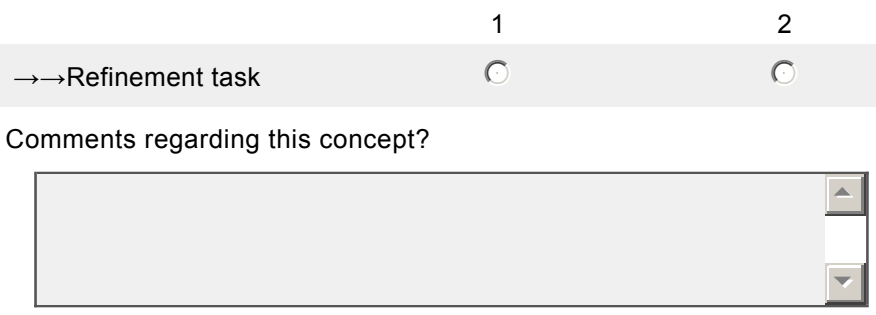

47. .

$\rightarrow \rightarrow$ Application task
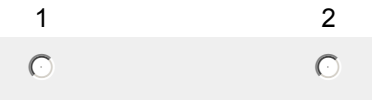

3

$0^{3}$

$\stackrel{4}{0}$

$0^{5}$

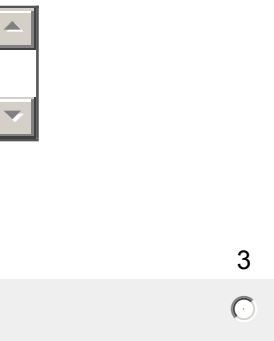

Comments regarding this concept?

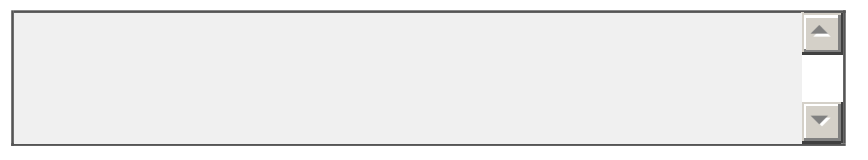

48. .

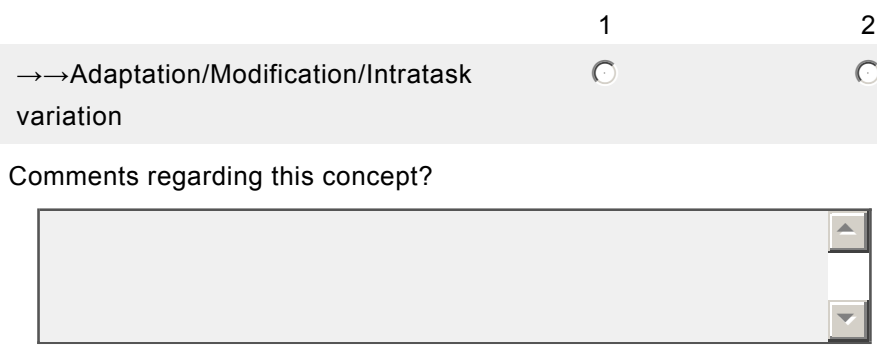

49. .

$\rightarrow \rightarrow$ Motivation

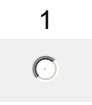

$0^{2}$

$0^{3}$

$\bigcirc^{4}$

5

2

$0^{4}$

$\bigcirc$

Comments regarding this concept?

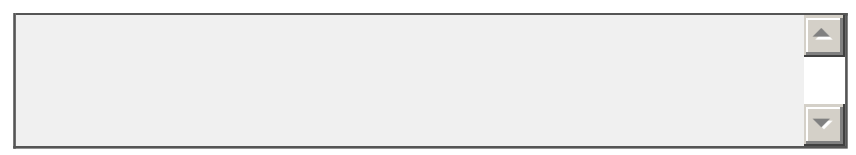




\section{Planning Delphi Round II}

\section{Modified Delphi Round II}

Please rate each lesson planning Concept below for IMPORTANCE using the 1-5 Likert Scale:

(5) or (4) - Concept is essential for a preservice lesson plan.

(3) You are neutral regarding the IMPORTANCE of the item.

(2) or (1) - Concept is NOT essential for inclusion in a preservice teacher lesson plan.

INSTRUCTION - continued

50. .

$\rightarrow$ Closure
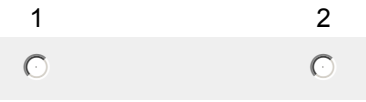

3

Comments regarding this concept?

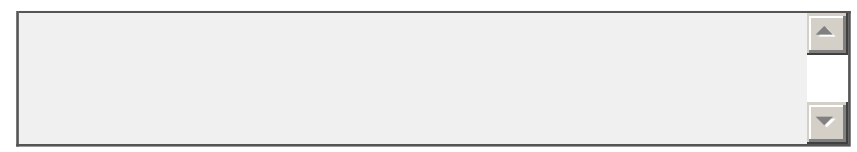

51. .

$\rightarrow$ Cool down

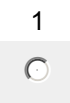

2

3

$0^{4}$

5

Comments regarding this concept?

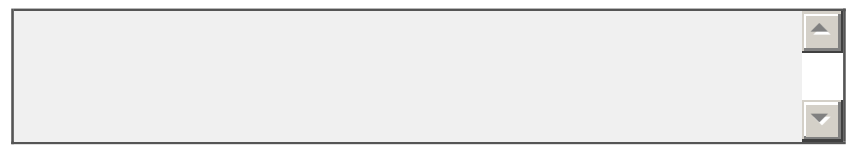




\section{Planning Delphi Round II}

\section{Modified Delphi Round II}

Please rate each lesson planning Concept below for IMPORTANCE using the 1-5 Likert Scale:

(5) or (4) - Concept is essential for a preservice lesson plan.

(3) You are neutral regarding the IMPORTANCE of the item.

(2) or (1) - Concept is NOT essential for inclusion in a preservice teacher lesson plan.

\section{POST-INSTRUCTION}

\section{2.}

Assessment/Evaluation
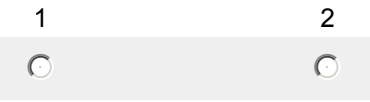

3

Comments regarding this concept?

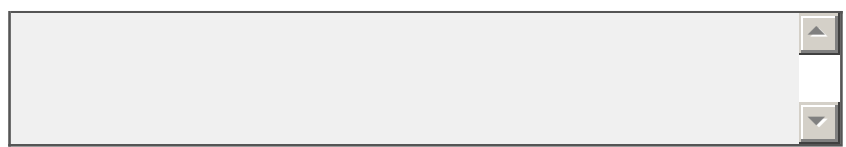

\section{3.}
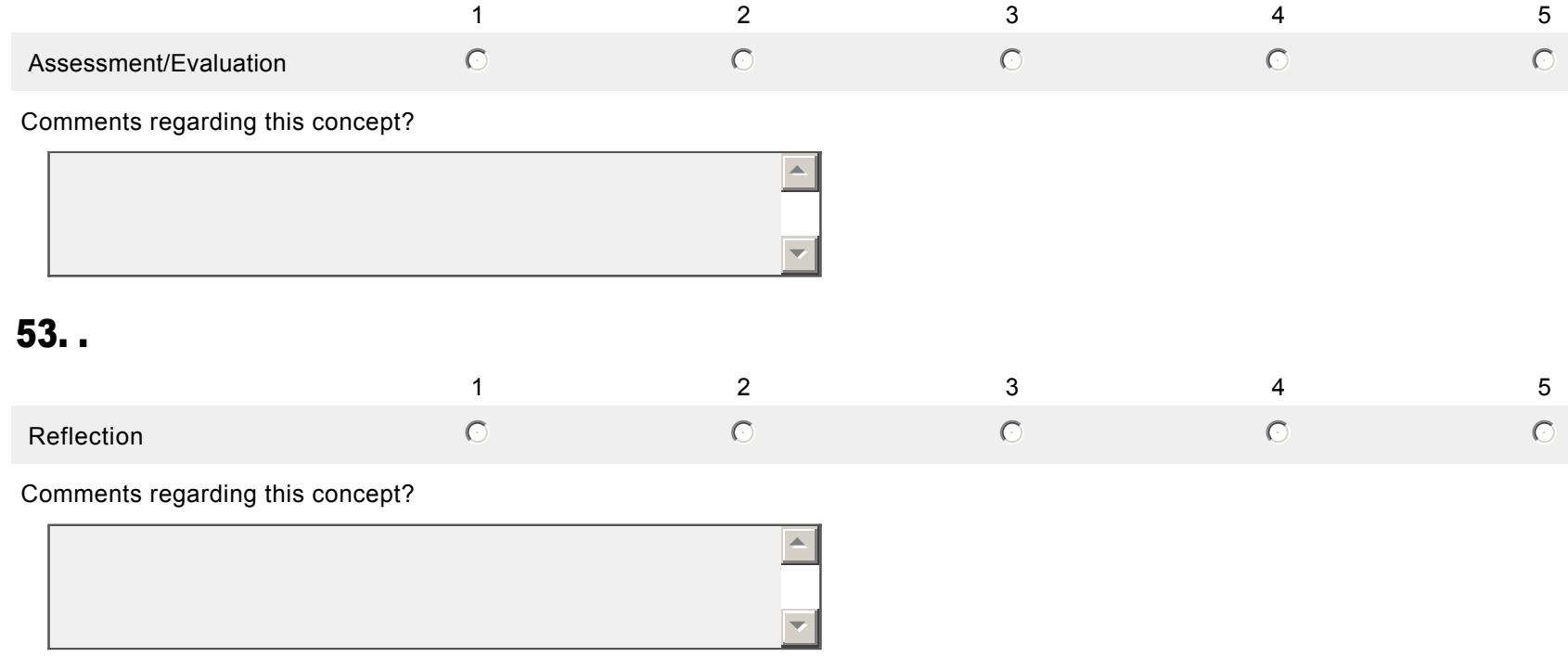

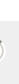

(1)

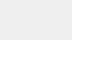

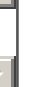

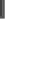




\section{Planning Delphi Round II}

\section{Modified Delphi Round II}

Thank you for completing the survey! Your input is greatly appreciated.

Once all Round II surveys have been completed and analyzed, I will email you a final report. I anticipate this taking place on 20 February, 2012.

You will know you are completely finished with the survey once you are redirected to the West Virginia University CPASS website. This will occur once you click the "Done" button below.

\section{Jack Sager}

West Virginia University

jsager@mix.wvu.edu

304.685.3267 
Appendix 19

Lesson Plan Final Concept List

Dear Delphi Panel Expert:

Thank you again for participating in both rounds of the lesson planning survey! I appreciate the time you took out of your busy schedule. The following pages contain a summary of the results of the study. To be accepted, each concept had to receive a mean rating of at least a four or higher in the area of importance and required a minimum of $75 \%$ of all individual ratings at the four level or higher. A total of 31 concepts were accepted by the expert panel.

Contextual Information

Concept

1. Unit

2. Lesson topic/Activity

3. Equipment

4. Materials/Resources

5. Grade: Pre-K to 12

6. Class size

7. Length of class

8. Safety

9. NASPE standards

Pre-Instruction Concepts

Concept

10. Objectives

11. Psychomotor objective

12. Cognitive objective

13. Affective objective

Instruction Concepts

Concept

14. Introductory/Instant/

Fitness activity \& Warm-up 4

15. Anticipatory set/

Set induction

16. Instruction

17. Cues

18. CFU

19. Content development/

\begin{tabular}{|c|c|c|}
\hline Your score & Group Mean & Percentage \\
\hline 4 & 4.19 & 75.00 \\
\hline 4 & 4.56 & 93.75 \\
\hline 4 & 4.56 & 93.75 \\
\hline 4 & 4.19 & 81.25 \\
\hline 4 & 4.56 & 93.75 \\
\hline 3 & 4.06 & 75.00 \\
\hline 4 & 4.19 & 75.00 \\
\hline 4 & 4.31 & 87.50 \\
\hline 4 & 4.06 & 81.25 \\
\hline
\end{tabular}

\begin{tabular}{|c|c|c|}
\hline Your score & Group Mean & Percentage \\
\hline 4 & 4.81 & 100 \\
\hline 4 & 4.56 & 87.50 \\
\hline 4 & 4.56 & 87.50 \\
\hline 4 & 4.56 & 87.50 \\
\hline
\end{tabular}

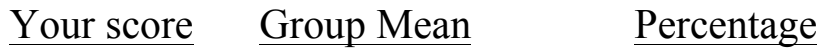

$4.13 \quad 81.25$

$4.40 \quad 86.66$

$4.14 \quad 78.57$

$4.81 \quad 100$

$4.40 \quad 93.33$ 
Activities/Lesson focus 4

20. Organization/Formation 4

4.81

100

21. Time

4

4.69

93.75

4.13

75.00

Instruction Concepts continued

\begin{tabular}{|c|c|c|c|}
\hline Concept & $\underline{\text { Your score }}$ & Group Mean & Percentage \\
\hline 22. Management/Procedures & 4 & 4.44 & 87.50 \\
\hline 23. Progression & 4 & 4.69 & 100 \\
\hline 24. Demonstration & 4 & 4.44 & 81.25 \\
\hline 25. Extension task & 5 & 4.44 & 87.50 \\
\hline 26. Refinement task & 5 & 4.25 & 75.00 \\
\hline 27. Application task & 4 & 4.60 & 93.33 \\
\hline \multicolumn{4}{|l|}{ 28. Adaptation/Modification } \\
\hline /Intratask variation & 4 & 4.13 & 86.66 \\
\hline 29. Closure & 5 & 4.88 & 100 \\
\hline
\end{tabular}

Post-Instruction Concepts

\begin{tabular}{|c|c|c|c|}
\hline Concept & Your score & Group Mean & Percentage \\
\hline 30. Assessment/Evaluation & 5 & 4.63 & 93.75 \\
\hline 31. Reflection & 5 & 4.67 & 93.33 \\
\hline
\end{tabular}

31. Reflection

4.63

93.33 
Appendix 20

Final Concept Outline

\begin{tabular}{|l|l|}
\hline \multicolumn{2}{|l|}{ Contextual Information } \\
\hline & Unit \\
\hline & Lesson topic/Activity \\
\hline & Equipment \\
\hline & Materials/Resources \\
\hline & Grade: Pre-K to 12 \\
\hline & Class size \\
\hline & Length of class \\
\hline & Safety \\
\hline & NASPE standards \\
\hline
\end{tabular}

\begin{tabular}{|l|}
\hline \multicolumn{2}{|l|}{ Pre-Instruction Concepts } \\
\hline \multicolumn{2}{|c|}{ Objectives } \\
\hline \\
$\qquad$\begin{tabular}{|l|l|}
\hline & Psychomotor \\
\hline & Cognitive \\
\hline & Affective \\
\hline
\end{tabular}
\end{tabular}

\begin{tabular}{|c|c|}
\hline \multicolumn{2}{|c|}{ Instruction Concepts } \\
\hline \multirow{2}{*}{\multicolumn{2}{|c|}{\begin{tabular}{l|l} 
& Introductory/Instant/Fitness activity \& Warm-up \\
Anticipatory set/Set induction
\end{tabular}}} \\
\hline & \\
\hline \multicolumn{2}{|c|}{ Instruction } \\
\hline \multirow{2}{*}{\multicolumn{2}{|c|}{\begin{tabular}{l|l} 
& Cues \\
& CFU
\end{tabular}}} \\
\hline & \\
\hline \multicolumn{2}{|c|}{ Content development/Activities/Lesson focus } \\
\hline \multicolumn{2}{|c|}{ 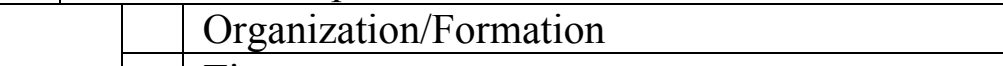 } \\
\hline & Time \\
\hline \multicolumn{2}{|r|}{ Management/Procedures } \\
\hline \multicolumn{2}{|r|}{\begin{tabular}{l|l} 
& Progression \\
\end{tabular}} \\
\hline \multicolumn{2}{|r|}{ Demonstration } \\
\hline \multicolumn{2}{|r|}{ Extension task } \\
\hline \multicolumn{2}{|r|}{ Refinement task } \\
\hline \multirow{2}{*}{\multicolumn{2}{|c|}{\begin{tabular}{l|l} 
& Application task \\
& Adaptation/Modification/Intratask variation
\end{tabular}}} \\
\hline & \\
\hline & Closure \\
\hline
\end{tabular}

\section{Post-Instruction Concepts \\ Assessment/Evaluation \\ Reflection}


Appendix 21

Lesson Plan Concept Definitions or Key Terms

Listed as found in concept outline

1. Unit: A scheduled block of lessons that covers days or weeks that covers one sport (soccer, frisbee) or group of activities (fitness).

2. Lesson topic/activity: The primary skill or activity to be learned on a particular day. Example: Passing would be the lesson topic for a unit on Soccer.

3. Equipment: Equipment: items used by students to practice skill, including balls, mats, sticks, poly spots and the like

4. Materials/resources: 2. This concept includes materials like task cards, handouts, pencils, as well as resources, such as text books, class notes, etc. used to prepare, and implement lessons.

5. Grade: Pre-K to 12: The specific grade level of the physical education class.

6. Class size: The number of students in a particular class.

7. Length of class: The time period in which a particular class period meets for physical education.

8. Safety: Specific concerns regarding a lesson that a teacher must be aware of in order to create and maintain a safe environment for students. Swinging bats during a softball lesson, a slippery gymnasium floor, and proper spotting of weight lifters are all examples of concerns.

9. NASPE standards: The National Association for Sport and Physical Education's six stated expectations that specify what K-12 students should know and be able to perform. (NASPE, 2004).

10. Objectives: "Specifically identified desired outcomes of an educational program usually specified for affective, cognitive, and psychomotor areas of development" (Rink, 2006, p. G-3).

11. Psychomotor objective: "An educational outcome specified for the development of physical abilities or neuromuscular skills of the learner" (Rink, 2006, p. G-4).

12. Cognitive objective: "An educational outcome specified for the development of knowledge and thinking-related processes" (Rink, 2006, p. G-1). 
13. Affective objective: "An educational outcome specified for the development of feelings, attitudes, values, and/or social skills" (Rink, 2006, p. G-1).

14. Introductory/instant/fitness activity \& warm-up: The initial physical activity that students engage in that prepare students for the remainder of the class.

15. Anticipatory set/set induction: "The part of the lesson in which the teacher orients the students to what they will be doing, how they will be doing it, and why they will be doing it" (Rink, 2006, p. G-4).

16. Instruction: In reviewing the pilot study lesson plans, this concept serves as a heading in the design of the main portion of the lesson. In round II of survey, the concepts under this heading are shown.

17. Cues: "The simple phrases-the 2 to 3 words that give children the cognitive reminder of what is needed to perform the skill correctly" (Lund \& Tannehill, 2010, p. 406).

18. CFU (Checking for understanding): Determining whether students comprehend a particular skill or idea that was just taught. This can be accomplished by questioning individual students or the entire class, through student demonstrations, or by guided practice (Davies \& Housner, 2009).

19. Content development: "The teaching process that takes the learner from one level of performance in a content area to another2" (Rink, 2006, p. G-2).

20. Organization/formation: This collapsed comment refers to the organization and position of students and equipment for each task.

21. Time: The estimated time for each portion of a lesson and/or activity.

22. Management/Procedures: "Refers to instructional behaviors relating to structuring, directing and reinforcing appropriate conduct" (Rink, 2006, p. G-2).

23. Progression: "Sequencing learning experiences from simple to complex or from easy to hard..." This is done by a series of extension tasks. (Rink, 2006, p. 114).

24. Demonstration: Modeling the desired performance. This can be executed by the teacher, students, or by the use of visual aids (Rink, 2006).

25. Extension task: "A teacher's move that communicates a concern for changing the complexity or difficulty of student performance" (Rink, 2006, p. G-2).

26. Refinement task: "A teacher move that communicates a concern for the quality of student performance, such as 'Work to get your toss a little higher'". (Rink, 2006, p. G-4). 
27. Application task: "A teacher move that communicates a concern for moving the student focus from how to do the movement to how to use the movement, or an assessment of form" (Rink, 2006, p. G-1).

28. Adaptation/Modification/Intratask variation: How teachers adapt tasks to meet individual student needs.

29. Closure: The two or three minutes at the end of a lesson where any or all of the following can occur: (a) the key points of a lesson are reviewed, (b) students complete a quick written assessment related to the day's lesson, (c) the teacher comments on the class' behavior, and (d) homework is assigned (Graham, 2001).

30. Assessment/Evaluation: 2. This concept refers to the assessment/evaluation of pre-k to 12 students by the preservice teacher. Assessment is "the process of gathering information about a student's level of achievement and making inferences based on that evidence for a variety of purposes" (NASPE, 2004, p. 53).

31. Reflection: The time following the lesson when a teacher gauges the strengths and weaknesses of their teaching in order to improve subsequent lessons. 